\title{
Identification of the Paternal Parent of 'Bing' Sweet Cherry and Confirmation of Descendants Using Single Nucleotide Polymorphism Markers
}

\author{
Umesh R. Rosyara and Audrey M. Sebolt \\ Michigan State University, Department of Horticulture, 1066 Bogue Street, East Lansing, MI 48824 \\ Cameron Peace \\ Washington State University, Department of Horticulture, Johnson Hall, Pullman, WA 99163 \\ Amy F. Iezzoni ${ }^{1}$ \\ Michigan State University, Department of Horticulture, 1066 Bogue Street, East Lansing, MI 48824
}

\begin{abstract}
AdDitional INDEX wORDs. coefficient of parentage, inbreeding, paternity test, pedigree reconstruction, Prunus avium, relatedness, single nucleotide polymorphism, SNP array

Abstract. 'Bing' is an iconic sweet cherry (Prunus avium L.) cultivar in the United States that even after more than 130 years of cultivation remains the most highly regarded dark sweet cherry and is the standard by which new sweet cherries are judged. 'Bing' has been repeatedly used as a parent in North American breeding programs and is found in the lineages of several important modern cultivars. The maternal parent of 'Bing' is reported to be 'Black Republican', an old cultivar commercially grown for fruit in the Willamette Valley, OR, after $\approx 1860$ and now is usually only grown as a pollenizer cultivar; however, the paternal parent of 'Bing' is unknown. The objective of this study was to deduce the paternal parent of 'Bing' and validate the pedigree records for the relatives of 'Bing' using statistical algorithms that use genomewide single nucleotide polymorphism (SNP) data. With a high probability, it was determined that the sweet cherry cultivar Napoleon, also known as Royal Ann in the Pacific northwestern United States, a large, firm, blush-type, light-fleshed, and productive cherry, is the paternal parent of 'Bing'. This parentage deduction results in an increase in the known relatedness among U.S. cultivated sweet cherry breeding germplasm because 'Napoleon' is an important founder previously known to be present in the ancestry of every self-compatible sweet cherry cultivar bred to date, directly and through 'Bing' and its descendants.
\end{abstract}

\begin{abstract}
'Bing' is the dominant fresh market sweet cherry cultivar grown in the western United States accounting for approximately half of the production acreage. The predominance of 'Bing' is the result of its heavy yields of large, firm, sweet, flavorful fruit with dark purplish flesh. Because of these desirable qualities, 'Bing' has been used in breeding and is well known as the mother of 'Rainier', the dominant U.S. cultivar in the yellow blush market class.

The original seedling that was later named 'Bing' was planted in 1875 in a nursery belonging to Seth Lewelling in Milwaukee, in the Willamette Valley of Oregon, and was later propagated and sold by the Lewelling Nursery (Hedrick, 1915). 'Bing' was derived from open pollination of 'Black Republican' and is believed to have been named after a Chinese workman (Hedrick, 1915). The seed parent, 'Black Republican', is an old and previously popular cultivar commercially grown for fruit in the Willamette Valley, OR, after $\approx 1860$ and now is usually only planted as a pollenizer. The pollen part of 'Bing' was not recorded. Because all sweet cherry cultivars grown in the United States before 1968 were self-incompatible, 'Bing' could not have originated from self-pollination of 'Black Republican' (Lapins, 1970). Instead, it must have resulted from pollen that was compatible in styles of 'Black Republican'.
\end{abstract}

Received for publication 24 Oct. 2013. Accepted for publication 18 Dec. 2013. This work was partially funded by USDA's National Institute of Food and Agriculture-Specialty Crop Research Initiative project, "RosBREED: Enabling marker-assisted breeding in Rosaceae" (2009-51181-05808).

${ }^{1}$ Corresponding author. E-mail: iezzoni@msu.edu.
Other common cultivars growing in the region at that time included 'Napoleon', 'Black Heart', and 'Black Tartarian' (Hedrick, 1915).

As a result of the importance of 'Bing' as a commercial cultivar and its value as a breeding parent, knowledge of the paternal parent of 'Bing' and confirmation of its contribution to the pedigrees of modern cultivars would provide useful insight to inform genetic studies and breeding decisions. Complete and correct pedigree records are critical for breeding decisionmaking and also where pedigree-based statistical methods are used for genetic analyses of trait inheritance (Bink et al., 2008; Rosyara et al., 2009). For example, pedigree records help to increase power and precision while reducing false discovery rate in quantitative trait locus discovery studies (Bink et al., 2012; Lebrec et al., 2008). In addition, complete pedigree records increase the accuracy of estimates of relatedness among breeding material, informing crossing decisions to avoid or exploit inbreeding. Thus, performing paternity tests to validate or correct pedigree information is an important goal for sweet cherry breeding.

Paternity testing is a process in which candidates are examined for the most likely parents of a target offspring. The availability of DNA marker information has greatly facilitated the development of computational methods for parentage determination, pedigree reconstruction, estimation of relatedness, and inferences about genealogical relationships (Blouin, 2003). Several statistical strategies based on probability theory have been developed for such purposes. Most notably, DNA-based parentage confirmation is an accepted tool 
used in human paternity identification (Li et al., 2012). In clonally propagated perennial plants such as cherry (Prunus L.), where centuries-old potential ancestors are frequently available, DNA markers have been used to determine paternity. Paternity analyses have been conducted in apple (Malus $\times$ domestica Borkh.) using random amplified polymorphic DNA markers (Harada et al., 1993) and chloroplast markers (Savolainen et al., 1995). Paternity analyses using simple sequence repeat (SSR) markers have been conducted in olive [Olea europaea L. (De la Rosa et al., 2004, 2013)], peach [Prunus persica L. (Yamamoto et al., 2003)], and wine grape [Vitis vinifera L. (Bowers et al., 1999)]. Schueler et al. (2003) used SSR markers for sweet cherry cultivar identification and studies of gene flow in wild sweet cherry where seed maternity and paternity were determined based on SSR genotypes of seed endocarp and embryos, respectively.

In the last two decades, SSR markers have been the DNA markers of choice for tests of paternity. However, SNP markers provide considerable advantages over SSRs including: 1) lower mutation rates; 2) suitability for standardized representation of genotyping results as a digital DNA signature (Fries and Durstewitz, 2001); and 3) suitability for high-throughput automation (Kruglyak, 1997). One disadvantage is that any individual SNP has a lower information content compared with a typical multiallelic SSR. However, this latter limitation can be compensated for by handling many more SNP markers.

Our objectives were to first determine the paternal parentage of 'Bing' sweet cherry and then to confirm the paternity of 'Bing' descendants. These analyses used statistical algorithms with different numbers of genomewide SNPs, thereby allowing a determination of optimal marker density for paternity analysis. The ability to identify the paternal parent of 'Bing' was facilitated by three factors. First, only a few sweet cherry cultivars existed in the United States in the 19th century and thus the number of potential paternal parents of 'Bing' is limited. These cultivars are still available. Second, sweet cherry is not native to the United States but rather to regions of Europe, the Middle East, and western Asia (Iezzoni et al., 1990). Finally, these analyses were possible as a result of the availability of new high-resolution genotypic data for sweet cherry. A genomewide 6K Infinium ${ }^{\circledR}$ II array (RosBREED 6K cherry SNP array v1) was developed and used to genotype a diverse array of 269 sweet cherry individuals (Peace et al., 2012). A total of 1825 SNPs were polymorphic in this germplasm (Peace et al., 2012), indicating that a large number of polymorphic markers suitable for paternity analysis were available.

\section{Materials and Methods}

Plant material and genotypic data. The sweet cherry germplasm used $(n=48)$ consisted of founder cultivars, modern cultivars, breeding selections, and germplasm collection accessions (Table 1). All 48 individuals, which are part of the larger RosBREED sweet cherry Crop Reference Set representing North American sweet cherry breeding germplasm (C. Peace, J. Luby, E. van de Weg, M. Bink, and A. Iezzoni, unpublished data), were previously genotyped using the RosBREED cherry 6K SNP array v1 (Peace et al., 2012). A further subset of 15 cultivars and selections was tested for their probability of being the paternal parent of 'Bing'. Of these, seven were included as negative controls because they were wild or landrace selections introduced to the United States after 1900 (Table 2). A subset of three descendant cultivars was tested to confirm 'Bing' as a parent, and eight descendant cultivars and selections were tested to confirm 'Bing' as a grandparent (Table 3).

Different numbers of genomewide SNPs from the $6 \mathrm{~K}$ array data set were used to evaluate whether marker number influenced the ability to determine parentage in sweet cherry. From all available SNPs, the first and largest set of 519 informative SNP markers was chosen that satisfied the following criteria: 1) minor allele frequency greater than 0.1 ; and 2) presence in the 48 accessions of all three genotypic classes, AA, $\mathrm{AB}$, and BB. From this set, a second set of 180 SNPs was chosen that spanned all eight pseudo-chromosomes and with one SNP positioned approximately every $2 \mathrm{Mbp}(\approx 8 \mathrm{cM})$ using the peach whole genome sequence, Peach v1.0 (Verde et al., 2013), as a proxy for the sweet cherry genome (Peace et al., 2012). A third set of 60 SNPs was chosen from the first set of SNPs using a wider spacing of approximately one marker at every $5 \mathrm{Mbp}(\approx 20 \mathrm{cM})$. In this set of 60 markers, the minor allele frequency threshold was increased to greater than 0.2 to improve marker informativeness. Alleles at the self-incompatibility locus were from Haldar et al. (2010) and Iezzoni et al. (2005).

Statistical DeTermination OF PARENT-OFFSPRING RElationships. Candidates for the paternal parent of 'Bing' and the likelihood that 'Bing' was the true parent of other modern sweet cherry cultivars were tested using two statistical approaches: composite paternity index (CPI) and pairwise calculation of genetic relatedness. The CPI is based on the null hypothesis that there is no relationship vs. the alternative hypothesis that the pair under consideration is a parent and offspring relationship (Evett and Weir, 1998). The calculation of genetic relatedness, however, provides a quantitative measure of the degree of relatedness without knowledge of the type of relationship.

Composite PATERnity Index. Likelihood of parentage, expressed as the paternity index (PI) of Evett and Weir (1998), was used. In our case, we assumed that the maternal parent was known and the potential paternal parent was sought. As described in Evett and Weir (1998), $\mathrm{X}_{\mathrm{i}}$ is the conditional probability that the alleged paternal parent is the true paternal parent, whereas $\mathrm{Y}_{\mathrm{i}}$ is the conditional probability that a random individual from the same population is the true paternal parent. Thus, PI for each marker $(i)$ can be expressed as the ratio of the probability that the alleged parent could be the source of the allele acquired from the paternal parent $\left(\mathrm{X}_{\mathrm{i}}\right)$ to the probability that a random individual of the same population could have contributed the allele $\left(\mathrm{Y}_{\mathrm{i}}\right)$. For the case of locus $i$ with two codominant alleles $A$ and $B$, as is the case with biallelic SNPs, with respective allele frequencies $p$ and $q(=1-p)$, the $\mathrm{X}_{\mathrm{i}}$ and $\mathrm{Y}_{\mathrm{i}}$ for each of the possible parent-offspring combinations was derived following Elston (1986).

For combining information from multiple markers, the logscaled CPI (LCPI) for $n$ markers was determined according to Elston (1986) as: $L C P I=-\log _{10}\left(P I_{1} \times P I_{2} \times . . \times P I_{n}\right)$, where the number of markers was 60,180 , or 519 depending on the SNP set used.

The LCPI was calculated using the program "paternity vs 1.0.0" written in R programming language and available from R-Forge mirror (Theußl and Zeileis, 2009). Positive evidence for paternity was set at a LCPI threshold of 1.3 or greater, which corresponds to a probability of paternity of 0.95 or greater. Therefore, if a candidate paternal parent had a LCPI of less than 
Table 1. Sweet cherry cultivars, selections, and wild accessions, their parents if known, coefficient of relatedness ( $\rho$ ) to 'Bing' using single nucleotide polymorphism markers $(\mathrm{n}=519)$, and $S$-locus genotype. ${ }^{\mathrm{z}}$

\begin{tabular}{|c|c|c|c|c|}
\hline Name & Maternal parent & Paternal parent & Relatedness coefficient & $S$-locus genotype \\
\hline AA & PMR-1 & Rainier & 0.34 &,$--^{\mathrm{y}}$ \\
\hline Ambrunes & $-^{\mathrm{y}}$ & - & $0^{\mathrm{x}}$ & 3,6 \\
\hline $\mathrm{BB}$ & PMR-1 & Rainier & 0.32 & 4,9 \\
\hline Benton & Stella & Beaulieu & 0.08 & $4^{\prime}, 9$ \\
\hline Black Republican & Napoleon & Unknown & 0.61 & 1,4 \\
\hline Brooks & Rainier & Early Burlat & 0.31 & 1,9 \\
\hline Cashmere & Stella & Early Burlat & 0.25 &,$- 4^{\prime}$ \\
\hline $\mathrm{CC}$ & PMR-1 & Rainier & 0.35 & 4,9 \\
\hline Chelan & Stella & Beaulieu & 0 & 3,9 \\
\hline Chinook & Bing & Gil Peck & 0.67 & 1,4 \\
\hline Cowiche & PC7147-4w & PC7146-11 ${ }^{\mathrm{v}}$ & 0.19 & 5,9 \\
\hline $\mathrm{DD}$ & PMR-1 & Rainier & 0.38 & 1,9 \\
\hline Early Burlat & - & - & 0.05 & 3,9 \\
\hline $\mathrm{EE}$ & PMR-1 & Rainier & 0.58 & 4,9 \\
\hline Emperor Francis & - & - & 0 & 3,4 \\
\hline GG & Rainier & PMR-1 & 0.38 & 1,4 \\
\hline Gil Peck & Napoleon & Giant & 0.40 & 1,3 \\
\hline Glacier & Stella & Early Burlat & 0.05 & $4^{\prime}, 9$ \\
\hline $\mathrm{JJ}$ & PMR-1 & Rainier & 0.18 &,-- \\
\hline Index & Stella & - & 0.55 &,$- 4^{\prime}$ \\
\hline Kiona & Glacier & Cashmere & 0.11 & $4^{\prime}, 9$ \\
\hline Lambert & Napoleon & Black Heart & 0.42 & 3,4 \\
\hline Lapins & Van & Stella & 0 & $1,4^{\prime}$ \\
\hline MIM 3 & - & - & 0 &,-- \\
\hline MIM 13 & - & - & 0 &,-- \\
\hline MIM 17 & - & - & 0 &,-- \\
\hline MIM 20 & - & - & 0 &,-- \\
\hline MIM 23 & - & - & 0 &,-- \\
\hline Napoleon & - & - & 0.66 & 3,4 \\
\hline New York 54 & - & - & 0 & 2,6 \\
\hline PMR-1 & - & - & 0.35 & 4,9 \\
\hline Rainier & Bing & Van & 0.50 & 1,4 \\
\hline Regina & Schneiders & Rube & 0 & 1,3 \\
\hline Sam & V1060140 & - & 0.31 & 2,4 \\
\hline Sato Nashiki & Governor Wood & Napoleon & 0.27 & 3,6 \\
\hline Schmidt & - & - & 0 & 2,4 \\
\hline Schneiders & - & - & 0 & 3,12 \\
\hline Selah & $P 8-79^{t}$ & Stella & 0.37 & $3,4^{\prime}$ \\
\hline Stella & Lambert & JI2420 & 0.18 & $3,4^{\prime}$ \\
\hline Summit & Van & Sam & 0.10 & 1,2 \\
\hline Sweetheart & Van & Newstar ${ }^{\mathrm{s}}$ & 0.03 & $3,4^{\prime}$ \\
\hline Tieton & Stella & Early Burlat & 0 & 3,9 \\
\hline Ulster & Schmidt & Lambert & 0.40 & 3,4 \\
\hline Van & Empress Eugenie & - & 0.03 & 1,3 \\
\hline Venus & Hedelfingen & Windsor & 0.28 & 1,3 \\
\hline Vic & Bing & Schmidt & 0.57 & 2,4 \\
\hline Walpurgis & - & - & 0.32 &,-- \\
\hline Windsor & - & - & 0.15 & 1,3 \\
\hline
\end{tabular}

${ }^{\mathrm{z}}$ The coefficient of relatedness was calculated following method of Queller and Goodnight (1989) implemented in software KINGROUP (Konovalov et al., 2004).

yUnknown.

${ }^{x}$ Estimates 0 or less are presented as zero indicating no relationship.

w'Stella' $\times$ unknown.

"Stella' $\times$ 'Beaulieu'.

u'Windsor' $x$ unknown.

t'Bing' $x$ 'Rainier'.

s'Van' $\times$ 'Stella'. 
Table 2. Six historical sweet cherry cultivars tested for their probability of being the paternal parent of 'Bing' where 'Black Republican' is the reported maternal parent. Seven landrace and wild accessions introduced into the United States after 1900 were included as negative controls (italics). ${ }^{\mathrm{z}}$

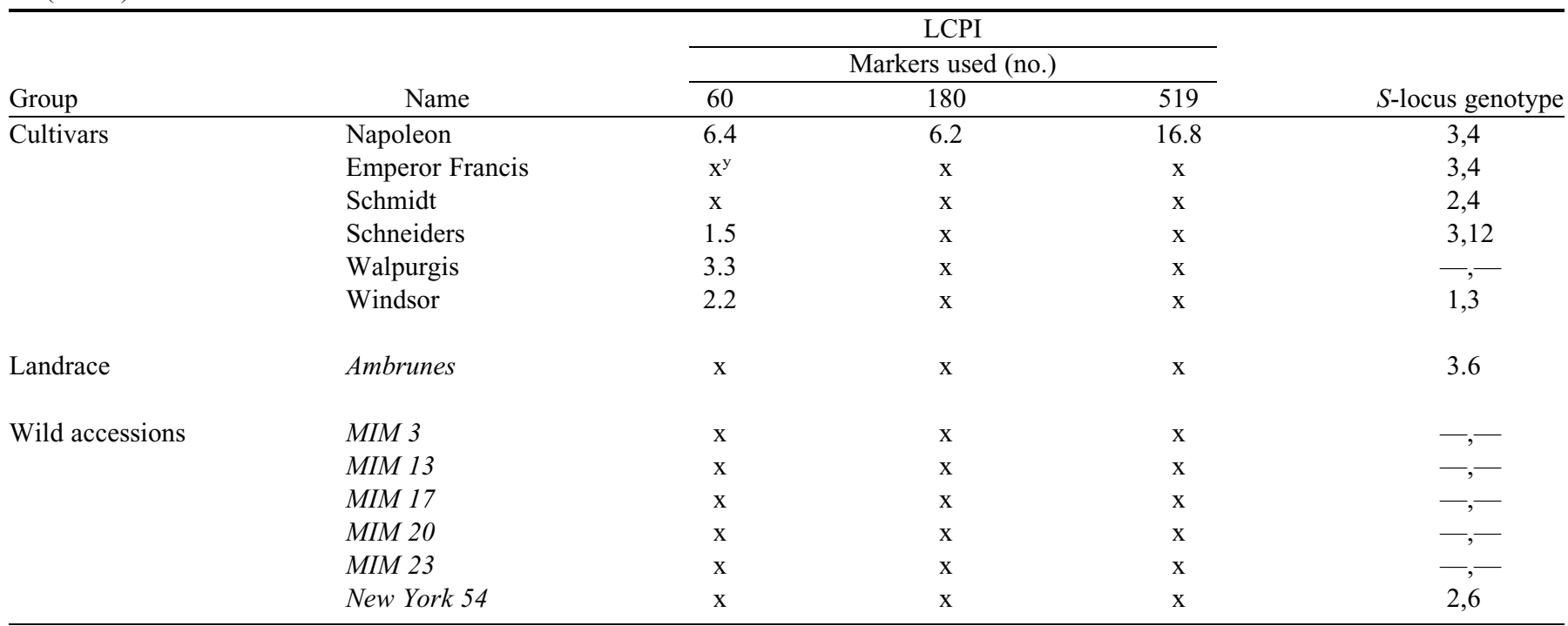

${ }^{\bar{z}}$ All individuals included in this table have unknown maternal and paternal parents. Log of composite paternity index (LCPI) was calculated using R software package "paternity vs. 1.0.0" (available from R-Forge: Theuß1 and Zeileis, 2009).

'Nonsignificant relationship with LCPI less than 1.3.

1.3, it was excluded as a "likely" paternal parent. Of the potential paternal parents identified, the one with the highest LCPI value was considered most likely.

Pairwise calculations of genetic relatedness. Pairwise calculations of the coefficient of relatedness between 'Bing' and other sweet cherry cultivars were done using the modified maximum likelihood method of Milligan (2003), Queller and Goodnight (1989), and Thompson (1975) implemented in the software KINGROUP (Konovalov et al., 2004). In this method, the coefficient of relatedness is calculated for two outbred diploid individuals $\mathrm{X}$ and $\mathrm{Y}$ that have been genotyped at L loci (in our analysis $L=519)$, where $(a, b)$ and $(c, d)$ denote their respective codominant alleles at a single locus. Using the marker information, the relatedness coefficient, $\rho$, can be defined as:

$$
\rho(X, Y)=\frac{\sum_{i=1}^{L}\left(\delta_{a c}+\delta_{a d}+\delta_{b c}+\delta_{b d}-p_{a}-p_{b}-p_{c}-p_{d}\right)}{\sum_{i=1}^{L}\left(2+\delta_{a b}+\delta_{c d}-p_{a}-p_{b}-p_{c}-p_{d}\right)}
$$

where $\delta_{x y}$ is the Kronecker delta variable $\left(\delta_{i j}=1\right.$ if $i=j$, $\delta_{i j}=0$ otherwise) and $\mathrm{a}, \mathrm{b}, \mathrm{c}, \mathrm{d}$ are alleles and their corresponding reference population allelic frequencies are $\mathrm{p}_{\mathrm{a}}, \mathrm{p}_{\mathrm{b}}$, $\mathrm{p}_{\mathrm{c}}, \mathrm{p}_{\mathrm{d}}$ (Konovalov and Heg, 2008; Queller and Goodnight, 1989). In our study, allele frequencies were calculated at 519 SNP marker loci using 48 accessions. We used the extension of

Table 3. Sweet cherry cultivars and selections tested to confirm the reported parentage using the log of composite paternity index (LPCI) calculated with varying single nucleotide polymorphism marker numbers in sweet cherry. ${ }^{\mathrm{z}}$

\begin{tabular}{|c|c|c|c|c|c|c|}
\hline \multirow[b]{3}{*}{ Name } & \multirow[b]{3}{*}{ Maternal parent } & \multirow[b]{3}{*}{ Paternal parent } & \multicolumn{3}{|c|}{$\mathrm{LPCI}^{\mathrm{y}}$} & \multirow[b]{3}{*}{$S$-locus genotype } \\
\hline & & & \multicolumn{3}{|c|}{ Markers used (no.) } & \\
\hline & & & 60 & 180 & 519 & \\
\hline Chinook & Bing & Gil Peck & 4.6 & 8.4 & 26.5 & 1,4 \\
\hline Rainier & Bing & Van & 3.9 & 7.2 & 9 & 1,4 \\
\hline Vic & Bing & Schmidt & 4.8 & 6.7 & 19.3 & 2,4 \\
\hline AA & PMR-1 & Rainier & 3.1 & 5.3 & 16.4 & -, - ${ }^{\mathrm{x}}$ \\
\hline BB & PMR-1 & Rainier & 4.2 & 6.3 & 17.2 & 4,9 \\
\hline Brooks & Rainier & Early Burlat & 2.9 & 11.7 & 32.1 & 1,9 \\
\hline $\mathrm{CC}$ & PMR-1 & Rainier & 3.8 & 5.3 & 13.8 & 4,9 \\
\hline $\mathrm{DD}$ & PMR-1 & Rainier & 3.9 & 4.8 & 14.9 & 1,9 \\
\hline $\mathrm{EE}$ & PMR-1 & Rainier & 5.2 & 6.4 & 18.6 & 4,9 \\
\hline GG & Rainier & PMR-1 & 3.2 & 6.2 & 25.7 & 1,4 \\
\hline $\mathrm{JJ}$ & PMR-1 & Rainier & 3.7 & 4.3 & 13.6 &,-- \\
\hline
\end{tabular}

zThe sweet cherry cultivars and selections listed were chosen based on 'Bing' as a reported parent or grandparent. LCPI was calculated using R software package "paternity vs. 1.0.0" (available from R-Forge: Theußl and Zeileis, 2009). The S-locus genotypes where available are also shown. yLCPI less than 1.3 indicates a nonsignificant relationship.

${ }^{x}$ Unknown. 
Konovalov and Heg (2008) that allows negative relatedness values, which are indications of no relationship. Using this formula, a coefficient of relatedness for a parent-offspring relationship would be $\approx 0.5$, whereas 1.0 would be the value for paired samples of the same individual (i.e., clonal replicates).

Calculations of inbreeding Coefficients. The inbreeding coefficient of a diploid individual is defined as the probability that the two alleles carried by the gametes are identical by descent (Kempthorne, 1957). For an individual $\mathrm{X}$, the inbreeding coefficient $F_{X}$ is equal to the coancestry between its parents. Thus, if $\mathrm{X}$ has parents $\mathrm{F}$ and $\mathrm{M}$, then the inbreeding coefficient of $\mathrm{X}$ is $\mathrm{F}_{\mathrm{X}}=\mathrm{F}_{\mathrm{FM}}$.

Inbreeding coefficients for hypothetical matings between 'Bing' and 'Stella' and their offspring (Fig. 1) were calculated based on pedigree information only using the "inbreeding" function of the R package "pedigreemm" (Vazquez et al., 2010). Inbreeding coefficients were first calculated with the paternal parent of 'Bing' listed as unknown. Then the most likely paternal parent of 'Bing' was listed, and the coefficients were recalculated.

\section{Results}

A total of 519 SNPs was available for paternity analysis because they met the first two SNP filtering criteria (Supplemental Table S1; Supplemental Fig. S1). The average marker density on the peach genome sequence for the 519 markers was 1 SNP per $0.41 \mathrm{Mbp}$ with a maximum gap of $5.2 \mathrm{Mbp}$ on scaffold 4 at the 21.6- to 26.8-Mbp interval. For the set of 180 markers, the average marker density was $1 \mathrm{SNP}$ per $1.22 \mathrm{Mbp}$ with a maximum gap of $5.62 \mathrm{Mbp}$ also on scaffold 4 at 21.6 to $27.2 \mathrm{Mbp}$. Finally, for the set of 60 markers, the average marker density was 1 SNP per $3.85 \mathrm{Mbp}$ with a maximum gap of $9.01 \mathrm{Mbp}$ on scaffold 2 at 3.4 to $12.4 \mathrm{Mbp}$.

Among the six historical cultivars tested as the alleged paternal parent of 'Bing', 'Napoleon' received by far the greatest support for paternity, and better resolution was achieved using more markers (Table 2). Because these analyses were done using 'Black Republican' as the known maternal parent, this analysis also supports 'Black Republican' as the maternal parent of 'Bing'. Although three other cultivars (Schneiders, Walpurgis, and Windsor) were supported as the possible parental parent of 'Bing' with the 60-SNP marker set, 'Napoleon' was the sole likely candidate when 180 and 519 SNPs were used, and support for 'Napoleon' was highest when 519 SNPs were used. 'Emperor Francis', 'Schmidt', and the seven landrace and wild selections used as negative controls were completely excluded as paternal parents of 'Bing' because they had LCPI values less than 1.3 for all marker sets indicating a probability of paternity of less than 0.95 .

The estimated coefficients of relatedness ( $\rho$ ) for 'Bing' paired with other individuals in the germplasm set ranged from 0 or less (unrelated) to 0.67 (Table 1). Individuals that had values consistent with a parent-offspring relationship $(\rho \approx 0.5)$ included 'Black Republican' $(\rho=0.61)$, EE $(\rho=$ $0.58)$, 'Rainier' $(\rho=0.50)$, 'Chinook' $(\rho=0.67)$, 'Index' $(\rho=$ $0.55)$, 'Napoleon' $(\rho=0.66)$, and 'Vic' $(\rho=0.57)$. Of these individuals, 'Black Republican' is the reported maternal parent of 'Bing', whereas 'Rainier', 'Chinook', and 'Vic' are reported to be 'Bing' offspring and ' $\mathrm{EE}$ ' is reported to be a secondgeneration 'Bing' offspring (Table 1). Therefore, these results also support 'Black Republican' as one of the parents of 'Bing' and 'Napoleon' as the likely other parent. The estimated coefficients of relatedness for 'Bing' and two individuals of unknown origin, PMR-1 and 'Walpurgis', were 0.35 and 0.32 , respectively, suggesting a relationship.

The 'Bing' parentage of 'Black Republican' $\times$ 'Napoleon' was further confirmed with the SNP data because no inheritance errors were found. Using the 60-SNP set, the exclusive parental source, either 'Black Republican' or 'Napoleon', of 31 of the 'Bing' alleles could be determined. The parental source of the remaining 29 alleles could be either 'Black Republican' or 'Napoleon' (Fig. 2). With the 519-SNP set, the 'Black Republican' or 'Napoleon' source of alleles could be exclusively determined for 362 of the SNPs (Supplemental Fig. S2).

The LCPI values for all SNP sets supported the pedigree records of 'Bing' as the parent of 'Chinook', 'Rainier', and 'Vic' (Table 3; Fig. 1A). The LCPI values also supported the reported paternal parents of these three 'Bing' offspring (i.e., 'Gil Peck', 'Van', and 'Schmidt', respectively). The correctness of the reported parents of the 'Brooks' ('Bing' grandchild through 'Rainier') and the seven other selections reported to have 'Rainier' as a parent was also supported with high probability. Similar to the 'Bing' analysis (Table 1), the reported parentages were probable with all marker numbers (i.e., 60,180 , and 519); however, the support was highest for 519 markers. The available $S$-locus genotypes (Table 3 ) also supported the reported parentages.

The finding that 'Napoleon' is the paternal parent of 'Bing' means that 'Bing' and 'Stella' share a common ancestor because 'Napoleon' is the grandparent of 'Stella' (Fig. 1AB). With such a relationship, the inbreeding coefficient would be expected to be 0.125 , which is consistent with the 0.18 coefficient of relatedness for 'Bing' and 'Stella' calculated using 519 SNP markers (Table 1). The expected inbreeding coefficients for hypothetical progeny between 'Bing' $\times$ 'Stella' and progeny from the 'Bing' and 'Stella' lineages with and without 'Napoleon' as the paternal parent of 'Bing' ranged from 0.008 to 0.328 (Table 4 ). In all cases, the pedigree-based inbreeding coefficients of the hypothetical offspring were much higher when 'Napoleon' was included as the paternal parent of 'Bing' compared with when they were calculated with the paternal parent of 'Bing' as unknown. The highest inbreeding coefficients were for hypothetical progeny from the use of 'Selah' as a parent because 'Selah' has parentage from both the 'Stella' and 'Bing' lineages (Fig. 1A-B). Inbreeding coefficients calculated for hypothetical progeny with and without the inclusion of 'Napoleon' as the parent of 'Bing' were also influenced by shared ancestry with other cultivars. 'Early Burlat' is a parent of 'Brooks', 'Glacier', and 'Tieton', whereas 'Van' is a parent of 'Lapins', 'Rainier', and 'Sweetheart' (Fig. 1). Therefore, pedigree-based inbreeding coefficients for hypothetical progeny from crosses within these groups of cultivars were increased beyond that expected with just shared 'Bing' ancestry (Table 4).

\section{Discussion}

'Napoleon' was identified as the paternal parent of 'Bing' and 'Black Republican' was confirmed as the maternal parent of 'Bing'. This cross was possible because 'Napoleon' was among the first cultivars planted in Oregon in the late 1800s. The $S$-locus genotypes are also consistent with the proposed parentage, because it is possible for an $S_{3}$-containing pollen 


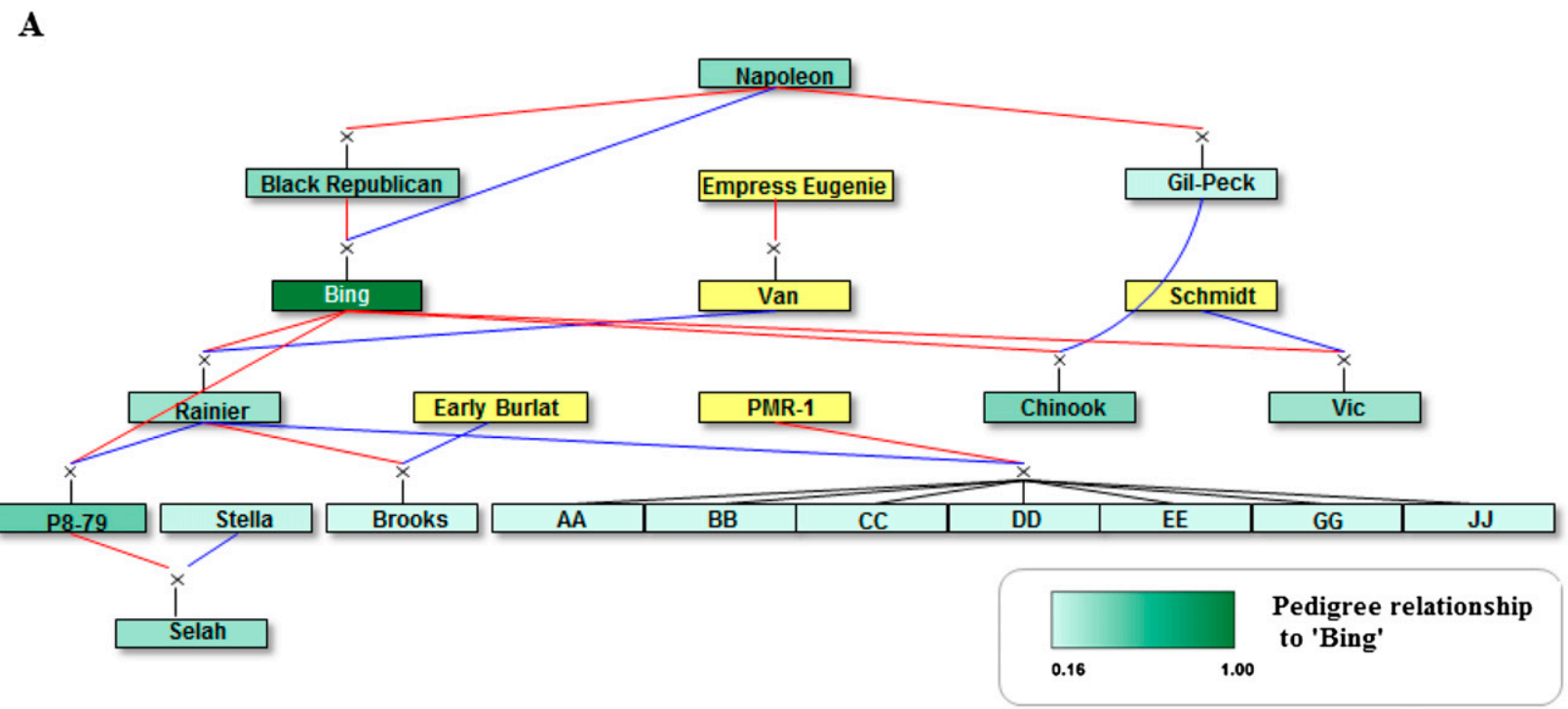

B

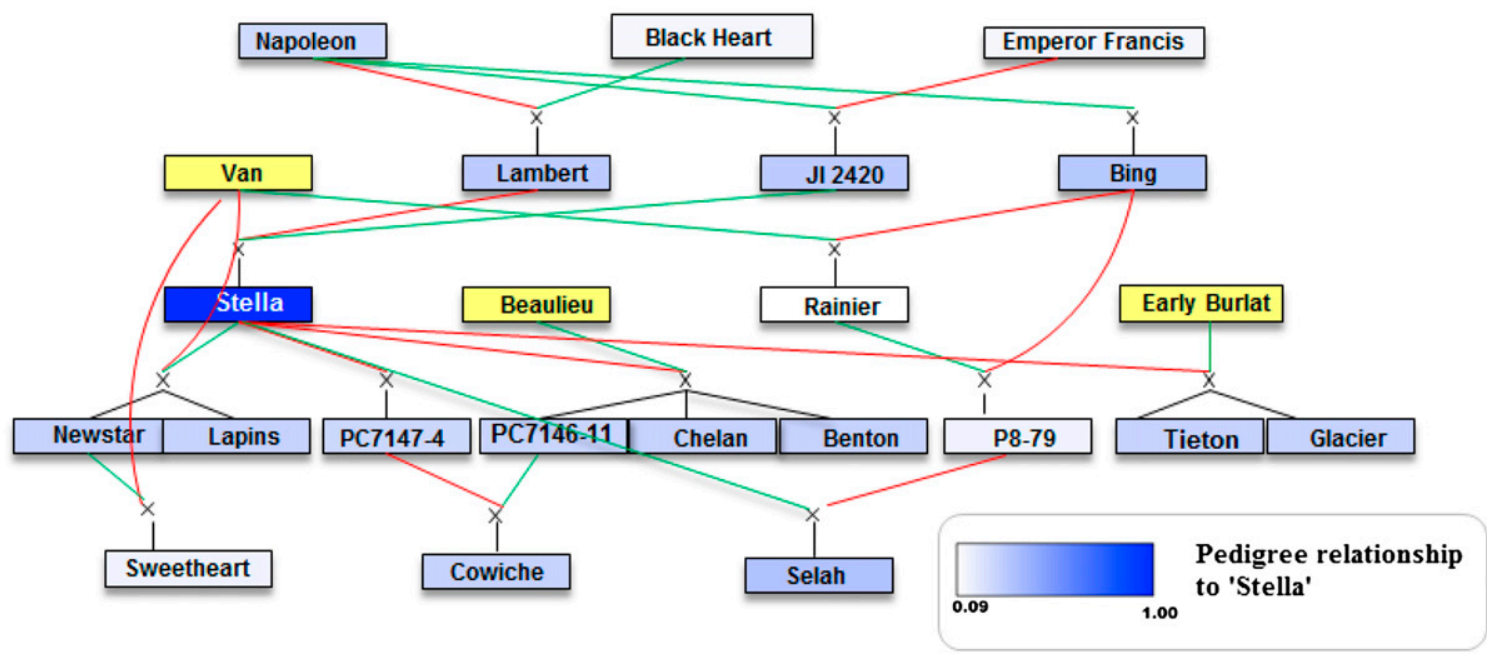

Fig. 1. (A) Pedigrees for sweet cherry individuals in the 'Bing' lineage. The sweet cherry cultivar Napoleon is included as the newly identified paternal parent of 'Bing'. The intensity of green illustrates the degree of relatedness $(\rho)$ to 'Bing' according to pedigree records, whereas yellow indicates no known pedigree relationship to 'Bing'. (B) Pedigrees of sweet cherry individuals in the 'Stella' lineage. The intensity of blue indicates the degree of relationship to 'Stella' according to pedigree records, whereas yellow indicates no known pedigree relationship to 'Stella'. The online version is in color.

grain from 'Napoleon' to have grown down a 'Black Republican' $\left(S_{1} S_{4}\right)$ style and fertilized an $S_{4}$ egg, resulting in the $S_{3} S_{4}$ pair of 'Bing'. This parentage is also consistent with the inheritance of skin and flesh color in sweet cherry in which yellow fruit with a red blush is recessive to mahogany fruit (Schmidt, 1998). 'Napoleon' and 'Rainier' have yellow skin with a red blush, whereas 'Bing' fruit is mahogany. 'Bing' is heterozygous at the fruit color locus and passed the recessive allele for yellow fruit to 'Rainier'.

Hedrick (1915) considered 'Napoleon' and 'Black Tartarian' to be the parents of 'Black Republican', thereby potentially increasing the contribution of 'Napoleon' to 'Bing' beyond the $50 \%$ of solely a parent-offspring relationship. The observed coefficients of relatedness based on 519 SNP makers $(0.66$ for 'Bing' and 'Napoleon', 0.61 for 'Bing' and 'Black Republican') are greater than would be expected for a solely parentoffspring relationship but lower than the 0.75 expected if
'Napoleon' were the parent of 'Black Republican'. 'Napoleon' parentage of 'Black Republican' was used by Choi and Kappel (2004) in their analysis of inbreeding and coancestry in sweet cherry. Using our 519-SNP data set, 'Napoleon' as a parent of 'Black Republican' was supported ( $\rho=0.48)$; however, 'Black Tartarian' could not be confirmed as a result of lack of a verified clone. An alternative hypothesis is that other unknown relationships exist among the founder cultivars, resulting in an increase in the SNP-based coefficients of relatedness compared with pedigree-based expectations.

'Bing' parentage of 'Chinook', 'Rainier', 'Vic', and eight other selections was also supported by the paternity analysis. Probabilities for detecting parentage (LCPI values) almost always increased when SNP numbers increased from 60 to 180 to 519 , yet importantly, the conclusion that 'Napoleon' is the paternal parent of 'Bing' and that 'Bing' is the true parent or grandparent of 11 cultivars and selections were the same 


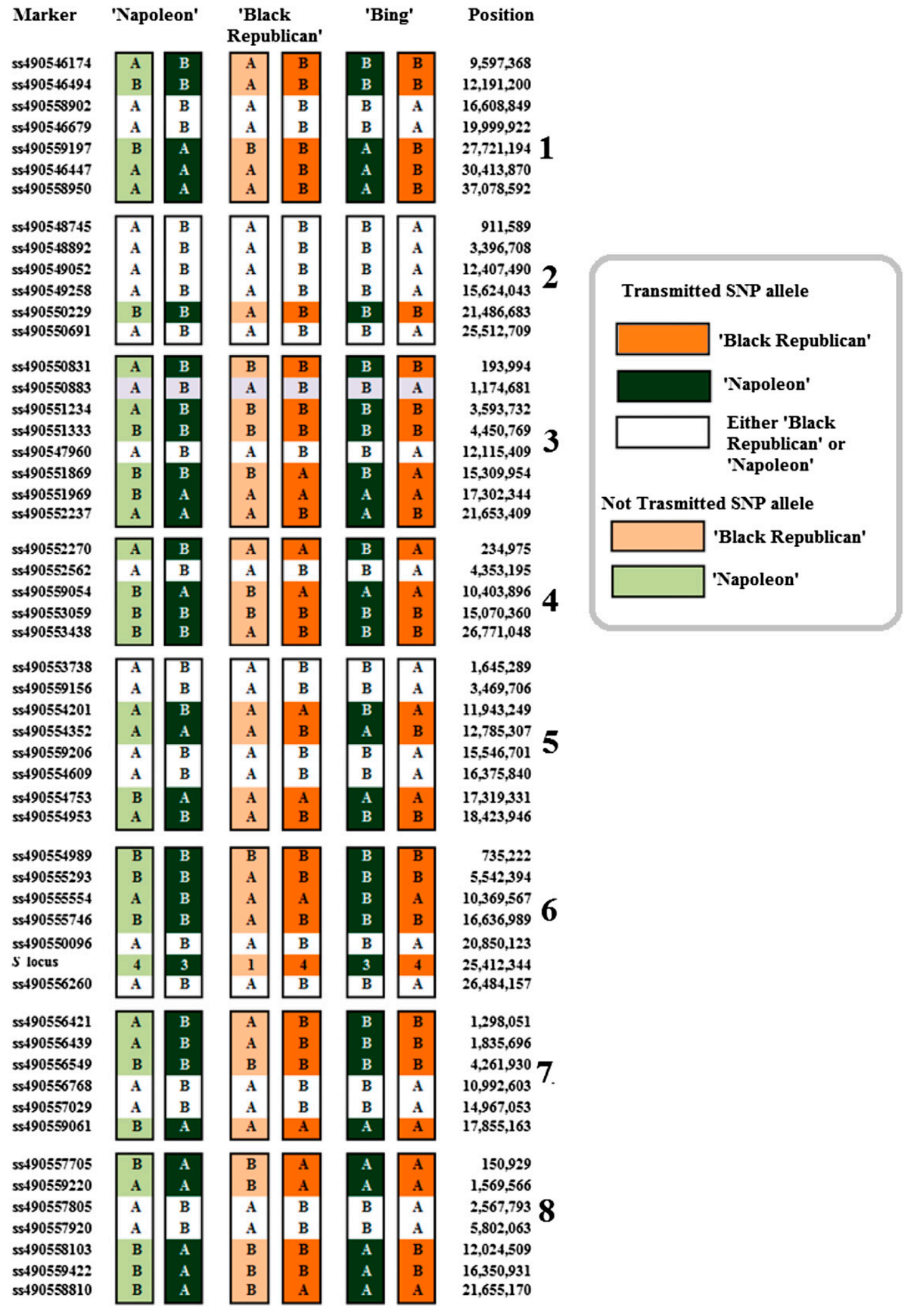

Fig. 2. Graphical representation of probable parental source of alleles in sweet cherry cultivar Bing. Only 60 single nucleotide polymorphism (SNP) markers and the $S$ locus are presented (for all markers, see Supplementary Fig. 2). Positions are physical positions (bp) of the peach whole genome sequence, Peach v1.0 (Verde et al., 2013). The online version is in color, where color indicates parent from which allele is inherited. 
Table 4. Inbreeding coefficients according to pedigree for progeny individuals generated from hypothetical crosses between sweet cherry cultivars Bing, Rainier, and Brooks and seven cultivars from the 'Stella' lineage.

\begin{tabular}{lccc}
\hline & \multicolumn{3}{c}{ Parent 1 } \\
\cline { 2 - 4 } Parent 2 & Bing & Rainier & Brooks \\
\hline Stella & $0.063(0.188)$ & $0.032(0.094)$ & $0.016(0.047)$ \\
Benton & $0.031(0.094)$ & $0.016(0.047)$ & $0.008(0.023)$ \\
Chelan & $0.031(0.094)$ & $0.016(0.047)$ & $0.008(0.023)$ \\
Glacier & $0.031(0.094)$ & $0.016(0.047)$ & $0.133(0.148)$ \\
Lapins & $0.031(0.094)$ & $0.141(0.172)$ & $0.070(0.086)$ \\
Selah & $0.219(0.328)$ & $0.203(0.250)$ & $0.101(0.125)$ \\
Sweetheart & $0.016(0.047)$ & $0.195(0.211)$ & $0.098(0.105)$ \\
Tieton & $0.031(0.094)$ & $0.016(0.047)$ & $0.133(0.148)$
\end{tabular}

${ }^{\mathrm{z}}$ The first coefficient was calculated assuming that the paternal parent was unknown and unrelated to all others, whereas the second coefficient in parentheses was calculated with 'Napoleon' as the paternal parent of 'Bing'.

regardless of marker number. The cultivars for which 'Bing' parentage could not be ruled out with only 60 SNP markers may have 'Napoleon' or 'Black Republican' ancestry as a result of the limited diversity of sweet cherry available in the Pacific northwestern United States in the 1800s. Additionally, when considering the offspring and grandchildren of 'Bing', the high LCPI values using 60 and 180 SNPs indicate that, for sweet cherry, the lower number of markers provided sufficient discriminatory power. As expected, the larger number of SNPs increased the power of excluding false candidates and identifying parents.

The finding that 'Bing' and 'Stella' have a common ancestor increases the known degree of relatedness among cultivated and breeding germplasm of North American sweet cherry with implications for breeding decisions. 'Stella' is an extensively used parent in sweet cherry breeding worldwide because it is the donor of self-compatibility caused by the presence of a mutated $S_{4}$ allele, i.e., $S_{4}$. This mutation originated from irradiated 'Napoleon' pollen that was used to pollinate 'Emperor Francis' (Lewis and Crowe, 1954). The cultivar Selah was unique in the germplasm set examined in having both 'Bing' and 'Stella' as ancestors and thus has 'Napoleon' ancestry from both sides. For other cultivars derived from 'Stella' and/or 'Napoleon', their close relatedness $(\rho>0.20)$ to 'Bing' could be the result of the common 'Napoleon' ancestor. For example, the maternal parent of 'Lambert' and 'Gil Peck' is 'Napoleon', and according to 520 markers, these cultivars had coefficients of relatedness with 'Bing' of 0.42 and 0.40 , respectively.

In this study, the coefficient of relatedness also suggested a close relationship of 'Bing' with PMR-1 and 'Walpurgis', although no pedigrees are available. PMR-1 originated as a chance seedling in Washington State in the 1970s (Toyama et al., 1993). Therefore, it is possible that the relatedness of PMR-1 to 'Bing' could be the result of ancestry with 'Bing', 'Napoleon', and/or 'Black Republican'. The $S_{9}$ allele of PMR-1 could have been derived from 'Early Burlat' or 'Beaulieu'. 'Walpurgis' on the other hand is a European cultivar; therefore, the relatedness to 'Bing' may be the result of ancestry with either 'Napoleon' or 'Black Republican' rather than directly with 'Bing'.

Establishing complete and correct pedigree records, as illustrated for 'Bing', is an important requirement to maximize the ability to identify and validate quantitative trait loci using pedigree-based methods (Bink et al., 2008; Rosyara et al., 2009, 2013). The identification of previously unknown parents enables more precise estimates of coefficients of identity by descent. Identifying which 'Napoleon'-derived chromosome segments, and which 'Black Republican'-derived chromosome segments, are maintained in superior cultivars is now possible as a result of confirmation of parentage and the available genomewide set of polymorphic SNP markers.

\section{Literature Cited}

Bink, M.C.A.M., M.P. Boer, C.J.F. ter Braak, J. Jansen, R.E. Voorrips, and W.E. van de Weg. 2008. Bayesian analysis of complex traits in pedigreed plant populations. Euphytica 161:85-96.

Bink, M.C.A.M., L.R. Totir, C.J.F. ter Braak, C.R. Winkler, M.P. Boer, and O.S. Smith. 2012. QTL linkage analysis of connected populations using ancestral marker and pedigree information. Theor. Appl. Genet. 124:1097-1113.

Blouin, M.S. 2003. DNA-based methods for pedigree reconstruction and kinship analysis in natural populations. Trends Ecol. Evol. 18:503-511.

Bowers, J., J.-M. Boursiquot, P. This, K. Chu, H. Johansson, and C. Meredith. 1999. Historical genetics: The parentage of Chardonnay, Gamay, and other wine grapes of northeastern France. Science 285:1562-1565.

Choi, C. and F. Kappel. 2004. Inbreeding, coancestry, and founding clones of sweet cherry from North America. J. Amer. Soc. Hort. Sci. 129:535-543.

De la Rosa, R., A. Belaj, A. Munoz-Merida, O. Trelles, I. Ortiz-Martin, J.J. Gonzalez-Plaza, V. Valpuesta, and C.R. Beuzon. 2013. Development of EST-derived SSR markers with long-core repeat in olive and their use for paternity testing. J. Amer. Soc. Hort. Sci. 138:290-296

De la Rosa, R., C.M. James, and K.R. Tobutt. 2004. Using microsatellites for paternity testing in olive progenies. HortScience 39: 351-354.

Elston, R.C. 1986. Probability and paternity testing. Amer. J. Hum. Genet. 39:112-122.

Evett, I.W. and B.S. Weir. 1998. Interpreting DNA evidence: Statistical genetics for forensic scientists. Sinauer Associates, Sunderland, MA.

Fries, R. and G. Durstewitz. 2001. Digital DNA signatures for animal tagging. Nat. Biotechnol. 19:508.

Haldar, S., S. Haedinges, D. Edge-Garza, N. Oraguzie, J. Olmstead, A. Iezzoni, and C. Peace. 2010. Applying genetic markers for selffertility in the WSU sweet cherry breeding program. Acta Hort. 859:375-380.

Harada, T., K. Matsukawa, T. Sato, R. Ishikawa, M. Niizeki, and K. Saito. 1993. DNA-RAPDs detect genetic variation and paternity in Malus. Euphytica 65:87-91.

Hedrick, U.P. 1915. The cherries of New York. New York Agr. Expt. Sta., Geneva, NY.

Iezzoni, A., H. Schmidt, and A. Albertini. 1990. Cherries (Prunus spp.), p. 110-173. In: Moore, J.N. (ed.). Genetic resources for temperate fruit and nut crops, Intl. Soc. Hort. Sci., Wageningen, The Netherlands.

Iezzoni, A.F., R.L. Andersen, H. Schmidt, R. Tao, K.R. Tobutt, and P.A. Wiersma. 2005. Proceedings of the S-allele workshop at the 2001 International Cherry Symposium. Acta Hort. 667:25-35.

Kempthorne, O. 1957. An introduction to genetic statistics. Wiley, New York, NY.

Konovalov, D.A. and D. Heg. 2008. A maximum-likelihood relatedness estimator allowing for negative relatedness values. Mol. Ecol. Resources 8:256-263.

Konovalov, D.A., C. Manning, and M.T. Henshaw. 2004. KINGROUP: A program for pedigree relationship reconstruction and kin group assignments using genetic markers. Mol. Ecol. Notes 4:779-782. 
Kruglyak, L. 1997. The use of a genetic map of biallelic markers in linkage studies. Nat. Genet. 17:21-24.

Lapins, K.O. 1970. The 'Stella' cherry. Fruit Var. Hort. Dig. 24:19-20.

Lebrec, J.J.P., H. Putter, J.J. Houwing-Duistermaat, and H.C. van Houwelingen. 2008. Influence of genotyping error in linkage mapping for complex traits-An analytic study. BMC Genet. 9:57.

Lewis, D. and L.K. Crowe. 1954. Structure of the incompatibility gene. IV. Types of mutation in Prunus avium L. Heredity 8:357-363.

Li, C., S. Zhang, L. Li, J. Chen, Y. Liu, and S. Zhao. 2012. Selection of 29 highly informative InDel markers for human identification and paternity analysis in Chinese Han population by the SNPlex genotyping system. Mol. Biol. Rpt. 39:3143-3152.

Milligan, B.G. 2003. Maximum-likelihood estimation of relatedness. Genetics 163:1153-1167.

Peace, C., N. Bassil, D.F.S. Main, U.R. Rosyara, T. Stegmeir, A. Sebolt, B. Gilmore, C. Lawley, T.C. Mockler, D.W. Bryant, L. Wilhelm, and A. Iezzoni. 2012. Genome-wide SNP detection, validation and development of a 6K SNP assay for sweet and sour cherry. PLoS One 7:e48305.

Queller, D.C. and K.F. Goodnight. 1989. Estimating relatedness using genetic-markers. Evolution 43:258-275.

Rosyara, U.R., M.C.A.M. Bink, E. van de Weg, G. Zhang, D. Wang, A. Sebolt, E. Dirlewanger, J. Quero-Garcia, M. Schuster, and A.F. Iezzoni. 2013. Fruit size QTL identification and the prediction of parental QTL genotypes and breeding values in multiple pedigreed populations of sweet cherry. Mol. Breed. 32:875-887.

Rosyara, U.R., J.L. Gonzalez-Hernandez, K.D. Glover, K.R. Gedye, and J.M. Stein. 2009. Family-based mapping of quantitative trait loci in plant breeding populations with resistance to Fusarium head blight in wheat as an illustration. Theor. Appl. Genet. 118:1617-1631.

Savolainen, V., R. Corbaz, C. Moncousin, R. Spichiger, and J.F. Manen. 1995. Chloroplast DNA variation and parentage analysis in 55 apples. Theor. Appl. Genet. 90:1138-1141.
Schmidt, H. 1998. On the genetics of fruit color in sweet cherries. Acta Hort. 468:77-81.

Schueler, S., A. Tusch, M. Schuster, and B. Ziegenhagen. 2003. Characterization of microsatellites in wild and sweet cherry (Prunus avium L.) markers for individual identification and reproductive processes. Genome 46:95-102.

Theuß1, S. and A. Zeileis. 2009. Collaborative software development using R-Forge. R J 1:9-14.

Thompson, E.A. 1975. Estimation of pairwise relationships. Ann. Hum. Genet. 39:173-188.

Toyama, T.K., D.R. Ophardt, W.E. Howell, and G.G. Grove. 1993. New powdery mildew resistant sweet cherry. Fruit Var. J. 47:234235.

Vazquez, A.I., D.M. Bates, G.J.M. Rosa, D. Gianola, and K.A. Weigel. 2010. Technical note: An R package for fitting generalized linear mixed models in animal breeding. J. Anim. Sci. 88:497-504.

Verde, I., A.G. Abbott, S. Scalabrin, S. Jung, S. Shu, F. Marroni, T. Zhebentyayeva, M.T. Dettori, J. Grimwood, F. Cattonaro, A. Zuccolo, L. Rossini, J. Jenkins, E. Vendramin, L.A. Meisel, V. Decroocq, B. Sosinski, S. Prochnik, T. Mitros, A. Policriti, G. Cipriani, L. Dondini, S. Ficklin, D. Mgoodstein, P. Xuan, C. Del Fabbro, V. Aramini, D. Copetti, S. Gonzalez, D. Shorner, R. Falchi, S. Lucas, E. Mica, J. Maldonado, B. Lazzari, D. Bielenberg, R. Pirona, M. Miculan, A. Barakat, R. Testolin, A. Stella, S. Tartarini, P. Tonutti, P. Arús, A. Orellana, C. Wells, D. Main, G. Vizzotto, H. Silva, F. Salamini, J. Schmutz, M. Morgante, and D.S. Rokhsar. 2013. The high-quality draft genome of peach (Prunus persica) identifies unique patterns of genetic diversity, domestication and genome evolution. Nat. Genet. 45:487-494.

Yamamoto, T., K. Mochida, T. Imai, T. Haji, H. Yaegaki, M. Yamaguchi, N. Matsuta, I. Ogiwara, and T. Hayashi. 2003. Parentage analysis in Japanese peaches using SSR markers. Breed. Sci. 53: 35-40. 


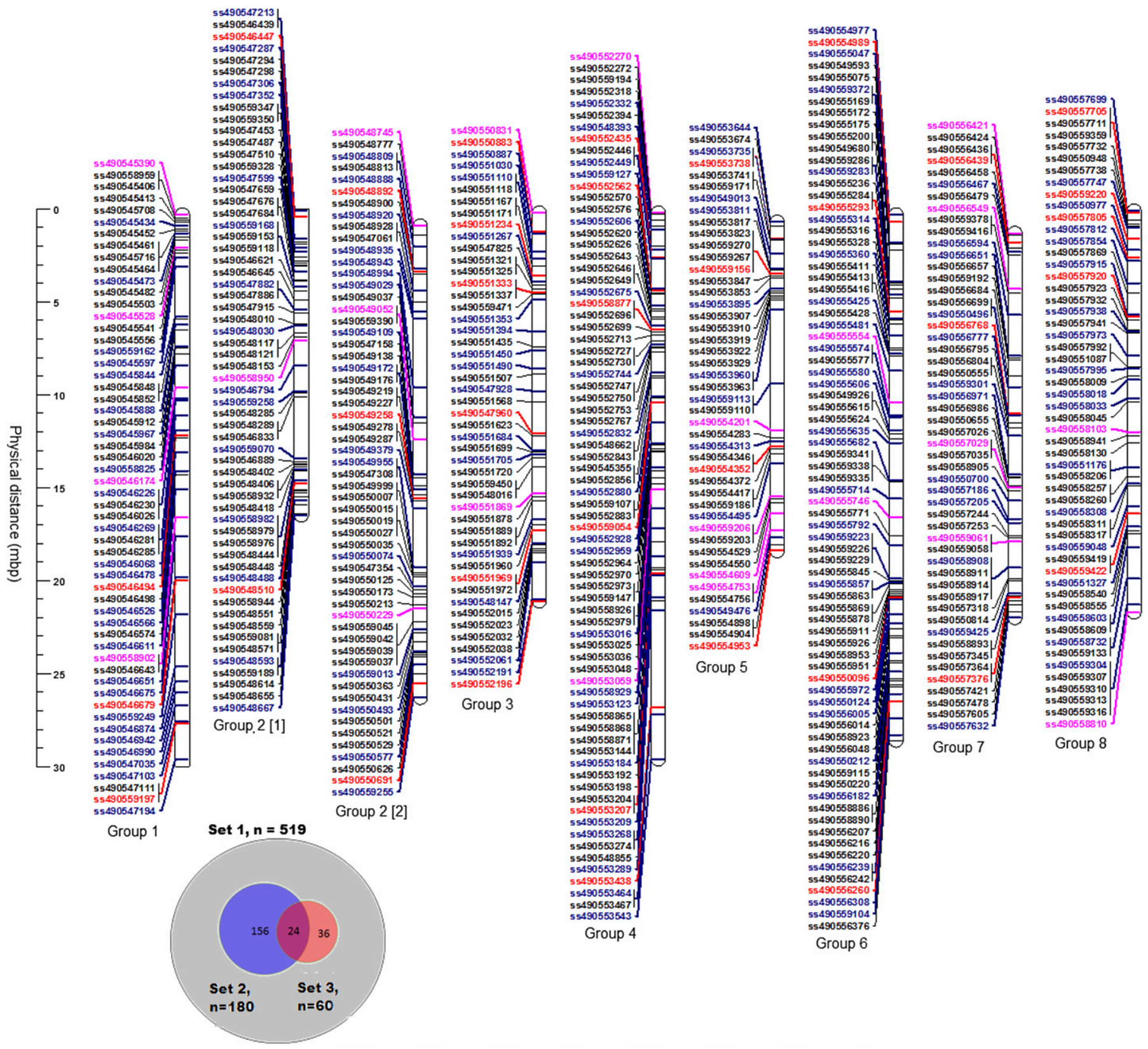

Supplemental Fig. S1. Physical map positions, according to the whole peach genome sequence, Peach v1.0 (Verde et al., 2013), of the 519 single nucleotide polymorphism (SNP) markers used in this sweet cherry paternity study. Three different sets were used for calculation of the log of composite paternity index (LCPI). Colors identify the set of 180 markers (blue and purple) and set of 60 markers (red and purple). The purple-colored markers are common in all marker sets $(519,180$, and 60 markers). 


\begin{tabular}{|c|c|c|c|c|c|c|c|c|}
\hline NCBI ss & Chr & Position & Nap & & Black & publican & Bing & \\
\hline ss490545390 & 1 & $1 \quad 348,730$ & A & B & A & B & A & B \\
\hline ss490558959 & 1 & 450,381 & A & B & A & A & B & A \\
\hline ss490545406 & 1 & 538,005 & $A$ & A & $A$ & $A$ & A & A \\
\hline ss490545413 & 1 & 599,759 & $A$ & A & $A$ & A & A & A \\
\hline ss490545708 & 1 & 694,731 & A & B & A & B & A & B \\
\hline ss490545434 & 1 & 885,553 & A & B & A & B & A & B \\
\hline ss490545452 & & $1,111,320$ & A & B & A & B & A & B \\
\hline ss490545461 & 1 & $1,197,874$ & A & A & A & A & A & A \\
\hline ss490545716 & 1 & $1,235,182$ & B & B & B & B & B & B \\
\hline ss490545464 & 1 & $1,238,095$ & B & B & B & B & B & B \\
\hline ss490545473 & 1 & $1,331,155$ & A & B & A & B & A & B \\
\hline ss490545482 & 1 & $1,450,317$ & A & B & A & B & A & B \\
\hline ss490545503 & 1 & $1,737,374$ & B & B & B & B & B & B \\
\hline ss490545528 & 1 & $2,115,377$ & $A$ & B & $A$ & B & A & B \\
\hline ss490545541 & 1 & $2,241,751$ & A & B & A & B & - & - \\
\hline ss490545556 & 1 & $2,441,717$ & A & B & A & B & A & B \\
\hline ss490559162 & 1 & $2,602,122$ & B & B & B & B & B & B \\
\hline ss490545597 & 1 & $3,137,813$ & A & A & A & $A$ & A & A \\
\hline ss490545844 & 1 & $5,839,154$ & A & B & A & $A$ & B & A \\
\hline ss490545848 & 1 & $5,878,432$ & B & A & B & B & A & B \\
\hline ss490545852 & 1 & $5,894,052$ & A & B & A & $A$ & B & A \\
\hline ss490545888 & 1 & $6,215,653$ & A & A & A & A & A & A \\
\hline ss490545912 & 1 & $6,460,845$ & B & B & B & B & B & B \\
\hline ss490545967 & 1 & $7,374,161$ & B & B & B & B & B & B \\
\hline ss490545984 & 1 & $7,504,437$ & B & B & B & B & B & B \\
\hline ss490546020 & 1 & $7,824,263$ & A & A & A & $A$ & A & A \\
\hline ss490558825 & 1 & $8,412,096$ & $A$ & A & $A$ & $A$ & A & $A$ \\
\hline ss490546174 & 1 & $9,597,368$ & A & B & A & B & B & B \\
\hline ss490546226 & 1 & $10,175,178$ & B & A & $A$ & A & A & A \\
\hline
\end{tabular}

Transmitted SNP alleles

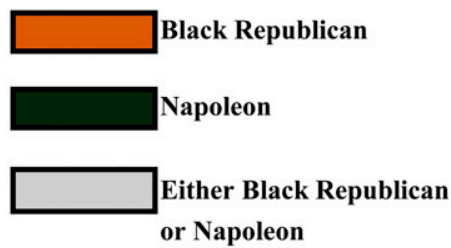

Not transmitted SNP alllele

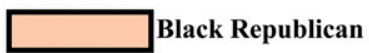

$\square$ Napoleon

Supplemental Fig. S2. Graphic representation of probable parental source of alleles in sweet cherry cultivar Bing with all 519 single nucleotide polymorphism (SNP) markers. Positions are physical positions (bp) of the peach whole genome sequence, Peach v1.0 (Verde et al., 2013); NCBI = National Center for Biotechnology Information (Bethesda, MD); ss = submitted SNP; Chr = chromosome. 


$\begin{array}{lll}\text { ss490546230 } & 1 & 10,176,147 \\ \text { ss490546026 } & 1 & 10,178,231 \\ \text { ss490546269 } & 1 & 10,284,090 \\ \text { ss490546281 } & 1 & 10,316,151 \\ \text { ss490546285 } & 1 & 10,330,576 \\ \text { ss490546068 } & 1 & 11,102,635 \\ \text { ss490546478 } & 1 & 11,855,405 \\ \text { ss490546494 } & 1 & 12,191,200 \\ \text { ss490546498 } & 1 & 12,292,557 \\ \text { ss490546526 } & 1 & 13,052,512 \\ \text { ss490546566 } & 1 & 14,110,306 \\ \text { ss490546574 } & 1 & 14,281,912 \\ \text { ss490546611 } & 1 & 15,061,804 \\ \text { ss490558902 } & 1 & 16,608,849 \\ \text { ss490546643 } & 1 & 16,612,689 \\ \text { ss490546651 } & 1 & 17,571,526 \\ \text { ss490546675 } & 1 & 19,836,475 \\ \text { ss490546679 } & 1 & 19,999,922 \\ \text { ss490559249 } & 1 & 21,773,370 \\ \text { ss490546874 } & 1 & 24,575,772 \\ \text { ss490546942 } & 1 & 25,423,943 \\ \text { ss490546990 } & 1 & 26,047,253 \\ \text { ss490547035 } & 1 & 26,698,128 \\ \text { ss490547103 } & 1 & 27,626,876 \\ \text { ss490547111 } & 1 & 27,714,539 \\ \text { ss490559197 } & 1 & 27,721,194 \\ \text { ss490547194 } & 1 & 29,638,469 \\ \text { ss490547213 } & 1 & 30,054,079 \\ \text { ss490546439 } & 1 & 30,065,891 \\ \text { ss490546447 } & 1 & 30,413,870 \\ \text { ss490547287 } & 1 & 31,633,964 \\ \text { ss490547294 } & 1 & 31,805,500 \\ \text { ss490547298 } & 1 & 31,881,572 \\ \text { ss490547306 } & 1 & 32,053,318 \\ \text { ss490547352 } & 1 & 32,270,077 \\ \text { ss490559347 } & 1 & 32,621,488\end{array}$

\begin{tabular}{|l|l|}
\hline B & A \\
A & B \\
A & B \\
A & A \\
B & A \\
B & B \\
B & B \\
B & B \\
A & A \\
A & B \\
\hline A & B \\
A & B \\
A & B \\
A & B \\
A & B \\
A & B \\
A & B \\
A & B \\
\hline B & B \\
\hline A & B \\
\hline A & A \\
B & B \\
A & B \\
A & B \\
A & B \\
B & A \\
A & B \\
A & A \\
A & A \\
A & A \\
A & B \\
A & B \\
A & B \\
A & B \\
B & A \\
B & A \\
\hline
\end{tabular}

\begin{tabular}{|c|c|}
\hline A & A \\
\hline B & $B$ \\
\hline B & B \\
\hline A & $A$ \\
\hline A & $A$ \\
\hline A & $B$ \\
\hline A & $B$ \\
\hline A & $B$ \\
\hline B & $A$ \\
\hline B & B \\
\hline A & B \\
\hline A & B \\
\hline A & B \\
\hline A & B \\
\hline A & B \\
\hline A & B \\
\hline A & B \\
\hline A & B \\
\hline B & B \\
\hline A & B \\
\hline A & A \\
\hline B & B \\
\hline A & $B$ \\
\hline A & $A$ \\
\hline A & $A$ \\
\hline B & $B$ \\
\hline A & $A$ \\
\hline A & $B$ \\
\hline A & $B$ \\
\hline A & $B$ \\
\hline A & A \\
\hline A & A \\
\hline $\begin{array}{l}\text { A } \\
A\end{array}$ & $\begin{array}{l}A \\
A\end{array}$ \\
\hline B & B \\
\hline B & B \\
\hline
\end{tabular}

\begin{tabular}{|c|c|}
\hline A & A \\
\hline B & $B$ \\
\hline B & B \\
\hline A & $A$ \\
\hline A & $A$ \\
\hline B & B \\
\hline $\begin{array}{l}\text { B } \\
\text { B }\end{array}$ & $B$ \\
\hline A & A \\
\hline B & B \\
\hline$A$ & B \\
\hline A & B \\
\hline A & B \\
\hline A & B \\
\hline A & B \\
\hline A & B \\
\hline A & B \\
\hline A & B \\
\hline B & B \\
\hline A & B \\
\hline A & $A$ \\
\hline B & B \\
\hline $\begin{array}{l}\text { B } \\
\text { B }\end{array}$ & $\begin{array}{l}B \\
A\end{array}$ \\
\hline B & $A$ \\
\hline A & B \\
\hline B & $A$ \\
\hline A & $\begin{array}{l}B \\
B\end{array}$ \\
\hline A & B \\
\hline B & $A$ \\
\hline B & $A$ \\
\hline B & $A$ \\
\hline B & A \\
\hline $\begin{array}{l}\mathbf{A} \\
\mathbf{A}\end{array}$ & B \\
\hline
\end{tabular}

Supplemental Fig. S2. Continued. 


$\begin{array}{lll}\text { ss490559350 } & 1 & 32,621,532 \\ \text { ss490547453 } & 1 & 32,759,983 \\ \text { ss490547487 } & 1 & 32,894,074 \\ \text { ss490547510 } & 1 & 33,007,179 \\ \text { ss490559328 } & 1 & 33,117,964 \\ \text { ss490547599 } & 1 & 33,392,756 \\ \text { ss490547659 } & 1 & 33,790,546 \\ \text { ss490547676 } & 1 & 33,883,266 \\ \text { ss490547684 } & 1 & 33,907,538 \\ \text { ss490559168 } & 1 & 34,168,048 \\ \text { ss490559153 } & 1 & 34,192,653 \\ \text { ss490559118 } & 1 & 34,197,844 \\ \text { ss490546621 } & 1 & 34,430,805 \\ \text { ss490546645 } & 1 & 34,916,586 \\ \text { ss490547882 } & 1 & 35,371,782 \\ \text { ss490547886 } & 1 & 35,408,469 \\ \text { ss490547915 } & 1 & 35,614,161 \\ \text { ss490548010 } & 1 & 36,188,884 \\ \text { ss490548030 } & 1 & 36,319,573 \\ \text { ss490548117 } & 1 & 36,725,185 \\ \text { ss490548121 } & 1 & 36,738,631 \\ \text { ss490548153 } & 1 & 36,865,299 \\ \text { ss490558950 } & 1 & 37,078,592 \\ \text { ss490546794 } & 1 & 38,376,904 \\ \text { ss490559258 } & 1 & 39,849,154 \\ \text { ss490548285 } & 1 & 39,922,772 \\ \text { ss490548289 } & 1 & 40,057,233 \\ \text { ss490546833 } & 1 & 40,061,065 \\ \text { ss490559070 } & 1 & 43,353,354 \\ \text { ss490546889 } & 1 & 43,556,762 \\ \text { ss490548402 } & 1 & 43,706,470 \\ \text { ss490548406 } & 1 & 43,806,891 \\ \text { ss490558932 } & 1 & 43,832,684 \\ \text { ss490548418 } & 1 & 43,875,207 \\ \text { ss490558982 } 490558979 & 1 & 44,008,459 \\ & 1 & 44,008,562\end{array}$

\begin{tabular}{|l|l|}
\hline A & B \\
A & B \\
A & A \\
\hline A & B \\
\hline A & A \\
B & A \\
A & B \\
\hline B & B \\
\hline B & B \\
B & B \\
\hline A & A \\
\hline A & A \\
\hline B & B \\
B & A \\
\hline A & B \\
\hline B & A \\
\hline A & B \\
A & B \\
\hline B & B \\
A & B \\
\hline B & A \\
B & A \\
\hline A & A \\
\hline A & A \\
A & B \\
\hline A & A \\
\hline A & A \\
A & B \\
A & B \\
A & A \\
A & B \\
B & A \\
B & B \\
\hline A & B \\
\hline A \\
\hline
\end{tabular}

\begin{tabular}{|c|c|}
\hline A & $A$ \\
\hline A & $B$ \\
\hline A & $B$ \\
\hline A & $A$ \\
\hline A & B \\
\hline B & B \\
\hline A & B \\
\hline B & $A$ \\
\hline B & $A$ \\
\hline B & $A$ \\
\hline A & B \\
\hline A & B \\
\hline B & B \\
\hline B & B \\
\hline A & B \\
\hline B & B \\
\hline A & B \\
\hline A & B \\
\hline B & B \\
\hline A & $A$ \\
\hline B & $B$ \\
\hline B & B \\
\hline A & B \\
\hline A & $B$ \\
\hline A & A \\
\hline A & B \\
\hline A & B \\
\hline A & $A$ \\
\hline A & $A$ \\
\hline A & B \\
\hline A & $A$ \\
\hline B & $B$ \\
\hline B & A \\
\hline A & B \\
\hline A & A \\
\hline A & A \\
\hline
\end{tabular}
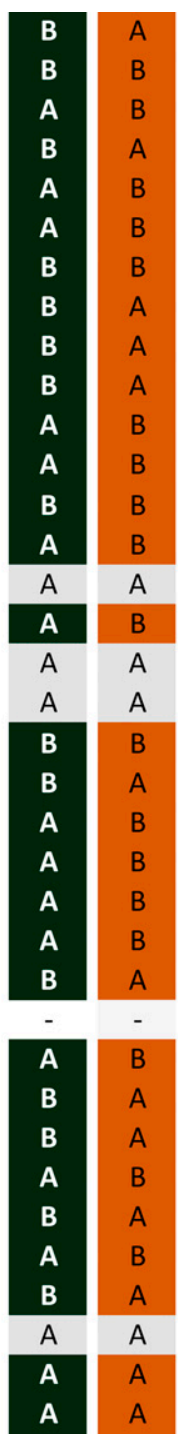

Supplemental Fig. S2. Continued. 


$\begin{array}{llr}\text { ss490558976 } & 1 & 44,008,658 \\ \text { ss490548444 } & 1 & 44,045,161 \\ \text { ss490548448 } & 1 & 44,090,182 \\ \text { ss490548488 } & 1 & 44,565,586 \\ \text { ss490548510 } & 1 & 44,764,542 \\ \text { ss490558944 } & 1 & 45,077,993 \\ \text { ss490548551 } & 1 & 45,163,766 \\ \text { ss490548559 } & 1 & 45,322,930 \\ \text { ss490559081 } & 1 & 45,469,715 \\ \text { ss490548571 } & 1 & 45,473,214 \\ \text { ss490548593 } & 1 & 45,680,542 \\ \text { ss490548614 } & 1 & 45,682,217 \\ \text { ss490548655 } & 1 & 45,924,398 \\ \text { ss490548667 } & 1 & 46,402,818 \\ \text { ss490548745 } & 1 & 46,530,908 \\ \text { ss490548777 } & 2 & 911,589 \\ \text { ss490548809 } & 2 & 1,435,086 \\ \text { ss490548813 } & 2 & 1,951,353 \\ \text { ss490548888 } & 2 & 2,008,976 \\ \text { ss490548892 } & 2 & 3,229,768 \\ \text { ss490548900 } & 2 & 3,396,708 \\ \text { ss490548920 } & 2 & 3,488,474 \\ \text { ss490548928 } & 2 & 4,354,053 \\ \text { ss490547061 } & 2 & 4,953,599 \\ \text { ss490548935 } & 2 & 4,976,130 \\ \text { ss490548943 } & 2 & 5,493,845 \\ \text { ss490548994 } & 2 & 5,865,200 \\ \text { ss490549029 } & 2 & 9,649,536 \\ \text { ss490549037 } & 2 & 11,187,571 \\ \text { ss490549052 } & 2 & 11,540,955 \\ \text { ss490559390 } & 2 & 12,407,490 \\ \text { ss490549109 } & 2 & 12,408,002 \\ \text { ss490547158 } & 2 & 14,255,547 \\ \text { ss490549138 } & 2 & 14,471,355\end{array}$

\begin{tabular}{|l|l|}
\hline B & B \\
B & B \\
\hline A & B \\
A & B \\
\hline B & B \\
A & B \\
\hline A & B \\
\hline A & B \\
\hline B & A \\
B & A \\
\hline A & A \\
\hline B & B \\
B & A \\
A & B \\
\hline A & B \\
\hline
\end{tabular}
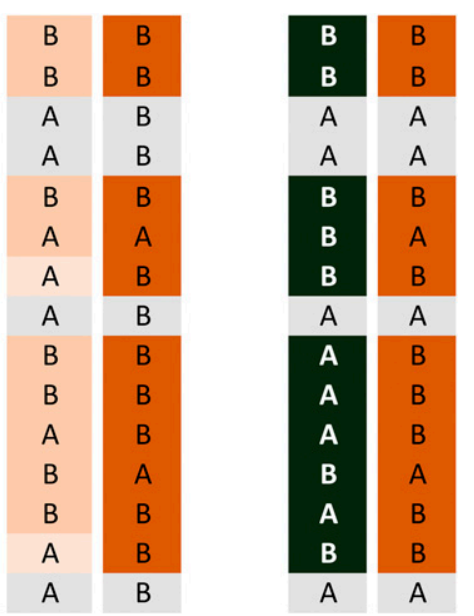

\begin{tabular}{|l|l|}
\hline A & B \\
\hline B & A \\
B & A \\
B & A \\
A & B \\
\hline A & B \\
\hline A & B \\
A & B \\
B & B \\
B & B \\
A & B \\
A & A \\
\hline A & B \\
A & B \\
A & B \\
A & B \\
A & B \\
A & B \\
A & B \\
\hline
\end{tabular}

\begin{tabular}{|l|l|}
\hline A & B \\
\hline B & B \\
B & B \\
B & B \\
\hline A & A \\
\hline A & B \\
\hline A & A \\
\hline A & A \\
\hline B & B \\
\hline B & B \\
\hline A & A \\
\hline A & A \\
\hline A & B \\
A & B \\
A & B \\
\hline A & B \\
\hline A & B \\
A & B \\
\hline A & B \\
\hline
\end{tabular}

\begin{tabular}{|l|l|}
\hline A & B \\
\hline A & B \\
\hline A & B \\
\hline A & B \\
\hline B & A \\
\hline A & B \\
\hline B & A \\
\hline B & A \\
\hline B & B \\
\hline B & B \\
\hline B & A \\
\hline A & A \\
\hline A & B \\
A & B \\
A & B \\
\hline A & B \\
\hline A & B \\
A & B \\
\hline A & B \\
\hline
\end{tabular}

Supplemental Fig. S2. Continued. 


$\begin{array}{lll}\text { ss490549172 } & 2 & 14,926,622 \\ \text { ss490549176 } & 2 & 15,084,429 \\ \text { ss490549219 } & 2 & 15,090,036 \\ \text { ss490549227 } & 2 & 15,355,971 \\ \text { ss490549258 } & 2 & 15,372,418 \\ \text { ss490549278 } & 2 & 15,624,043 \\ \text { ss490549287 } & 2 & 15,711,952 \\ \text { ss490549379 } & 2 & 15,747,822 \\ \text { ss490549955 } & 2 & 16,118,423 \\ \text { ss490549999 } & 2 & 19,297,736 \\ \text { ss490550007 } & 2 & 19,304,771 \\ \text { ss490550015 } & 2 & 19,581,374 \\ \text { ss490550019 } & 2 & 19,615,344 \\ \text { ss490550027 } & 2 & 19,664,779 \\ \text { ss490550035 } & 2 & 19,684,679 \\ \text { ss490550074 } & 2 & 19,724,366 \\ \text { ss490550125 } & 2 & 19,752,871 \\ \text { ss490550173 } & 2 & 20,340,464 \\ \text { ss490550213 } & 2 & 20,470,247 \\ \text { ss490550229 } & 2 & 20,694,575 \\ \text { ss490559045 } & 2 & 20,925,443 \\ \text { ss490559042 } & 2 & 21,264,736 \\ \text { ss490559039 } & 2 & 21,486,683 \\ \text { ss490559037 } & 2 & 22,162,871 \\ \text { ss490559013 } & 2 & 22,162,942 \\ \text { ss490550363 } & 2 & 22,163,062 \\ \text { ss490550431 } & 2 & 22,163,199 \\ \text { ss490550493 } & 2 & 22,593,260 \\ \text { ss490550501 } & 2 & 22,763,311 \\ \text { ss490550521 } & 2 & 23,331,142 \\ \text { ss490550529 } & 2 & 23,843,142 \\ \text { ss490550577 } & 2 & 23,891,054 \\ \text { ss490550626 } & 2 & 24,033,313 \\ \text { ss490550691 } & 2 & 24,131,520 \\ \text { ss490559255 } & 2 & 24,536,908 \\ \text { ss490550831 } & 2 & 25,004,410\end{array}$

\begin{tabular}{|l|l|}
\hline A & B \\
\hline A & B \\
\hline B & A \\
B & A \\
B & A \\
\hline A & B \\
A & B \\
A & B \\
\hline B & A \\
B & B \\
B & B \\
\hline A & B \\
\hline B & A \\
\hline A & B \\
\hline B & A \\
\hline A & B \\
\hline A & B \\
\hline A & B \\
B & A \\
\hline A & B \\
A & A \\
A & B \\
B & B \\
\hline A & B \\
A & B \\
A & B \\
A & B \\
\hline A & A \\
A & A \\
B & B \\
B & A \\
B & A \\
A & B \\
B & B \\
B & B \\
\hline A & \\
\hline
\end{tabular}

\begin{tabular}{|c|c|}
\hline A & A \\
\hline A & B \\
\hline B & B \\
\hline B & $B$ \\
\hline B & B \\
\hline A & B \\
\hline A & B \\
\hline A & B \\
\hline B & B \\
\hline B & B \\
\hline B & B \\
\hline A & B \\
\hline B & B \\
\hline A & B \\
\hline B & B \\
\hline A & B \\
\hline A & A \\
\hline A & $A$ \\
\hline B & $B$ \\
\hline A & $A$ \\
\hline A & $A$ \\
\hline A & $A$ \\
\hline A & B \\
\hline A & B \\
\hline A & B \\
\hline A & B \\
\hline A & B \\
\hline A & A \\
\hline B & $A$ \\
\hline A & $B$ \\
\hline B & B \\
\hline B & B \\
\hline A & $A$ \\
\hline A & B \\
\hline A & B \\
\hline A & B \\
\hline
\end{tabular}

\begin{tabular}{|l|l|}
\hline B & A \\
\hline A & B \\
\hline A & B \\
\hline A & B \\
\hline A & B \\
\hline A & B \\
\hline A & B \\
\hline A & B \\
\hline A & B \\
\hline B & B \\
\hline B & B \\
\hline A & B \\
\hline A & B \\
\hline A & B \\
\hline A & B \\
\hline A & B \\
\hline B & A \\
\hline B & A \\
\hline A & B \\
\hline B & A \\
\hline A & A \\
\hline B & A \\
B & B \\
\hline A & B \\
\hline A & B \\
\hline A & B \\
\hline A & B \\
\hline A & A \\
\hline A & A \\
\hline B & B \\
\hline A & B \\
\hline A & B \\
\hline
\end{tabular}

Supplemental Fig. S2. Continued. 


$\begin{array}{llr}\text { ss490550883 } & 2 & 25,512,709 \\ \text { ss490550887 } & 2 & 26,346,122 \\ \text { ss490551030 } & 3 & 193,994 \\ \text { ss490551110 } & 3 & 1,174,681 \\ \text { ss490551118 } & 3 & 1,257,143 \\ \text { ss490551167 } & 3 & 2,262,982 \\ \text { ss490551234 } & 3 & 2,699,030 \\ \text { ss490551267 } & 3 & 2,743,517 \\ \text { ss490547825 } & 3 & 3,086,237 \\ \text { ss490551321 } & 3 & 3,136,656 \\ \text { ss490551325 } & 3 & 3,593,732 \\ \text { ss490551333 } & 3 & 3,927,957 \\ \text { ss490551337 } & 3 & 4,138,750 \\ \text { ss490559471 } & 3 & 4,301,861 \\ \text { ss490551353 } & 3 & 4,334,085 \\ \text { ss490551394 } & 3 & 4,450,769 \\ \text { ss490551435 } & 3 & 4,468,725 \\ \text { ss490551450 } & 3 & 4,571,814 \\ \text { ss490551490 } & 3 & 4,934,519 \\ \text { ss490551507 } & 3 & 6,646,570 \\ \text { ss490547928 } & 3 & 7,412,958 \\ \text { ss490551568 } & 3 & 7,622,320 \\ \text { ss490547960 } & 3 & 8,552,044 \\ \text { ss490551623 } & 3 & 8,859,929 \\ \text { ss490551684 } & 3 & 9,782,875 \\ \text { ss490551699 } & 3 & 10,399,039 \\ \text { ss490551705 } & 3 & 12,188,902 \\ \text { ss490551720 } & 3 & 13,025,963 \\ \text { ss490559450 } & 3 & 13,144,730 \\ \text { ss490548016 } & 3 & 13,208,005 \\ \text { ss490551869 } & 3 & 13,406,263 \\ \text { ss490551878 } & 3 & 13,878,008 \\ \text { ss490551889 } & 3 & 13,881,088 \\ \text { ss490551892 } & 3 & 15,309,954 \\ \text { s } 4513\end{array}$

\begin{tabular}{|l|l|}
\hline A & B \\
\hline A & A \\
\hline A & B \\
\hline A & B \\
A & B \\
A & B \\
\hline A & B \\
\hline A & A \\
\hline B & B \\
\hline A & B \\
\hline A & B \\
\hline A & B \\
A & B \\
\hline A & A \\
\hline A & A \\
\hline B & B \\
\hline B & B \\
B & B \\
\hline A & A \\
\hline A & B \\
\hline A & A \\
\hline A & A \\
\hline B & B \\
A & A \\
\hline B & B \\
\hline A & - \\
\hline B & B \\
\hline A & B \\
\hline A & B \\
\hline
\end{tabular}

\begin{tabular}{|c|c|}
\hline A & B \\
\hline B & A \\
\hline B & B \\
\hline A & B \\
\hline A & B \\
\hline A & B \\
\hline B & B \\
\hline A & B \\
\hline B & $A$ \\
\hline A & B \\
\hline B & B \\
\hline A & B \\
\hline A & B \\
\hline A & B \\
\hline A & $A$ \\
\hline B & B \\
\hline B & B \\
\hline B & B \\
\hline A & A \\
\hline A & B \\
\hline A & B \\
\hline A & $B$ \\
\hline B & B \\
\hline A & $A$ \\
\hline B & A \\
\hline- & - \\
\hline B & B \\
\hline B & $A$ \\
\hline A & $B$ \\
\hline A & $B$ \\
\hline A & B \\
\hline A & B \\
\hline A & B \\
\hline B & $A$ \\
\hline
\end{tabular}

\begin{tabular}{|l|l|}
\hline$A$ & $B$ \\
\hline$A$ & $A$ \\
\hline
\end{tabular}

\begin{tabular}{|l|l|}
\hline B & B \\
\hline A & B \\
A & B \\
A & B \\
\hline B & B \\
A & B \\
B & A \\
\hline A & B \\
\hline B & B \\
\hline A & B \\
\hline A & B \\
\hline
\end{tabular}
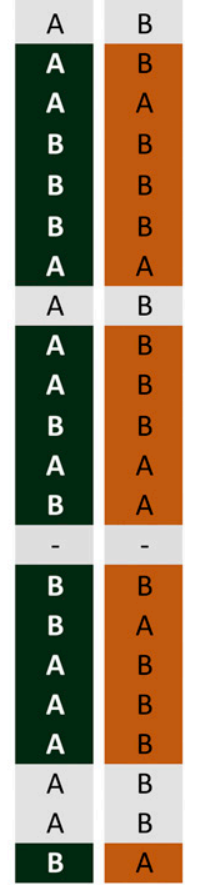

Supplemental Fig. S2. Continued. 


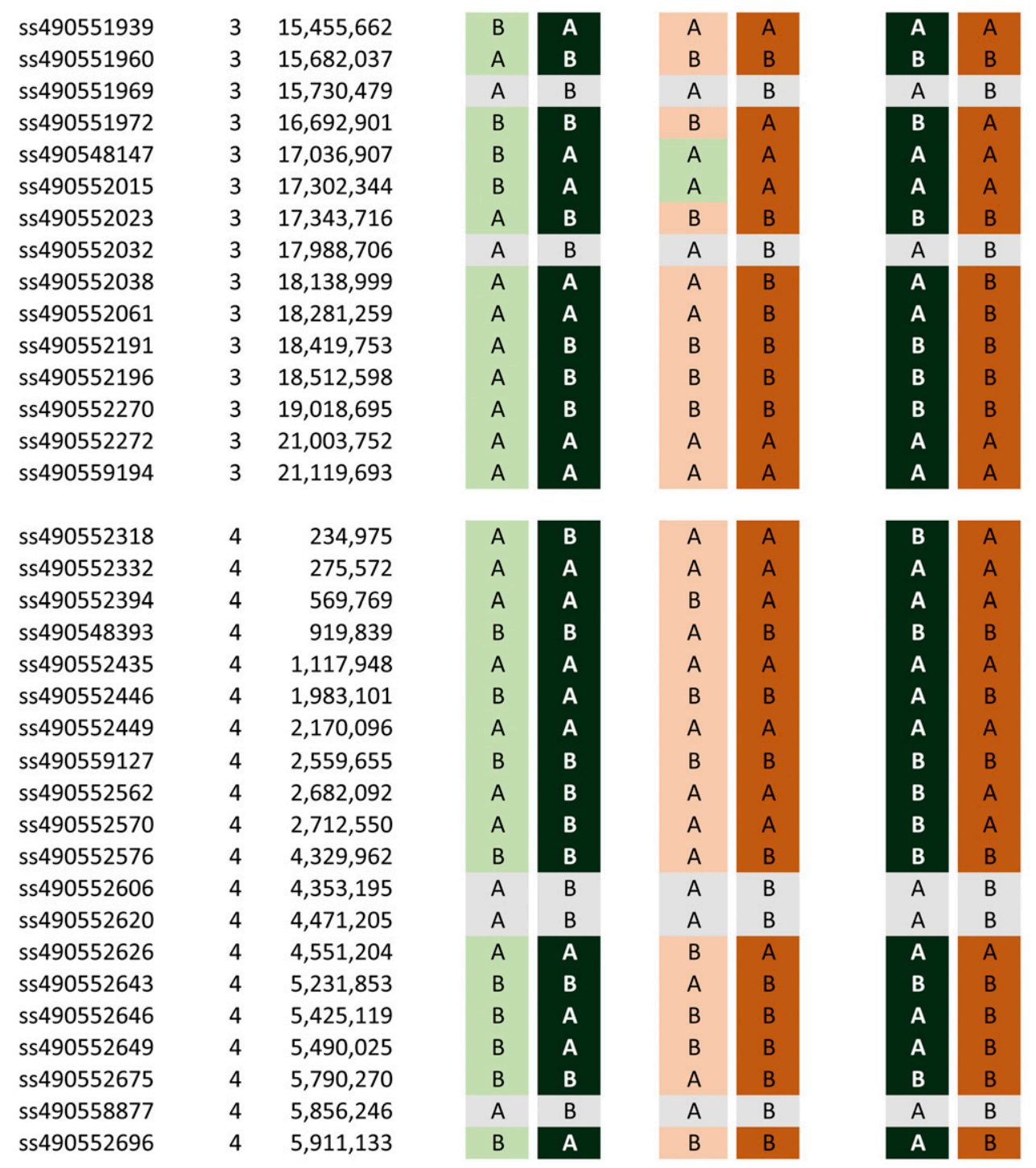

Supplemental Fig. S2. Continued. 


$\begin{array}{llr}\text { ss490552699 } & 4 & 6,348,991 \\ \text { ss490552713 } & 4 & 6,464,070 \\ \text { ss490552727 } & 4 & 6,545,181 \\ \text { ss490552730 } & 4 & 6,580,288 \\ \text { ss490552744 } & 4 & 6,828,082 \\ \text { ss490552747 } & 4 & 7,065,857 \\ \text { ss490552750 } & 4 & 7,148,241 \\ \text { ss490552753 } & 4 & 7,349,971 \\ \text { ss490552767 } & 4 & 7,402,206 \\ \text { ss490552832 } & 4 & 7,429,956 \\ \text { ss490548662 } & 4 & 7,456,033 \\ \text { ss490552843 } & 4 & 7,706,352 \\ \text { ss490545355 } & 4 & 8,827,326 \\ \text { ss490552856 } & 4 & 8,955,576 \\ \text { ss490552880 } & 4 & 8,985,625 \\ \text { ss490559107 } & 4 & 9,145,953 \\ \text { ss490552883 } & 4 & 9,148,953 \\ \text { ss490559054 } & 4 & 10,145,480 \\ \text { ss490552928 } & 4 & 10,225,433 \\ \text { ss490552959 } & 4 & 10,230,259 \\ \text { ss490552964 } & 4 & 10,403,896 \\ \text { ss490552970 } & 4 & 11,462,176 \\ \text { ss490552973 } & 4 & 12,567,325 \\ \text { ss490559147 } & 4 & 12,715,001 \\ \text { ss490558926 } & 4 & 12,865,643 \\ \text { ss490552979 } & 4 & 12,955,416 \\ \text { ss490553016 } & 4 & 12,987,703 \\ \text { ss490553025 } & 4 & 13,089,513 \\ \text { ss490553036 } & 4 & 13,093,284 \\ \text { ss490553048 } & 4 & 13,886,648 \\ \text { ss490553059 } & 4 & 14,081,510 \\ \text { ss490558929 } & 4 & 14,516,715 \\ \text { ss490553123 } & 4 & 14,821,190 \\ \text { ss490558865 } & 4 & 15,070,360 \\ \text { ss490558868 } & 4 & 16,075,683\end{array}$

\begin{tabular}{|l|l|}
\hline B & B \\
A & A \\
A & A \\
B & B \\
B & B \\
A & B \\
B & B \\
A & B \\
A & A \\
A & B \\
A & B \\
A & A \\
B & B \\
B & B \\
A & A \\
B & A \\
A & B \\
\hline A & B \\
\hline B & B \\
\hline A & B \\
A & B \\
\hline B & B \\
A & A \\
A & A \\
B & B \\
A & A \\
B & B \\
\hline B & B \\
A & A \\
B & B \\
B & B \\
B & B \\
A & A \\
B & B \\
A & B \\
\hline
\end{tabular}

\begin{tabular}{|c|c|}
\hline B & B \\
\hline A & $A$ \\
\hline A & $A$ \\
\hline B & $B$ \\
\hline B & $B$ \\
\hline A & $\mathrm{A}$ \\
\hline B & $\mathrm{B}$ \\
\hline A & $A$ \\
\hline A & $\mathrm{A}$ \\
\hline A & $A$ \\
\hline A & $A$ \\
\hline A & $A$ \\
\hline A & B \\
\hline B & $B$ \\
\hline A & $A$ \\
\hline$A$ & A \\
\hline B & B \\
\hline A & B \\
\hline B & B \\
\hline A & B \\
\hline A & B \\
\hline B & B \\
\hline B & $A$ \\
\hline B & $A$ \\
\hline A & $B$ \\
\hline B & $A$ \\
\hline A & B \\
\hline A & B \\
\hline B & A \\
\hline A & $B$ \\
\hline A & B \\
\hline B & $B$ \\
\hline A & A \\
\hline B & B \\
\hline A & B \\
\hline
\end{tabular}

\begin{tabular}{|c|c|}
\hline B & \\
\hline$A$ & 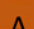 \\
\hline A & $A$ \\
\hline B & $B$ \\
\hline B & $B$ \\
\hline B & $A$ \\
\hline B & $B$ \\
\hline B & A \\
\hline A & $A$ \\
\hline B & A \\
\hline $\begin{array}{l}B \\
\text { B }\end{array}$ & $A$ \\
\hline B & B \\
\hline B & B \\
\hline A & $A$ \\
\hline A & A \\
\hline B & B \\
\hline A & A \\
\hline B & B \\
\hline A & A \\
\hline A & A \\
\hline B & B \\
\hline A & $A$ \\
\hline A & $A$ \\
\hline B & $A$ \\
\hline B & B \\
\hline- & - \\
\hline A & $A$ \\
\hline B & B \\
\hline B & $B$ \\
\hline B & $\begin{array}{l}B \\
A\end{array}$ \\
\hline $\begin{array}{l}\text { A } \\
\text { B }\end{array}$ & B \\
\hline$A$ & B \\
\hline
\end{tabular}

Supplemental Fig. S2. Continued. 


\begin{tabular}{|c|c|c|c|c|c|c|c|c|}
\hline ss490558871 & 4 & $17,222,313$ & B & B & B & B & B & B \\
\hline ss490553144 & 4 & $17,859,388$ & B & B & A & B & B & B \\
\hline ss490553184 & 4 & $17,859,446$ & A & A & B & $A$ & A & A \\
\hline ss490553192 & 4 & $17,859,661$ & B & B & A & B & B & B \\
\hline ss490553198 & 4 & $17,943,880$ & A & A & B & A & A & A \\
\hline ss490553204 & 4 & $18,701,563$ & A & B & A & B & A & A \\
\hline ss490553207 & 4 & $19,293,490$ & A & A & B & A & A & A \\
\hline ss490553209 & 4 & $19,411,509$ & A & B & A & B & B & B \\
\hline ss490553268 & 4 & $19,561,278$ & B & B & B & B & B & B \\
\hline ss490553274 & 4 & $19,599,189$ & A & A & A & A & A & A \\
\hline ss490548855 & 4 & $19,657,873$ & A & A & A & A & A & A \\
\hline ss490553289 & 4 & $20,865,038$ & A & B & A & B & A & B \\
\hline ss490553438 & 4 & $20,926,979$ & A & B & A & B & A & B \\
\hline ss490553464 & 4 & $21,145,128$ & A & B & A & B & A & B \\
\hline ss490553467 & 4 & $21,580,914$ & B & B & B & B & B & B \\
\hline ss490553543 & 4 & $27,192,075$ & A & B & A & B & B & B \\
\hline ss490553644 & 4 & $27,218,201$ & A & A & A & A & A & A \\
\hline ss490553674 & 4 & $29,560,911$ & A & A & A & B & - & - \\
\hline ss490553735 & 5 & 689,941 & B & A & A & A & A & A \\
\hline ss490553738 & 5 & 934,368 & B & B & B & B & B & B \\
\hline ss490553741 & 5 & $1,629,739$ & A & B & A & B & A & B \\
\hline ss490559171 & 5 & $1,645,289$ & A & B & A & B & A & B \\
\hline ss490549013 & 5 & $1,658,127$ & A & B & A & B & A & B \\
\hline ss490553811 & 5 & $1,709,155$ & A & B & B & B & B & B \\
\hline ss490553817 & 5 & $2,351,581$ & A & B & B & B & B & B \\
\hline ss490553823 & 5 & $3,193,567$ & A & B & A & B & A & B \\
\hline ss490559270 & 5 & $3,299,986$ & A & B & A & B & A & B \\
\hline ss490559267 & 5 & $3,464,400$ & B & B & B & A & B & A \\
\hline ss490559156 & 5 & $3,464,457$ & A & B & A & B & A & B \\
\hline ss490553847 & 5 & $3,464,517$ & A & B & A & B & A & B \\
\hline ss490553853 & 5 & $3,469,706$ & A & B & A & B & A & B \\
\hline ss490553895 & 5 & $3,644,242$ & A & B & A & B & A & B \\
\hline ss490553907 & 5 & $3,695,755$ & B & A & A & A & A & A \\
\hline ss490553910 & 5 & $4,302,944$ & A & B & A & B & B & B \\
\hline
\end{tabular}

Supplemental Fig. S2. Continued. 


\begin{tabular}{|c|c|c|c|c|c|c|c|c|}
\hline ss490553919 & 5 & $4,413,731$ & B & A & B & B & A & B \\
\hline ss490553922 & 5 & $4,486,238$ & A & B & A & B & B & B \\
\hline ss490553929 & 5 & $4,710,627$ & A & B & A & B & B & B \\
\hline ss490553960 & 5 & $4,755,463$ & A & B & A & B & A & A \\
\hline ss490553963 & 5 & $4,897,952$ & A & B & A & B & A & A \\
\hline ss490559113 & 5 & $5,409,519$ & A & B & A & B & B & B \\
\hline ss490559110 & 5 & $5,429,352$ & A & $B$ & A & B & A & A \\
\hline ss490554201 & 5 & $9,393,638$ & A & B & A & B & B & B \\
\hline ss490554283 & 5 & $9,393,745$ & A & B & A & B & B & B \\
\hline ss490554313 & 5 & $11,943,249$ & A & B & A & A & A & B \\
\hline ss490554346 & 5 & $12,331,780$ & A & $B$ & A & B & A & A \\
\hline ss490554352 & 5 & $12,506,702$ & B & A & B & B & A & B \\
\hline ss490554372 & 5 & $12,750,950$ & A & A & A & B & A & B \\
\hline ss490554417 & 5 & $12,785,307$ & A & A & A & B & A & B \\
\hline ss490559186 & 5 & $12,917,888$ & A & B & A & B & A & B \\
\hline ss490554495 & 5 & $13,191,542$ & A & B & A & B & A & B \\
\hline ss490559206 & 5 & $13,240,090$ & A & B & A & B & A & B \\
\hline ss490559203 & 5 & $13,715,106$ & A & B & A & B & A & B \\
\hline ss490554529 & 5 & $15,546,701$ & A & B & A & B & A & B \\
\hline ss490554550 & 5 & $15,546,817$ & A & B & A & B & A & B \\
\hline ss490554609 & 5 & $15,559,243$ & A & B & B & B & B & B \\
\hline ss490554753 & 5 & $15,817,487$ & A & B & A & B & A & B \\
\hline ss490554756 & 5 & $16,375,840$ & A & B & A & B & A & B \\
\hline ss490549476 & 5 & $17,319,331$ & B & A & A & A & A & A \\
\hline ss490554898 & 5 & $17,328,363$ & A & A & A & A & A & A \\
\hline ss490554904 & 5 & $17,743,459$ & A & B & A & B & B & B \\
\hline ss490554953 & 5 & $18,100,331$ & A & B & A & B & B & B \\
\hline ss490554977 & 5 & $18,146,501$ & A & B & A & B & B & B \\
\hline ss490554989 & 6 & 286,381 & A & A & A & A & A & A \\
\hline ss490555047 & 6 & 735,222 & B & B & B & B & B & B \\
\hline ss490549593 & 6 & $1,811,133$ & A & B & A & B & A & B \\
\hline ss490555075 & 6 & $1,852,409$ & A & A & A & A & A & A \\
\hline ss490559372 & 6 & $2,247,834$ & A & B & A & A & B & A \\
\hline ss490555169 & 6 & $3,912,624$ & A & B & A & B & A & B \\
\hline ss490555172 & 6 & $3,920,291$ & A & B & A & B & A & B \\
\hline
\end{tabular}

Supplemental Fig. S2. Continued. 


$\begin{array}{llr}\text { ss490555175 } & 6 & 3,973,271 \\ \text { ss490555200 } & 6 & 4,050,337 \\ \text { ss490549680 } & 6 & 4,315,623 \\ \text { ss490559286 } & 6 & 4,331,813 \\ \text { ss490559283 } & 6 & 4,620,418 \\ \text { ss490555236 } & 6 & 4,620,420 \\ \text { ss490555284 } & 6 & 4,806,232 \\ \text { ss490555293 } & 6 & 5,460,138 \\ \text { ss490555314 } & 6 & 5,542,394 \\ \text { ss490555316 } & 6 & 5,931,170 \\ \text { ss490555328 } & 6 & 5,978,925 \\ \text { ss490555360 } & 6 & 6,245,490 \\ \text { ss490555411 } & 6 & 6,843,830 \\ \text { ss490555413 } & 6 & 7,537,950 \\ \text { ss490555416 } & 6 & 7,575,939 \\ \text { ss490555425 } & 6 & 7,626,959 \\ \text { ss490555428 } & 6 & 7,838,040 \\ \text { ss490555481 } & 6 & 7,901,830 \\ \text { ss490555554 } & 6 & 8,691,599 \\ \text { ss490555574 } & 6 & 10,369,567 \\ \text { ss490555577 } & 6 & 11,072,866 \\ \text { ss490555580 } & 6 & 11,128,369 \\ \text { ss490555606 } & 6 & 11,210,515 \\ \text { ss490549926 } & 6 & 11,910,096 \\ \text { ss490555615 } & 6 & 12,119,303 \\ \text { ss490555624 } & 6 & 12,126,728 \\ \text { ss490555635 } & 6 & 12,400,263 \\ \text { ss490555682 } & 6 & 12,638,852 \\ \text { ss490559341 } & 6 & 14,555,604 \\ \text { ss490559338 } & 6 & 14,662,485 \\ \text { ss490559335 } & 6 & 14,662,583 \\ \text { ss490555714 } & 6 & 14,662,633 \\ \text { ss490555746 } & 6 & 15,628,669 \\ \text { ss490555771 } & 6 & 16,636,989 \\ \text { ss490555792 } & 6 & 17,629,589\end{array}$

\begin{tabular}{|l|l|}
\hline A & B \\
A & B \\
A & A \\
A & A \\
\hline A & B \\
A & B \\
A & B \\
\hline B & B \\
B & B \\
B & B \\
B & B \\
A & A \\
B & A \\
B & B \\
A & A \\
B & A \\
B & B \\
\hline A & B \\
\hline A & A \\
A & B \\
A & A \\
B & B \\
B & B \\
B & B \\
A & A \\
B & B \\
A & A \\
A & A \\
B & B \\
A & B \\
A & B \\
A & A \\
B & A \\
B & B \\
A & B \\
\hline
\end{tabular}

\begin{tabular}{|c|c|}
\hline A & B \\
\hline A & B \\
\hline A & A \\
\hline A & A \\
\hline A & B \\
\hline A & B \\
\hline A & B \\
\hline A & B \\
\hline A & B \\
\hline A & $B$ \\
\hline A & B \\
\hline A & A \\
\hline B & B \\
\hline B & $B$ \\
\hline A & $A$ \\
\hline B & B \\
\hline B & B \\
\hline A & B \\
\hline A & A \\
\hline A & $A$ \\
\hline B & $A$ \\
\hline A & $B$ \\
\hline B & B \\
\hline B & $B$ \\
\hline B & A \\
\hline A & B \\
\hline B & A \\
\hline B & A \\
\hline A & $B$ \\
\hline A & A \\
\hline $\begin{array}{l}A \\
B\end{array}$ & $\begin{array}{l}A \\
A\end{array}$ \\
\hline B & $\begin{array}{l}A \\
B\end{array}$ \\
\hline A & B \\
\hline A & A \\
\hline
\end{tabular}

\begin{tabular}{|c|c|}
\hline A & $B$ \\
\hline A & B \\
\hline A & A \\
\hline A & A \\
\hline$A$ & B \\
\hline A & B \\
\hline A & B \\
\hline B & B \\
\hline B & B \\
\hline B & $B$ \\
\hline A & A \\
\hline A & B \\
\hline B & $B$ \\
\hline A & A \\
\hline A & B \\
\hline$A$ & B \\
\hline A & $A$ \\
\hline B & $A$ \\
\hline A & $A$ \\
\hline B & B \\
\hline $\begin{array}{l}\text { B } \\
\text { B }\end{array}$ & $\begin{array}{l}B \\
B\end{array}$ \\
\hline A & A \\
\hline B & B \\
\hline A & $A$ \\
\hline $\begin{array}{l}\mathbf{A} \\
\mathbf{R}\end{array}$ & $A$ \\
\hline $\begin{array}{l}\text { B } \\
\text { B }\end{array}$ & $\begin{array}{l}B \\
A\end{array}$ \\
\hline B & A \\
\hline $\mathbf{A}$ & $A$ \\
\hline A & $B$ \\
\hline $\begin{array}{l}\text { B } \\
\text { B }\end{array}$ & $\begin{array}{l}B \\
A\end{array}$ \\
\hline
\end{tabular}

Supplemental Fig. S2. Continued. 


$\begin{array}{lll}\text { ss490559223 } & 6 & 18,081,683 \\ \text { ss490559226 } & 6 & 19,912,441 \\ \text { ss490559229 } & 6 & 19,912,562 \\ \text { ss490555845 } & 6 & 19,912,697 \\ \text { ss490555857 } & 6 & 19,982,724 \\ \text { ss490555863 } & 6 & 20,091,471 \\ \text { ss490555869 } & 6 & 20,112,900 \\ \text { ss490555878 } & 6 & 20,150,761 \\ \text { ss490555911 } & 6 & 20,209,981 \\ \text { ss490555926 } & 6 & 20,514,744 \\ \text { ss490558953 } & 6 & 20,604,253 \\ \text { ss490555951 } & 6 & 20,719,389 \\ \text { ss490550096 } & 6 & 20,786,682 \\ \text { ss490555972 } & 6 & 20,850,123 \\ \text { ss490550124 } & 6 & 20,982,940 \\ \text { ss490556005 } & 6 & 21,758,738 \\ \text { ss490556014 } & 6 & 22,296,379 \\ \text { ss490558923 } & 6 & 22,578,566 \\ \text { ss490556048 } & 6 & 22,953,307 \\ \text { ss490550212 } & 6 & 23,138,881 \\ \text { ss490559115 } & 6 & 23,941,299 \\ \text { ss490550220 } & 6 & 24,324,785 \\ \text { ss490556182 } & 6 & 24,433,974 \\ \text { ss490558886 } & 6 & 24,914,294 \\ \text { ss490558890 } & 6 & 25,325,556 \\ \text { ss490556207 } & 6 & 25,325,607 \\ \text { ss490556216 } & 6 & 25,429,330 \\ \text { ss490556220 } & 6 & 25,631,852 \\ \text { ss490556239 } & 6 & 25,713,330 \\ \text { ss490556242 } & 6 & 26,089,443 \\ \text { ss490556260 } & 6 & 26,149,926 \\ \text { ss490556308 } & 6 & 26,484,157 \\ \text { ss490559104 } & 6 & 27,373,564 \\ \text { ss490556376 } & 6 & 28,294,400 \\ \text { ss490556421 } & 6 & 28,590,655\end{array}$

\begin{tabular}{|c|c|}
\hline B & A \\
\hline A & B \\
\hline A & B \\
\hline A & B \\
\hline A & B \\
\hline A & B \\
\hline A & B \\
\hline A & B \\
\hline A & B \\
\hline A & B \\
\hline B & B \\
\hline A & B \\
\hline A & B \\
\hline A & B \\
\hline A & B \\
\hline A & B \\
\hline A & B \\
\hline B & A \\
\hline A & B \\
\hline A & B \\
\hline A & B \\
\hline A & B \\
\hline A & B \\
\hline B & B \\
\hline B & B \\
\hline B & B \\
\hline B & A \\
\hline A & B \\
\hline A & B \\
\hline A & B \\
\hline A & B \\
\hline A & B \\
\hline A & B \\
\hline A & B \\
\hline A & B \\
\hline
\end{tabular}

\begin{tabular}{|l|l|}
\hline B & B \\
\hline$A$ & $B$ \\
\hline$A$ & $B$ \\
\hline$A$ & $B$ \\
\hline$A$ & $B$ \\
\hline$A$ & $B$ \\
\hline$A$ & $B$ \\
\hline$A$ & $B$ \\
\hline$A$ & $B$ \\
\hline$B$ & $B$ \\
\hline$A$ & $B$ \\
\hline$A$ & $B$ \\
\hline$A$ & $B$ \\
\hline$A$ & $B$ \\
\hline$A$ & $B$ \\
\hline$A$ & $A$ \\
\hline$B$ & $B$ \\
\hline$A$ & $B$ \\
$A A$ & $B$ \\
\hline$A$ & $B$ \\
\hline$A$ & $A$ \\
\hline$A$ & $A$ \\
\hline$A$ & $B$ \\
\hline$A$ & $B$ \\
\hline$A$ & $B$ \\
\hline$B$ & $B$ \\
\hline$A$ & $A$ \\
\hline$A$ & $B$ \\
$A$ & $B$ \\
$A$ & $B$ \\
$A$ & $B$ \\
\hline$A$ & $B$ \\
\hline$A$ & $B$ \\
\hline
\end{tabular}

\begin{tabular}{|c|c|}
\hline A & B \\
\hline A & B \\
\hline A & B \\
\hline$A$ & B \\
\hline A & B \\
\hline A & B \\
\hline A & B \\
\hline A & B \\
\hline A & B \\
\hline A & B \\
\hline B & B \\
\hline A & B \\
\hline A & B \\
\hline A & B \\
\hline A & B \\
\hline A & B \\
\hline B & A \\
\hline A & B \\
\hline A & B \\
\hline A & B \\
\hline A & B \\
\hline A & B \\
\hline A & B \\
\hline$B$ & B \\
\hline$B$ & B \\
\hline B & B \\
\hline A & B \\
\hline A & B \\
\hline A & B \\
\hline A & B \\
\hline A & B \\
\hline A & B \\
\hline A & B \\
\hline A & B \\
\hline
\end{tabular}

Supplemental Fig. S2. Continued. 


$\begin{array}{llr}\text { ss490556424 } & 7 & 1,298,051 \\ \text { ss490556436 } & 7 & 1,392,399 \\ \text { ss490556439 } & 7 & 1,783,512 \\ \text { ss490556458 } & 7 & 1,835,696 \\ \text { ss490556467 } & 7 & 2,085,075 \\ \text { ss490556479 } & 7 & 2,252,124 \\ \text { ss490556549 } & 7 & 2,530,796 \\ \text { ss490559378 } & 7 & 4,261,930 \\ \text { ss490559416 } & 7 & 4,466,543 \\ \text { ss490556594 } & 7 & 4,467,254 \\ \text { ss490556651 } & 7 & 5,729,126 \\ \text { ss490556657 } & 7 & 7,884,834 \\ \text { ss490559192 } & 7 & 8,002,087 \\ \text { ss490556684 } & 7 & 8,149,634 \\ \text { ss490556699 } & 7 & 8,954,812 \\ \text { ss490550496 } & 7 & 9,635,219 \\ \text { ss490556768 } & 7 & 9,642,445 \\ \text { ss490556777 } & 7 & 10,992,603 \\ \text { ss490556795 } & 7 & 11,125,571 \\ \text { ss490556804 } & 7 & 11,504,432 \\ \text { ss490550555 } & 7 & 11,774,569 \\ \text { ss490559301 } & 7 & 11,790,341 \\ \text { ss490556971 } & 7 & 12,192,907 \\ \text { ss490556986 } & 7 & 14,253,560 \\ \text { ss490550655 } & 7 & 14,418,839 \\ \text { ss490557026 } & 7 & 14,527,951 \\ \text { ss490557029 } & 7 & 14,929,134 \\ \text { ss490557035 } & 7 & 14,967,053 \\ \text { ss490558905 } & 7 & 15,029,527 \\ \text { ss490550700 } & 7 & 15,241,465 \\ \text { ss490557186 } & 7 & 15,744,830 \\ \text { ss490557205 } & 7 & 16,660,251 \\ \text { ss490557244 } & 7 & 16,890,828 \\ \text { ss490557253 } & 7 & 17,591,054 \\ \text { ss490559061 } & 7 & 17,697,521\end{array}$

\begin{tabular}{|l|l|}
\hline A & B \\
\hline A & B \\
A & B \\
\hline A & B \\
B & A \\
B & A \\
A & B \\
B & B \\
B & B \\
B & B \\
\hline A & B \\
\hline B & B \\
B & B \\
\hline A & B \\
\hline A & A \\
B & B \\
B & B \\
\hline A & B \\
A & B \\
A & B \\
\hline B & A \\
\hline A & B \\
A & B \\
\hline A & B \\
A & A \\
B & B \\
B & B \\
\hline A & B \\
\hline A & A \\
B & B \\
\hline A & B \\
A & B \\
A & B \\
A & A \\
B & A \\
\hline
\end{tabular}

\begin{tabular}{|c|c|}
\hline A & B \\
\hline A & B \\
\hline A & B \\
\hline A & B \\
\hline B & $\mathrm{B}$ \\
\hline B & $B$ \\
\hline A & $A$ \\
\hline B & $B$ \\
\hline B & $A$ \\
\hline B & A \\
\hline A & B \\
\hline B & B \\
\hline B & B \\
\hline A & B \\
\hline A & B \\
\hline B & $B$ \\
\hline B & B \\
\hline A & B \\
\hline A & B \\
\hline$A$ & B \\
\hline B & B \\
\hline A & B \\
\hline$A$ & B \\
\hline B & B \\
\hline A & $A$ \\
\hline B & $B$ \\
\hline B & B \\
\hline A & B \\
\hline A & $A$ \\
\hline B & A \\
\hline A & B \\
\hline B & B \\
\hline B & $B$ \\
\hline A & A \\
\hline A & A \\
\hline
\end{tabular}

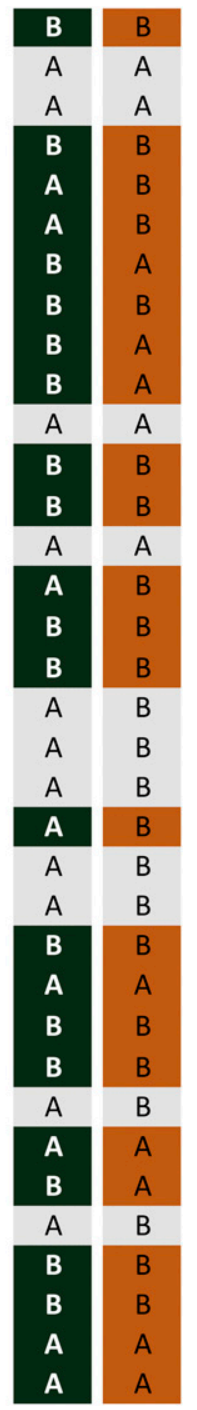

Supplemental Fig. S2. Continued. 


\begin{tabular}{|c|c|c|c|c|c|c|c|c|}
\hline ss490559058 & 7 & $17,855,163$ & B & A & A & A & A & A \\
\hline ss490558908 & 7 & $17,855,350$ & A & B & B & B & B & B \\
\hline ss490558911 & 7 & $19,283,645$ & B & B & B & $A$ & B & $A$ \\
\hline ss490558914 & 7 & $19,283,697$ & B & B & B & $A$ & B & $A$ \\
\hline ss490558917 & 7 & $19,283,789$ & A & A & A & B & A & B \\
\hline ss490557318 & 7 & $19,283,829$ & B & B & B & A & B & A \\
\hline ss490550814 & 7 & $19,919,742$ & $A$ & B & $A$ & B & A & B \\
\hline ss490559425 & 7 & $19,981,542$ & A & A & A & A & A & A \\
\hline ss490558893 & 7 & $20,690,600$ & B & B & B & A & B & A \\
\hline ss490557345 & 7 & $20,819,981$ & $A$ & B & A & B & A & B \\
\hline ss490557364 & 7 & $20,835,592$ & A & B & A & B & A & B \\
\hline ss490557376 & 7 & $20,894,129$ & $A$ & A & A & B & A & B \\
\hline ss490557421 & 7 & $20,941,604$ & B & B & B & B & B & B \\
\hline ss490557478 & 7 & $21,112,835$ & $A$ & B & $A$ & B & A & B \\
\hline ss490557605 & 7 & $21,282,777$ & A & A & A & B & A & B \\
\hline ss490557632 & 7 & $21,747,135$ & A & B & A & B & A & B \\
\hline ss490557699 & 7 & $22,024,984$ & B & A & A & A & A & A \\
\hline ss490557705 & 8 & 79,992 & A & B & A & B & B & B \\
\hline ss490557711 & 8 & 150,929 & A & B & A & B & A & A \\
\hline ss490559359 & 8 & 233,014 & A & B & A & B & B & B \\
\hline ss490557732 & 8 & 241,070 & B & B & B & B & B & B \\
\hline ss490550948 & 8 & 629,163 & A & B & A & B & A & A \\
\hline ss490557738 & 8 & 831,811 & A & B & A & B & B & B \\
\hline ss490557747 & 8 & 876,457 & A & B & A & B & A & A \\
\hline ss490559220 & 8 & $1,044,709$ & A & B & A & B & B & B \\
\hline ss490550977 & 8 & $2,188,896$ & B & B & A & B & B & B \\
\hline ss490557805 & 8 & $2,567,793$ & A & B & A & B & A & B \\
\hline ss490557812 & 8 & $2,835,801$ & A & B & A & B & A & B \\
\hline ss490557854 & 8 & $3,993,707$ & B & B & B & B & B & B \\
\hline ss490557869 & 8 & $4,491,335$ & A & B & A & A & B & A \\
\hline ss490557915 & 8 & $5,668,188$ & A & B & A & B & A & B \\
\hline ss490557920 & 8 & $5,802,063$ & A & B & A & B & A & B \\
\hline ss490557923 & 8 & $6,011,965$ & B & B & B & B & B & B \\
\hline ss490557932 & 8 & $6,475,367$ & A & B & A & B & A & B \\
\hline
\end{tabular}

Supplemental Fig. S2. Continued. 


$\begin{array}{llr}\text { ss490557938 } & 8 & 6,563,189 \\ \text { ss490557941 } & 8 & 6,724,389 \\ \text { ss490557973 } & 8 & 7,919,697 \\ \text { ss490557992 } & 8 & 8,493,539 \\ \text { ss490551087 } & 8 & 8,546,822 \\ \text { ss490557995 } & 8 & 8,558,749 \\ \text { ss490558009 } & 8 & 9,004,156 \\ \text { ss490558018 } & 8 & 9,204,806 \\ \text { ss490558033 } & 8 & 10,189,188 \\ \text { ss490558045 } & 8 & 10,401,185 \\ \text { ss490558103 } & 8 & 12,024,509 \\ \text { ss490558941 } & 8 & 12,227,080 \\ \text { ss490558130 } & 8 & 12,634,796 \\ \text { ss490551176 } & 8 & 13,901,359 \\ \text { ss490558206 } & 8 & 13,903,589 \\ \text { ss490558257 } & 8 & 14,357,714 \\ \text { ss490558260 } & 8 & 14,374,888 \\ \text { ss490558308 } & 8 & 14,841,426 \\ \text { ss490558311 } & 8 & 14,888,590 \\ \text { ss490558317 } & 8 & 14,923,589 \\ \text { ss490559048 } & 8 & 16,036,151 \\ \text { ss490559419 } & 8 & 16,350,869 \\ \text { ss490559422 } & 8 & 16,350,931 \\ \text { ss490551327 } & 8 & 17,114,381 \\ \text { ss490558540 } & 8 & 17,307,331 \\ \text { ss490558555 } & 8 & 17,492,237 \\ \text { ss490558603 } & 8 & 18,157,624 \\ \text { ss490558609 } & 8 & 18,215,533 \\ \text { ss490558732 } & 8 & 19,869,798 \\ \text { ss490559133 } & 8 & 19,873,761 \\ \text { ss490559304 } & 8 & 21,311,784 \\ \text { ss490559307 } & 8 & 21,311,977 \\ \text { ss490559310 } & 8 & 21,311,991 \\ \text { ss490559313 } & 8 & 21,312,240 \\ \text { ss490559316 } & 8 & 21,312,298 \\ \text { ss490558810 } & 8 & 21,655,170\end{array}$

\begin{tabular}{l|l}
\hline B & B \\
\hline A & B \\
A & B \\
\hline B & A \\
B & A \\
B & A \\
A & A \\
B & B \\
\hline A & B \\
B & A \\
B & A \\
A & B \\
A & B \\
B & A \\
B & A \\
A & A \\
A & B \\
A & A \\
B & A \\
A & B \\
B & A \\
B & A \\
B & A \\
B & A \\
A & B \\
A & B \\
A & B \\
B & A \\
B & B \\
A & A \\
A & B \\
A & B \\
\hline A & B \\
A & B \\
\hline A & B \\
A & B \\
\hline & \\
\hline
\end{tabular}

\begin{tabular}{|l|l|}
\hline A & B \\
A & B \\
A & B \\
B & B \\
B & B \\
B & B \\
A & A \\
B & B \\
A & B \\
B & B \\
B & B \\
A & A \\
A & A \\
B & B \\
B & B \\
A & A \\
A & A \\
A & A \\
B & B \\
A & A \\
B & B \\
B & B \\
B & B \\
B & B \\
A & A \\
A & A \\
A & A \\
B & B \\
A & B \\
B & A \\
A & B \\
A & B \\
A & B \\
A & B \\
\hline
\end{tabular}

\begin{tabular}{|c|c|}
\hline B & B \\
\hline$A$ & B \\
\hline A & B \\
\hline A & B \\
\hline A & $B$ \\
\hline A & $B$ \\
\hline $\mathbf{A}$ & $A$ \\
\hline B & B \\
\hline A & B \\
\hline A & B \\
\hline A & $B$ \\
\hline B & $A$ \\
\hline B & $A$ \\
\hline $\begin{array}{l}\mathbf{A} \\
\mathbf{A}\end{array}$ & B \\
\hline A & $A$ \\
\hline B & $A$ \\
\hline A & A \\
\hline $\begin{array}{l}\mathbf{A} \\
\mathbf{R}\end{array}$ & B \\
\hline A & B \\
\hline A & $B$ \\
\hline A & B \\
\hline A & B \\
\hline $\begin{array}{l}\text { B } \\
\text { B }\end{array}$ & $A$ \\
\hline B & $A$ \\
\hline $\mathbf{A}$ & B \\
\hline B & B \\
\hline A & $A$ \\
\hline B & $B$ \\
\hline B & B \\
\hline B & B \\
\hline A & $A$ \\
\hline A & $A$ \\
\hline
\end{tabular}

Supplemental Fig. S2. Continued. 
Supplemental Table S1. List of 519 single nucleotide polymorphism markers, $S$-locus, and their peach physical map positions on the peach whole genome sequence, Peach v1.0 (Verde et al., 2013). ${ }^{\mathrm{z}}$

\begin{tabular}{|c|c|c|c|c|c|c|c|}
\hline \multirow[b]{2}{*}{ SN } & \multirow[b]{2}{*}{ NCBI SS } & \multirow[b]{2}{*}{ Original Full Name } & \multirow[b]{2}{*}{ Chr } & \multirow[b]{2}{*}{ Physical position (bp) } & \multicolumn{3}{|c|}{ Present in sample sets } \\
\hline & & & & & 1 & 2 & 3 \\
\hline$\overline{1}$ & ss490545390 & RosBREED_snp_sweet_cherry_Pp1_00348730 & 1 & 348730 & $\mathrm{Y}$ & $\mathrm{Y}$ & $\mathrm{Y}$ \\
\hline 2 & ss490558959 & RosCOS1201-071_snp_sweet_cherry_Pp1_00450381 & 1 & 450381 & $\mathrm{Y}$ & $\mathrm{N}$ & $\mathrm{N}$ \\
\hline 3 & ss490545406 & RosBREED_snp_sweet_cherry_Pp1_00538005 & 1 & 538005 & $\mathrm{Y}$ & $\mathrm{N}$ & $\mathrm{N}$ \\
\hline 4 & ss490545413 & RosBREED_snp_sweet_cherry_Pp1_00599759 & 1 & 599759 & Y & $\mathrm{N}$ & $\mathrm{N}$ \\
\hline 5 & ss490545708 & RosBREED_snp_tart_cherry_a_Pp1_00694731 & 1 & 694731 & $\mathrm{Y}$ & $\mathrm{N}$ & $\mathrm{N}$ \\
\hline 6 & ss490545434 & RosBREED_snp_sweet_cherry_Pp1_00885553 & 1 & 885553 & Y & $\mathrm{N}$ & $\mathrm{Y}$ \\
\hline 7 & ss490545452 & RosBREED_snp_sweet_cherry_Pp1_01111320 & 1 & 1111320 & $\mathrm{Y}$ & $\mathrm{N}$ & $\mathrm{N}$ \\
\hline 8 & ss490545461 & RosBREED_snp_sweet_cherry_Pp1_01197874 & 1 & 1197874 & $\mathrm{Y}$ & $\mathrm{N}$ & $\mathrm{N}$ \\
\hline 9 & ss490545716 & RosBREED_snp_tart_cherry_a_Pp1_01235182 & 1 & 1235182 & $\mathrm{Y}$ & $\mathrm{N}$ & $\mathrm{N}$ \\
\hline 10 & ss490545464 & RosBREED_snp_sweet_cherry_Pp1_01238095 & 1 & 1238095 & $\mathrm{Y}$ & $\mathrm{N}$ & $\mathrm{N}$ \\
\hline 11 & ss490545473 & RosBREED_snp_sweet_cherry_Pp1_01331155 & 1 & 1331155 & Y & $\mathrm{N}$ & Y \\
\hline 12 & ss490545482 & RosBREED_snp_sweet_cherry_Pp1_01450317 & 1 & 1450317 & Y & $\mathrm{N}$ & $\mathrm{N}$ \\
\hline 13 & ss490545503 & RosBREED_snp_sweet_cherry_Pp1_01737374 & 1 & 1737374 & $\mathrm{Y}$ & $\mathrm{N}$ & $\mathrm{N}$ \\
\hline 14 & ss490545528 & RosBREED_snp_sweet_cherry_Pp1_02115377 & 1 & 2115377 & $\mathrm{Y}$ & $\mathrm{Y}$ & $\mathrm{Y}$ \\
\hline 15 & ss490545541 & RosBREED_snp_sweet_cherry_Pp1_02241751 & 1 & 2241751 & $\mathrm{Y}$ & $\mathrm{N}$ & $\mathrm{N}$ \\
\hline 16 & ss490545556 & RosBREED_snp_sweet_cherry_Pp1_02441717 & 1 & 2441717 & Y & $\mathrm{N}$ & $\mathrm{N}$ \\
\hline 17 & ss490559162 & RosCOS1602-202_snp_sweet_cherry_Pp1_02602122 & 1 & 2602122 & Y & $\mathrm{N}$ & Y \\
\hline 18 & ss490545597 & RosBREED_snp_sweet_cherry_Pp1_03137813 & 1 & 3137813 & $\mathrm{Y}$ & $\mathrm{N}$ & $\mathrm{Y}$ \\
\hline 19 & ss490545844 & RosBREED_snp_sweet_cherry_Pp1_05839154 & 1 & 5839154 & $\mathrm{Y}$ & $\mathrm{N}$ & $\mathrm{Y}$ \\
\hline 20 & ss490545848 & RosBREED_snp_sweet_cherry_Pp1_05878432 & 1 & 5878432 & $\mathrm{Y}$ & $\mathrm{N}$ & $\mathrm{N}$ \\
\hline 21 & ss490545852 & RosBREED_snp_sweet_cherry_Pp1_05894052 & 1 & 5894052 & $\mathrm{Y}$ & $\mathrm{N}$ & $\mathrm{N}$ \\
\hline 22 & ss490545888 & RosBREED_snp_sweet_cherry_Pp1_06215653 & 1 & 6215653 & $\mathrm{Y}$ & $\mathrm{N}$ & $\mathrm{Y}$ \\
\hline 23 & ss490545912 & RosBREED_snp_sweet_cherry_Pp1_06460845 & 1 & 6460845 & $\mathrm{Y}$ & $\mathrm{N}$ & $\mathrm{N}$ \\
\hline 24 & ss490545967 & RosBREED_snp_sweet_cherry_Pp1_07374161 & 1 & 7374161 & $\mathrm{Y}$ & $\mathrm{N}$ & Y \\
\hline 25 & ss490545984 & RosBREED_snp_sweet_cherry_Pp1_07504437 & 1 & 7504437 & $\mathrm{Y}$ & $\mathrm{N}$ & $\mathrm{N}$ \\
\hline 26 & ss490546020 & RosBREED_snp_sweet_cherry_Pp1_07824263 & 1 & 7824263 & $\mathrm{Y}$ & $\mathrm{N}$ & $\mathrm{N}$ \\
\hline 27 & ss490558825 & RosCOS0478-267_snp_sweet_cherry_Pp1_08412096 & 1 & 8412096 & $\mathrm{Y}$ & $\mathrm{N}$ & $\mathrm{Y}$ \\
\hline 28 & ss490546174 & RosBREED_snp_sweet_cherry_Pp1_09597368 & 1 & 9597368 & $\mathrm{Y}$ & $\mathrm{Y}$ & $\mathrm{Y}$ \\
\hline 29 & ss490546226 & RosBREED_snp_sweet_cherry_Pp1_10175178 & 1 & 10175178 & $\mathrm{Y}$ & $\mathrm{N}$ & Y \\
\hline 30 & ss490546230 & RosBREED_snp_sweet_cherry_Pp1_10176147 & 1 & 10176147 & $\mathrm{Y}$ & $\mathrm{N}$ & $\mathrm{N}$ \\
\hline 31 & ss490546026 & RosBREED_snp_tart_cherry_a_Pp1_10178231 & 1 & 10178231 & $\mathrm{Y}$ & $\mathrm{N}$ & $\mathrm{N}$ \\
\hline 32 & ss490546269 & RosBREED_snp_sweet_cherry_Pp1_10284090 & 1 & 10284090 & $\mathrm{Y}$ & $\mathrm{N}$ & Y \\
\hline 33 & ss490546281 & RosBREED_snp_sweet_cherry_Pp1_10316151 & 1 & 10316151 & $\mathrm{Y}$ & $\mathrm{N}$ & $\mathrm{N}$ \\
\hline 34 & ss490546285 & RosBREED_snp_sweet_cherry_Pp1_10330576 & 1 & 10330576 & $\mathrm{Y}$ & $\mathrm{N}$ & $\mathrm{N}$ \\
\hline 35 & ss490546068 & RosBREED_snp_tart_cherry_a_Pp1_11102635 & 1 & 11102635 & Y & $\mathrm{N}$ & $\mathrm{Y}$ \\
\hline 36 & ss490546478 & RosBREED_snp_sweet_cherry_Pp1_11855405 & 1 & 11855405 & $\mathrm{Y}$ & $\mathrm{N}$ & $\mathrm{Y}$ \\
\hline 37 & ss490546494 & RosBREED_snp_sweet_cherry_Pp1_12191200 & 1 & 12191200 & $\mathrm{Y}$ & $\mathrm{Y}$ & $\mathrm{N}$ \\
\hline 38 & ss490546498 & RosBREED_snp_sweet_cherry_Pp1_12292557 & 1 & 12292557 & $\mathrm{Y}$ & $\mathrm{N}$ & $\mathrm{N}$ \\
\hline 39 & ss490546526 & RosBREED_snp_sweet_cherry_Pp1_13052512 & 1 & 13052512 & $\mathrm{Y}$ & $\mathrm{N}$ & $\mathrm{Y}$ \\
\hline 40 & ss490546566 & RosBREED_snp_sweet_cherry_Pp1_14110306 & 1 & 14110306 & $\mathrm{Y}$ & $\mathrm{N}$ & $\mathrm{Y}$ \\
\hline 41 & ss490546574 & RosBREED_snp_sweet_cherry_Pp1_14281912 & 1 & 14281912 & $\mathrm{Y}$ & $\mathrm{N}$ & $\mathrm{N}$ \\
\hline 42 & ss490546611 & RosBREED_snp_sweet_cherry_Pp1_15061804 & 1 & 15061804 & Y & $\mathrm{N}$ & Y \\
\hline 43 & ss490558902 & RosCOS1084-357_snp_sweet_cherry_Pp1_16608849 & 1 & 16608849 & Y & $\mathrm{Y}$ & $\mathrm{Y}$ \\
\hline 44 & ss490546643 & RosBREED_snp_sweet_cherry_Pp1_16612689 & 1 & 16612689 & $\mathrm{Y}$ & $\mathrm{N}$ & $\mathrm{N}$ \\
\hline 45 & ss490546651 & RosBREED_snp_sweet_cherry_Pp1_17571526 & 1 & 17571526 & $\mathrm{Y}$ & $\mathrm{N}$ & $\mathrm{Y}$ \\
\hline 46 & ss490546675 & RosBREED_snp_sweet_cherry_Pp1_19836475 & 1 & 19836475 & $\mathrm{Y}$ & $\mathrm{N}$ & $\mathrm{Y}$ \\
\hline 47 & ss490546679 & RosBREED_snp_sweet_cherry_Pp1_19999922 & 1 & 19999922 & $\mathrm{Y}$ & $\mathrm{Y}$ & $\mathrm{N}$ \\
\hline 48 & ss490559249 & RosCOS2143-270_snp_sweet_cherry_Pp1_21773370 & 1 & 21773370 & $\mathrm{Y}$ & $\mathrm{N}$ & $\mathrm{Y}$ \\
\hline 49 & ss490546874 & RosBREED_snp_sweet_cherry_Pp1_24575772 & 1 & 24575772 & $\mathrm{Y}$ & $\mathrm{N}$ & $\mathrm{Y}$ \\
\hline 50 & ss490546942 & RosBREED_snp_sweet_cherry_Pp1_25423943 & 1 & 25423943 & Y & $\mathrm{N}$ & Y \\
\hline 51 & ss490546990 & RosBREED_snp_sweet_cherry_Pp1_26047253 & 1 & 26047253 & $\mathrm{Y}$ & $\mathrm{N}$ & $\mathrm{Y}$ \\
\hline 52 & ss490547035 & RosBREED_snp_sweet_cherry_Pp1_26698128 & 1 & 26698128 & $\mathrm{Y}$ & $\mathrm{N}$ & $\mathrm{Y}$ \\
\hline 53 & ss490547103 & RosBREED_snp_sweet_cherry_Pp1_27626876 & 1 & 27626876 & $\mathrm{Y}$ & $\mathrm{N}$ & Y \\
\hline 54 & ss490547111 & RosBREED_snp_sweet_cherry_Pp1_27714539 & 1 & 27714539 & $\mathrm{Y}$ & $\mathrm{N}$ & $\mathrm{N}$ \\
\hline 55 & ss490559197 & RosCOS1756-104_snp_sweet_cherry_Pp1_27721194 & 1 & 27721194 & $\mathrm{Y}$ & $\mathrm{Y}$ & $\mathrm{N}$ \\
\hline 56 & ss490547194 & RosBREED_snp_sweet_cherry_Pp1_29638469 & 1 & 29638469 & $\mathrm{Y}$ & $\mathrm{N}$ & Y \\
\hline
\end{tabular}




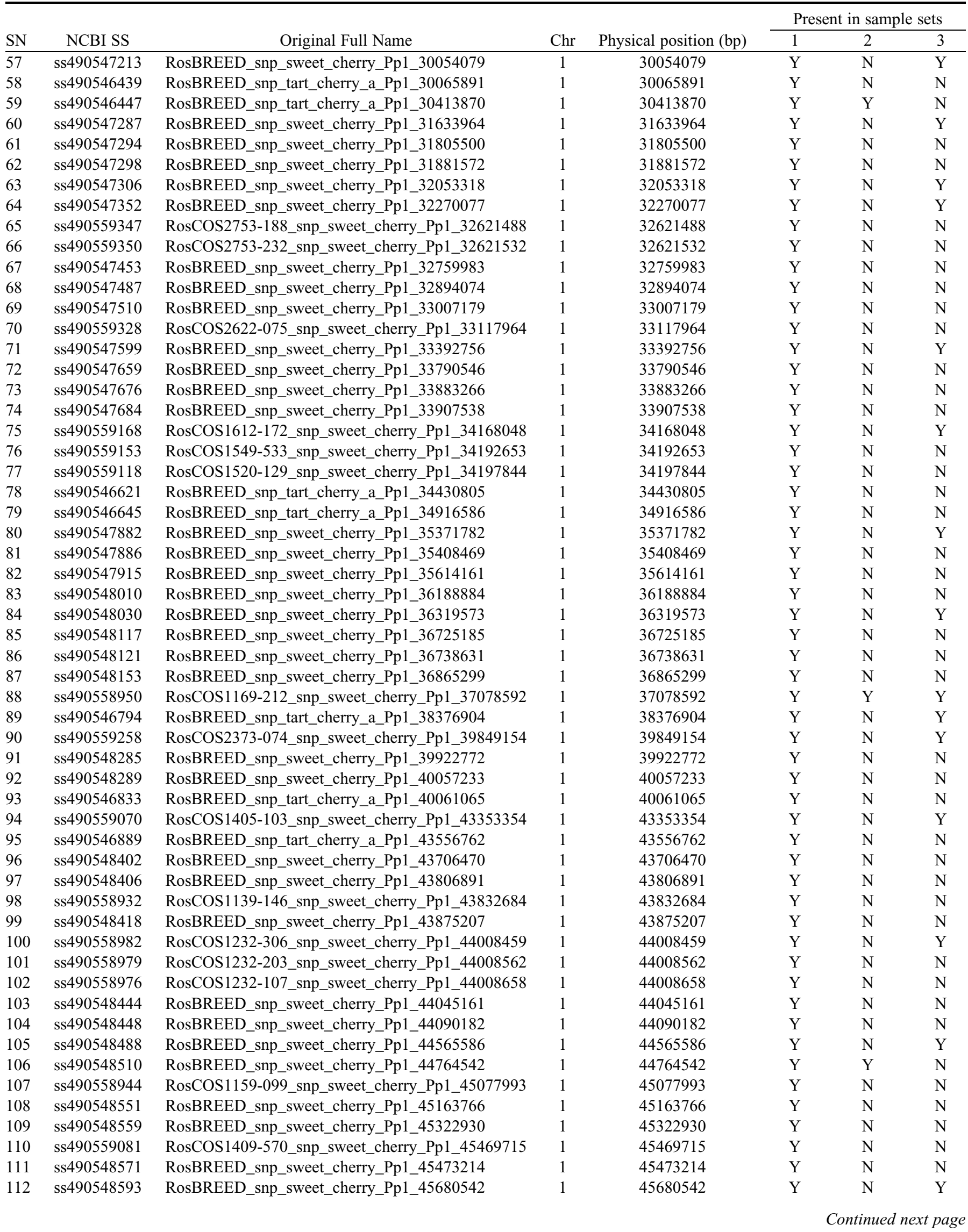


Supplemental Table S1. Continued.

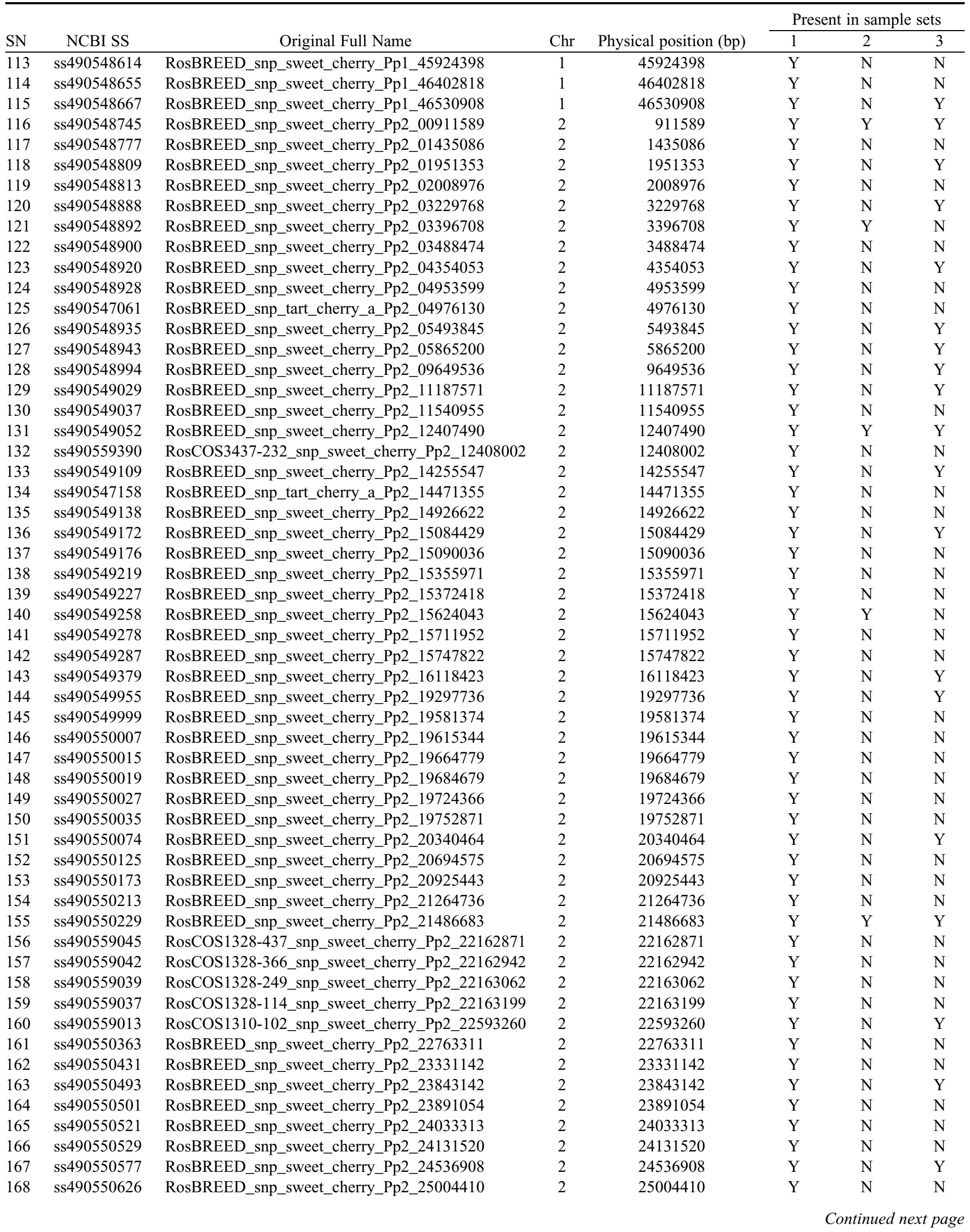


Supplemental Table S1. Continued.

\begin{tabular}{|c|c|c|c|c|c|c|c|}
\hline \multirow[b]{2}{*}{$\mathrm{SN}$} & \multirow[b]{2}{*}{ NCBI SS } & \multirow[b]{2}{*}{$\begin{array}{l}\text { Original Full Name } \\
\end{array}$} & \multirow[b]{2}{*}{ Chr } & \multirow[b]{2}{*}{ Physical position (bp) } & \multicolumn{3}{|c|}{ Present in sample sets } \\
\hline & & & & & 1 & 2 & 3 \\
\hline 169 & ss490550691 & RosBREED_snp_sweet_cherry_Pp2_25512709 & 2 & 25512709 & $\mathrm{Y}$ & $\mathrm{Y}$ & $\mathrm{N}$ \\
\hline 170 & ss490559255 & RosCOS2370-108_snp_sweet_cherry_Pp2_26346122 & 2 & 26346122 & Y & $\mathrm{N}$ & Y \\
\hline 172 & ss490550883 & RosBREED_snp_sweet_cherry_Pp3_01174681 & 3 & 1174681 & Y & Y & $\mathrm{N}$ \\
\hline 173 & ss490550887 & RosBREED_snp_sweet_cherry_Pp3_01257143 & 3 & 1257143 & Y & $\mathrm{N}$ & $\mathrm{Y}$ \\
\hline 174 & ss490551030 & RosBREED_snp_sweet_cherry_Pp3_02262982 & 3 & 2262982 & $\mathrm{Y}$ & $\mathrm{N}$ & Y \\
\hline 176 & ss490551118 & RosBREED_snp_sweet_cherry_Pp3_02743517 & 3 & 2743517 & Y & $\mathrm{N}$ & $\mathrm{N}$ \\
\hline 177 & ss490551167 & RosBREED_snp_sweet_cherry_Pp3_03086237 & 3 & 3086237 & Y & $\mathrm{N}$ & $\mathrm{N}$ \\
\hline 178 & ss490551234 & RosBREED_snp_sweet_cherry_Pp3_03593732 & 3 & 3593732 & $\mathrm{Y}$ & $\mathrm{Y}$ & $\mathrm{N}$ \\
\hline 179 & ss490551267 & RosBREED_snp_sweet_cherry_Pp3_03927957 & 3 & 3927957 & Y & $\mathrm{N}$ & Y \\
\hline 180 & ss490547825 & RosBREED_snp_tart_cherry_a_Pp3_04138750 & 3 & 4138750 & Y & $\mathrm{N}$ & $\mathrm{N}$ \\
\hline 181 & ss490551321 & RosBREED_snp_sweet_cherry_Pp3_04301861 & 3 & 4301861 & Y & $\mathrm{N}$ & $\mathrm{N}$ \\
\hline 186 & ss490551353 & RosBREED_snp_sweet_cherry_Pp3_04934519 & 3 & 4934519 & Y & $\mathrm{N}$ & $\mathrm{Y}$ \\
\hline 187 & ss490551394 & RosBREED_snp_sweet_cherry_Pp3_06646570 & 3 & 6646570 & $\mathrm{Y}$ & $\mathrm{N}$ & $\mathrm{Y}$ \\
\hline 188 & ss490551435 & RosBREED_snp_sweet_cherry_Pp3_07412958 & 3 & 7412958 & $\mathrm{Y}$ & $\mathrm{N}$ & $\mathrm{N}$ \\
\hline 189 & ss 490551450 & RosBREED_snp_sweet_cherry_Pp3_07622320 & 3 & 7622320 & $\mathrm{Y}$ & $\mathrm{N}$ & Y \\
\hline 190 & ss490551490 & RosBREED_snp_sweet_cherry_Pp3_08552044 & 3 & 8552044 & $\mathrm{Y}$ & $\mathrm{N}$ & Y \\
\hline 191 & ss490551507 & RosBREED_snp_sweet_cherry_Pp3_08859929 & 3 & 8859929 & Y & $\mathrm{N}$ & $\mathrm{N}$ \\
\hline 192 & ss490547928 & RosBREED_snp_tart_cherry_a_Pp3_09782875 & 3 & 9782875 & $\mathrm{Y}$ & $\mathrm{N}$ & $\mathrm{Y}$ \\
\hline 193 & ss490551568 & RosBREED_snp_sweet_cherry_Pp3_10399039 & 3 & 10399039 & Y & $\mathrm{N}$ & $\mathrm{N}$ \\
\hline 194 & ss490547960 & RosBREED_snp_tart_cherry_a_Pp3_12115409 & 3 & 12115409 & $\mathrm{Y}$ & $\mathrm{Y}$ & $\mathrm{N}$ \\
\hline 195 & ss490551623 & RosBREED_snp_sweet_cherry_Pp3_12188902 & 3 & 12188902 & Y & $\mathrm{N}$ & $\mathrm{N}$ \\
\hline 196 & ss490551684 & RosBREED_snp_sweet_cherry_Pp3_13025963 & 3 & 13025963 & $\mathrm{Y}$ & $\mathrm{N}$ & $\mathrm{Y}$ \\
\hline 204 & ss490551889 & RosBREED_snp_sweet_cherry_Pp3_15682037 & 3 & 15682037 & $\mathrm{Y}$ & $\mathrm{N}$ & $\mathrm{N}$ \\
\hline 205 & ss490551892 & RosBREED_snp_sweet_cherry_Pp3_15730479 & 3 & 15730479 & Y & $\mathrm{N}$ & $\mathrm{N}$ \\
\hline 206 & ss490551939 & RosBREED_snp_sweet_cherry_Pp3_16692901 & 3 & 16692901 & $\mathrm{Y}$ & $\mathrm{N}$ & $\mathrm{Y}$ \\
\hline 207 & ss490551960 & RosBREED_snp_sweet_cherry_Pp3_17036907 & 3 & 17036907 & $\mathrm{Y}$ & $\mathrm{N}$ & $\mathrm{N}$ \\
\hline 208 & ss490551969 & RosBREED_snp_sweet_cherry_Pp3_17302344 & 3 & 17302344 & $\mathrm{Y}$ & $\mathrm{Y}$ & $\mathrm{N}$ \\
\hline 209 & ss490551972 & RosBREED_snp_sweet_cherry_Pp3_17343716 & 3 & 17343716 & Y & $\mathrm{N}$ & $\mathrm{N}$ \\
\hline 210 & ss490548147 & RosBREED_snp_tart_cherry_a_Pp3_17988706 & 3 & 17988706 & Y & $\mathrm{N}$ & $\mathrm{Y}$ \\
\hline 211 & ss490552015 & RosBREED_snp_sweet_cherry_Pp3_18138999 & 3 & 18138999 & Y & $\mathrm{N}$ & $\mathrm{N}$ \\
\hline 212 & ss490552023 & RosBREED_snp_sweet_cherry_Pp3_18281259 & 3 & 18281259 & Y & $\mathrm{N}$ & $\mathrm{N}$ \\
\hline 213 & ss490552032 & RosBREED_snp_sweet_cherry_Pp3_18419753 & 3 & 18419753 & Y & $\mathrm{N}$ & $\mathrm{N}$ \\
\hline 214 & ss490552038 & RosBREED_snp_sweet_cherry_Pp3_18512598 & 3 & 18512598 & $\mathrm{Y}$ & $\mathrm{N}$ & $\mathrm{N}$ \\
\hline 215 & ss490552061 & RosBREED_snp_sweet_cherry_Pp3_19018695 & 3 & 19018695 & $\mathrm{Y}$ & $\mathrm{N}$ & $\mathrm{Y}$ \\
\hline 216 & ss490552191 & RosBREED_snp_sweet_cherry_Pp3_21003752 & 3 & 21003752 & $\mathrm{Y}$ & $\mathrm{N}$ & $\mathrm{Y}$ \\
\hline 217 & ss490552196 & RosBREED_snp_sweet_cherry_Pp3_21119693 & 3 & 21119693 & $\mathrm{Y}$ & $\mathrm{Y}$ & $\mathrm{N}$ \\
\hline 218 & ss490552270 & RosBREED_snp_sweet_cherry_Pp4_00234975 & 4 & 234975 & $\mathrm{Y}$ & $\mathrm{Y}$ & $\mathrm{Y}$ \\
\hline 219 & ss490552272 & RosBREED_snp_sweet_cherry_Pp4_00275572 & 4 & 275572 & Y & $\mathrm{N}$ & $\mathrm{N}$ \\
\hline 220 & ss490559194 & RosCOS1689-287_snp_sweet_cherry_Pp4_00569769 & 4 & 569769 & Y & $\mathrm{N}$ & $\mathrm{N}$ \\
\hline 221 & ss490552318 & RosBREED_snp_sweet_cherry_Pp4_00919839 & 4 & 919839 & Y & $\mathrm{N}$ & $\mathrm{N}$ \\
\hline 222 & ss490552332 & RosBREED_snp_sweet_cherry_Pp4_01117948 & 4 & 1117948 & $\mathrm{Y}$ & $\mathrm{N}$ & $\mathrm{Y}$ \\
\hline 223 & ss490552394 & RosBREED_snp_sweet_cherry_Pp4_01983101 & 4 & 1983101 & $\mathrm{Y}$ & $\mathrm{N}$ & $\mathrm{N}$ \\
\hline 224 & ss490548393 & RosBREED_snp_tart_cherry_a_Pp4_02170096 & 4 & 2170096 & $\mathrm{Y}$ & $\mathrm{N}$ & $\mathrm{Y}$ \\
\hline
\end{tabular}


Supplemental Table S1. Continued.

\begin{tabular}{|c|c|c|c|c|c|c|c|}
\hline \multirow[b]{2}{*}{$\mathrm{SN}$} & \multirow[b]{2}{*}{ NCBI SS } & \multirow[b]{2}{*}{ Original Full Name } & \multirow[b]{2}{*}{ Chr } & \multirow[b]{2}{*}{ Physical position (bp) } & \multicolumn{3}{|c|}{ Present in sample sets } \\
\hline & & & & & 1 & 2 & 3 \\
\hline 225 & ss490552435 & RosBREED_snp_sweet_cherry_Pp4_02559655 & 4 & 2559655 & $\mathrm{Y}$ & $\mathrm{Y}$ & $\mathrm{N}$ \\
\hline 226 & ss490552446 & RosBREED_snp_sweet_cherry_Pp4_02682092 & 4 & 2682092 & $\mathrm{Y}$ & $\mathrm{N}$ & $\mathrm{N}$ \\
\hline 227 & ss490552449 & RosBREED_snp_sweet_cherry_Pp4_02712550 & 4 & 2712550 & Y & $\mathrm{N}$ & Y \\
\hline 228 & ss490559127 & RosCOS1533-077_snp_sweet_cherry_Pp4_04329962 & 4 & 4329962 & $\mathrm{Y}$ & $\mathrm{N}$ & $\mathrm{Y}$ \\
\hline 229 & ss490552562 & RosBREED_snp_sweet_cherry_Pp4_04353195 & 4 & 4353195 & $\mathrm{Y}$ & $\mathrm{Y}$ & $\mathrm{N}$ \\
\hline 230 & ss490552570 & RosBREED_snp_sweet_cherry_Pp4_04471205 & 4 & 4471205 & Y & $\mathrm{N}$ & $\mathrm{N}$ \\
\hline 231 & ss490552576 & RosBREED_snp_sweet_cherry_Pp4_04551204 & 4 & 4551204 & Y & $\mathrm{N}$ & $\mathrm{N}$ \\
\hline 232 & ss490552606 & RosBREED_snp_sweet_cherry_Pp4_05231853 & 4 & 5231853 & Y & $\mathrm{N}$ & Y \\
\hline 233 & ss490552620 & RosBREED_snp_sweet_cherry_Pp4_05425119 & 4 & 5425119 & Y & $\mathrm{N}$ & $\mathrm{N}$ \\
\hline 234 & ss490552626 & RosBREED_snp_sweet_cherry_Pp4_05490025 & 4 & 5490025 & $\mathrm{Y}$ & $\mathrm{N}$ & $\mathrm{N}$ \\
\hline 235 & ss490552643 & RosBREED_snp_sweet_cherry_Pp4_05790270 & 4 & 5790270 & $\mathrm{Y}$ & $\mathrm{N}$ & $\mathrm{N}$ \\
\hline 236 & ss490552646 & RosBREED_snp_sweet_cherry_Pp4_05856246 & 4 & 5856246 & Y & $\mathrm{N}$ & $\mathrm{N}$ \\
\hline 237 & ss490552649 & RosBREED_snp_sweet_cherry_Pp4_05911133 & 4 & 5911133 & $\mathrm{Y}$ & $\mathrm{N}$ & $\mathrm{N}$ \\
\hline 238 & ss490552675 & RosBREED_snp_sweet_cherry_Pp4_06348991 & 4 & 6348991 & Y & $\mathrm{N}$ & $\mathrm{Y}$ \\
\hline 239 & ss490558877 & RosCOS0546-209_snp_sweet_cherry_Pp4_06464070 & 4 & 6464070 & Y & $\mathrm{Y}$ & $\mathrm{N}$ \\
\hline 240 & ss490552696 & RosBREED_snp_sweet_cherry_Pp4_06545181 & 4 & 6545181 & Y & $\mathrm{N}$ & $\mathrm{N}$ \\
\hline 241 & ss490552699 & RosBREED_snp_sweet_cherry_Pp4_06580288 & 4 & 6580288 & Y & $\mathrm{N}$ & $\mathrm{N}$ \\
\hline 242 & ss490552713 & RosBREED_snp_sweet_cherry_Pp4_06828082 & 4 & 6828082 & Y & $\mathrm{N}$ & $\mathrm{N}$ \\
\hline 243 & ss490552727 & RosBREED_snp_sweet_cherry_Pp4_07065857 & 4 & 7065857 & $\mathrm{Y}$ & $\mathrm{N}$ & $\mathrm{N}$ \\
\hline 244 & ss490552730 & RosBREED_snp_sweet_cherry_Pp4_07148241 & 4 & 7148241 & $\mathrm{Y}$ & $\mathrm{N}$ & $\mathrm{N}$ \\
\hline 245 & ss490552744 & RosBREED_snp_sweet_cherry_Pp4_07349971 & 4 & 7349971 & Y & $\mathrm{N}$ & Y \\
\hline 246 & ss490552747 & RosBREED_snp_sweet_cherry_Pp4_07402206 & 4 & 7402206 & $\mathrm{Y}$ & $\mathrm{N}$ & $\mathrm{N}$ \\
\hline 247 & ss490552750 & RosBREED_snp_sweet_cherry_Pp4_07429956 & 4 & 7429956 & $\mathrm{Y}$ & $\mathrm{N}$ & $\mathrm{N}$ \\
\hline 248 & ss490552753 & RosBREED_snp_sweet_cherry_Pp4_07456033 & 4 & 7456033 & Y & $\mathrm{N}$ & $\mathrm{N}$ \\
\hline 249 & ss490552767 & RosBREED_snp_sweet_cherry_Pp4_07706352 & 4 & 7706352 & $\mathrm{Y}$ & $\mathrm{N}$ & $\mathrm{N}$ \\
\hline 250 & ss490552832 & RosBREED_snp_sweet_cherry_Pp4_08827326 & 4 & 8827326 & $\mathrm{Y}$ & $\mathrm{N}$ & $\mathrm{Y}$ \\
\hline 251 & ss490548662 & RosBREED_snp_tart_cherry_a_Pp4_08955576 & 4 & 8955576 & Y & $\mathrm{N}$ & $\mathrm{N}$ \\
\hline 252 & ss490552843 & RosBREED_snp_sweet_cherry_Pp4_08985625 & 4 & 8985625 & $\mathrm{Y}$ & $\mathrm{N}$ & $\mathrm{N}$ \\
\hline 253 & ss490545355 & Pa1Cl_snp_sweet_cherry_Pp4_09145953 & 4 & 9145953 & $\mathrm{Y}$ & $\mathrm{N}$ & $\mathrm{N}$ \\
\hline 254 & ss490552856 & RosBREED_snp_sweet_cherry_Pp4_09148953 & 4 & 9148953 & $\mathrm{Y}$ & $\mathrm{N}$ & $\mathrm{N}$ \\
\hline 255 & ss490552880 & RosBREED_snp_sweet_cherry_Pp4_10145480 & 4 & 10145480 & Y & $\mathrm{N}$ & $\mathrm{Y}$ \\
\hline 256 & ss490559107 & RosCOS1499-100_snp_sweet_cherry_Pp4_10225433 & 4 & 10225433 & $\mathrm{Y}$ & $\mathrm{N}$ & $\mathrm{N}$ \\
\hline 257 & ss490552883 & RosBREED_snp_sweet_cherry_Pp4_10230259 & 4 & 10230259 & $\mathrm{Y}$ & $\mathrm{N}$ & $\mathrm{N}$ \\
\hline 258 & ss490559054 & RosCOS1363-161_snp_sweet_cherry_Pp4_10403896 & 4 & 10403896 & $\mathrm{Y}$ & $\mathrm{Y}$ & $\mathrm{N}$ \\
\hline 259 & ss490552928 & RosBREED_snp_sweet_cherry_Pp4_11462176 & 4 & 11462176 & Y & $\mathrm{N}$ & Y \\
\hline 260 & ss490552959 & RosBREED_snp_sweet_cherry_Pp4_12567325 & 4 & 12567325 & $\mathrm{Y}$ & $\mathrm{N}$ & Y \\
\hline 261 & ss490552964 & RosBREED_snp_sweet_cherry_Pp4_12715001 & 4 & 12715001 & $\mathrm{Y}$ & $\mathrm{N}$ & $\mathrm{N}$ \\
\hline 262 & ss490552970 & RosBREED_snp_sweet_cherry_Pp4_12865643 & 4 & 12865643 & $\mathrm{Y}$ & $\mathrm{N}$ & $\mathrm{N}$ \\
\hline 263 & ss490552973 & RosBREED_snp_sweet_cherry_Pp4_12955416 & 4 & 12955416 & $\mathrm{Y}$ & $\mathrm{N}$ & $\mathrm{N}$ \\
\hline 264 & ss490559147 & RosCOS1546-059_snp_sweet_cherry_Pp4_12987703 & 4 & 12987703 & $\mathrm{Y}$ & $\mathrm{N}$ & $\mathrm{N}$ \\
\hline 265 & ss490558926 & RosCOS1132-199_snp_sweet_cherry_Pp4_13089513 & 4 & 13089513 & $\mathrm{Y}$ & $\mathrm{N}$ & $\mathrm{N}$ \\
\hline 266 & ss490552979 & RosBREED_snp_sweet_cherry_Pp4_13093284 & 4 & 13093284 & $\mathrm{Y}$ & $\mathrm{N}$ & $\mathrm{N}$ \\
\hline 267 & ss490553016 & RosBREED_snp_sweet_cherry_Pp4_13886648 & 4 & 13886648 & Y & $\mathrm{N}$ & Y \\
\hline 268 & ss490553025 & RosBREED_snp_sweet_cherry_Pp4_14081510 & 4 & 14081510 & $\mathrm{Y}$ & $\mathrm{N}$ & $\mathrm{N}$ \\
\hline 269 & ss490553036 & RosBREED_snp_sweet_cherry_Pp4_14516715 & 4 & 14516715 & $\mathrm{Y}$ & $\mathrm{N}$ & $\mathrm{N}$ \\
\hline 270 & ss490553048 & RosBREED_snp_sweet_cherry_Pp4_14821190 & 4 & 14821190 & $\mathrm{Y}$ & $\mathrm{N}$ & $\mathrm{N}$ \\
\hline 271 & ss490553059 & RosBREED_snp_sweet_cherry_Pp4_15070360 & 4 & 15070360 & $\mathrm{Y}$ & $\mathrm{Y}$ & $\mathrm{Y}$ \\
\hline 272 & ss490558929 & RosCOS1134-107_snp_sweet_cherry_Pp4_16075683 & 4 & 16075683 & $\mathrm{Y}$ & $\mathrm{N}$ & Y \\
\hline 273 & ss490553123 & RosBREED_snp_sweet_cherry_Pp4_17222313 & 4 & 17222313 & $\mathrm{Y}$ & $\mathrm{N}$ & Y \\
\hline 274 & ss490558865 & RosCOS0544-090_snp_sweet_cherry_Pp4_17859388 & 4 & 17859388 & $\mathrm{Y}$ & $\mathrm{N}$ & $\mathrm{N}$ \\
\hline 275 & ss490558868 & RosCOS0544-148_snp_sweet_cherry_Pp4_17859446 & 4 & 17859446 & $\mathrm{Y}$ & $\mathrm{N}$ & $\mathrm{N}$ \\
\hline 276 & ss490558871 & RosCOS0544-363_snp_sweet_cherry_Pp4_17859661 & 4 & 17859661 & $\mathrm{Y}$ & $\mathrm{N}$ & $\mathrm{N}$ \\
\hline 277 & ss490553144 & RosBREED_snp_sweet_cherry_Pp4_17943880 & 4 & 17943880 & $\mathrm{Y}$ & $\mathrm{N}$ & $\mathrm{N}$ \\
\hline 278 & ss490553184 & RosBREED_snp_sweet_cherry_Pp4_18701563 & 4 & 18701563 & $\mathrm{Y}$ & $\mathrm{N}$ & Y \\
\hline 279 & ss490553192 & RosBREED_snp_sweet_cherry_Pp4_19293490 & 4 & 19293490 & $\mathrm{Y}$ & $\mathrm{N}$ & $\mathrm{N}$ \\
\hline 280 & ss490553198 & RosBREED_snp_sweet_cherry_Pp4_19411509 & 4 & 19411509 & $\mathrm{Y}$ & $\mathrm{N}$ & $\mathrm{N}$ \\
\hline
\end{tabular}


Supplemental Table S1. Continued.

\begin{tabular}{|c|c|c|c|c|c|c|c|}
\hline \multirow[b]{2}{*}{ SN } & \multirow[b]{2}{*}{ NCBI SS } & \multirow[b]{2}{*}{ Original Full Name } & \multirow[b]{2}{*}{ Chr } & \multirow[b]{2}{*}{ Physical position (bp) } & \multicolumn{3}{|c|}{ Present in sample sets } \\
\hline & & & & & 1 & 2 & 3 \\
\hline 281 & ss490553204 & RosBREED_snp_sweet_cherry_Pp4_19561278 & 4 & 19561278 & $\mathrm{Y}$ & $\mathrm{N}$ & $\mathrm{N}$ \\
\hline 282 & ss490553207 & RosBREED_snp_sweet_cherry_Pp4_19599189 & 4 & 19599189 & Y & $\mathrm{Y}$ & $\mathrm{N}$ \\
\hline 283 & ss490553209 & RosBREED_snp_sweet_cherry_Pp4_19657873 & 4 & 19657873 & Y & $\mathrm{N}$ & Y \\
\hline 284 & ss490553268 & RosBREED_snp_sweet_cherry_Pp4_20865038 & 4 & 20865038 & $\mathrm{Y}$ & $\mathrm{N}$ & Y \\
\hline 285 & ss490553274 & RosBREED_snp_sweet_cherry_Pp4_20926979 & 4 & 20926979 & $\mathrm{Y}$ & $\mathrm{N}$ & $\mathrm{N}$ \\
\hline 286 & ss490548855 & RosBREED_snp_tart_cherry_a_Pp4_21145128 & 4 & 21145128 & $\mathrm{Y}$ & $\mathrm{N}$ & $\mathrm{N}$ \\
\hline 287 & ss490553289 & RosBREED_snp_sweet_cherry_Pp4_21580914 & 4 & 21580914 & $\mathrm{Y}$ & $\mathrm{N}$ & $\mathrm{Y}$ \\
\hline 288 & ss490553438 & RosBREED_snp_sweet_cherry_Pp4_26771048 & 4 & 26771048 & $\mathrm{Y}$ & $\mathrm{Y}$ & $\mathrm{N}$ \\
\hline 289 & ss490553464 & RosBREED_snp_sweet_cherry_Pp4_27192075 & 4 & 27192075 & $\mathrm{Y}$ & $\mathrm{N}$ & $\mathrm{Y}$ \\
\hline 290 & ss490553467 & RosBREED_snp_sweet_cherry_Pp4_27218201 & 4 & 27218201 & $\mathrm{Y}$ & $\mathrm{N}$ & $\mathrm{N}$ \\
\hline 291 & ss490553543 & RosBREED_snp_sweet_cherry_Pp4_29560911 & 4 & 29560911 & $\mathrm{Y}$ & $\mathrm{N}$ & $\mathrm{Y}$ \\
\hline 292 & ss490553644 & RosBREED_snp_sweet_cherry_Pp5_00689941 & 5 & 689941 & $\mathrm{Y}$ & $\mathrm{N}$ & Y \\
\hline 293 & ss490553674 & RosBREED_snp_sweet_cherry_Pp5_00934368 & 5 & 934368 & $\mathrm{Y}$ & $\mathrm{N}$ & $\mathrm{N}$ \\
\hline 294 & ss490553735 & RosBREED_snp_sweet_cherry_Pp5_01629739 & 5 & 1629739 & $\mathrm{Y}$ & $\mathrm{N}$ & Y \\
\hline 295 & ss490553738 & RosBREED_snp_sweet_cherry_Pp5_01645289 & 5 & 1645289 & $\mathrm{Y}$ & $\mathrm{Y}$ & $\mathrm{N}$ \\
\hline 296 & ss490553741 & RosBREED_snp_sweet_cherry_Pp5_01658127 & 5 & 1658127 & $\mathrm{Y}$ & $\mathrm{N}$ & $\mathrm{N}$ \\
\hline 297 & ss490559171 & RosCOS1616-297_snp_sweet_cherry_Pp5_01709155 & 5 & 1709155 & $\mathrm{Y}$ & $\mathrm{N}$ & $\mathrm{N}$ \\
\hline 298 & ss490549013 & RosBREED_snp_tart_cherry_a_Pp5_02351581 & 5 & 2351581 & $\mathrm{Y}$ & $\mathrm{N}$ & Y \\
\hline 299 & ss490553811 & RosBREED_snp_sweet_cherry_Pp5_03193567 & 5 & 3193567 & $\mathrm{Y}$ & $\mathrm{N}$ & $\mathrm{Y}$ \\
\hline 300 & ss490553817 & RosBREED_snp_sweet_cherry_Pp5_03299986 & 5 & 3299986 & $\mathrm{Y}$ & $\mathrm{N}$ & $\mathrm{N}$ \\
\hline 301 & ss490553823 & RosBREED_snp_sweet_cherry_Pp5_03464400 & 5 & 3464400 & Y & $\mathrm{N}$ & $\mathrm{N}$ \\
\hline 302 & ss490559270 & RosCOS2380-161_snp_sweet_cherry_Pp5_03464457 & 5 & 3464457 & $\mathrm{Y}$ & $\mathrm{N}$ & $\mathrm{N}$ \\
\hline 303 & ss490559267 & RosCOS2380-101_snp_sweet_cherry_Pp5_03464517 & 5 & 3464517 & $\mathrm{Y}$ & $\mathrm{N}$ & $\mathrm{N}$ \\
\hline 304 & ss490559156 & RosCOS1551-132_snp_sweet_cherry_Pp5_03469706 & 5 & 3469706 & $\mathrm{Y}$ & $\mathrm{Y}$ & $\mathrm{N}$ \\
\hline 305 & ss490553847 & RosBREED_snp_sweet_cherry_Pp5_03644242 & 5 & 3644242 & $\mathrm{Y}$ & $\mathrm{N}$ & $\mathrm{N}$ \\
\hline 306 & ss490553853 & RosBREED_snp_sweet_cherry_Pp5_03695755 & 5 & 3695755 & $\mathrm{Y}$ & $\mathrm{N}$ & $\mathrm{N}$ \\
\hline 307 & ss490553895 & RosBREED_snp_sweet_cherry_Pp5_04302944 & 5 & 4302944 & $\mathrm{Y}$ & $\mathrm{N}$ & Y \\
\hline 308 & ss490553907 & RosBREED_snp_sweet_cherry_Pp5_04413731 & 5 & 4413731 & $\mathrm{Y}$ & $\mathrm{N}$ & $\mathrm{N}$ \\
\hline 309 & ss490553910 & RosBREED_snp_sweet_cherry_Pp5_04486238 & 5 & 4486238 & $\mathrm{Y}$ & $\mathrm{N}$ & $\mathrm{N}$ \\
\hline 310 & ss490553919 & RosBREED_snp_sweet_cherry_Pp5_04710627 & 5 & 4710627 & $\mathrm{Y}$ & $\mathrm{N}$ & $\mathrm{N}$ \\
\hline 311 & ss490553922 & RosBREED_snp_sweet_cherry_Pp5_04755463 & 5 & 4755463 & $\mathrm{Y}$ & $\mathrm{N}$ & $\mathrm{N}$ \\
\hline 312 & ss490553929 & RosBREED_snp_sweet_cherry_Pp5_04897952 & 5 & 4897952 & $\mathrm{Y}$ & $\mathrm{N}$ & $\mathrm{N}$ \\
\hline 313 & ss490553960 & RosBREED_snp_sweet_cherry_Pp5_05409519 & 5 & 5409519 & $\mathrm{Y}$ & $\mathrm{N}$ & $\mathrm{Y}$ \\
\hline 314 & ss490553963 & RosBREED_snp_sweet_cherry_Pp5_05429352 & 5 & 5429352 & $\mathrm{Y}$ & $\mathrm{N}$ & $\mathrm{N}$ \\
\hline 315 & ss490559113 & RosCOS1500-271_snp_sweet_cherry_Pp5_09393638 & 5 & 9393638 & $\mathrm{Y}$ & $\mathrm{N}$ & Y \\
\hline 316 & ss490559110 & RosCOS1500-163_snp_sweet_cherry_Pp5_09393745 & 5 & 9393745 & $\mathrm{Y}$ & $\mathrm{N}$ & $\mathrm{N}$ \\
\hline 317 & ss490554201 & RosBREED_snp_sweet_cherry_Pp5_11943249 & 5 & 11943249 & $\mathrm{Y}$ & $\mathrm{Y}$ & $\mathrm{Y}$ \\
\hline 318 & ss490554283 & RosBREED_snp_sweet_cherry_Pp5_12331780 & 5 & 12331780 & $\mathrm{Y}$ & $\mathrm{N}$ & $\mathrm{N}$ \\
\hline 319 & ss490554313 & RosBREED_snp_sweet_cherry_Pp5_12506702 & 5 & 12506702 & $\mathrm{Y}$ & $\mathrm{N}$ & Y \\
\hline 320 & ss490554346 & RosBREED_snp_sweet_cherry_Pp5_12750950 & 5 & 12750950 & $\mathrm{Y}$ & $\mathrm{N}$ & $\mathrm{N}$ \\
\hline 321 & ss490554352 & RosBREED_snp_sweet_cherry_Pp5_12785307 & 5 & 12785307 & $\mathrm{Y}$ & $\mathrm{Y}$ & $\mathrm{N}$ \\
\hline 322 & ss490554372 & RosBREED_snp_sweet_cherry_Pp5_12917888 & 5 & 12917888 & $\mathrm{Y}$ & $\mathrm{N}$ & $\mathrm{N}$ \\
\hline 323 & ss490554417 & RosBREED_snp_sweet_cherry_Pp5_13191542 & 5 & 13191542 & $\mathrm{Y}$ & $\mathrm{N}$ & $\mathrm{N}$ \\
\hline 324 & ss490559186 & RosCOS1619-289_snp_sweet_cherry_Pp5_13240090 & 5 & 13240090 & $\mathrm{Y}$ & $\mathrm{N}$ & $\mathrm{N}$ \\
\hline 325 & ss490554495 & RosBREED_snp_sweet_cherry_Pp5_13715106 & 5 & 13715106 & Y & $\mathrm{N}$ & Y \\
\hline 326 & ss490559206 & RosCOS1765-517_snp_sweet_cherry_Pp5_15546701 & 5 & 15546701 & $\mathrm{Y}$ & $\mathrm{Y}$ & $\mathrm{Y}$ \\
\hline 327 & ss490559203 & RosCOS1765-401_snp_sweet_cherry_Pp5_15546817 & 5 & 15546817 & $\mathrm{Y}$ & $\mathrm{N}$ & $\mathrm{N}$ \\
\hline 328 & ss490554529 & RosBREED_snp_sweet_cherry_Pp5_15559243 & 5 & 15559243 & $\mathrm{Y}$ & $\mathrm{N}$ & $\mathrm{N}$ \\
\hline 329 & ss490554550 & RosBREED_snp_sweet_cherry_Pp5_15817487 & 5 & 15817487 & $\mathrm{Y}$ & $\mathrm{N}$ & $\mathrm{N}$ \\
\hline 330 & ss490554609 & RosBREED_snp_sweet_cherry_Pp5_16375840 & 5 & 16375840 & $\mathrm{Y}$ & $\mathrm{Y}$ & $\mathrm{Y}$ \\
\hline 331 & ss490554753 & RosBREED_snp_sweet_cherry_Pp5_17319331 & 5 & 17319331 & $\mathrm{Y}$ & $\mathrm{Y}$ & $\mathrm{Y}$ \\
\hline 332 & ss490554756 & RosBREED_snp_sweet_cherry_Pp5_17328363 & 5 & 17328363 & $\mathrm{Y}$ & $\mathrm{N}$ & $\mathrm{N}$ \\
\hline 333 & ss490549476 & RosBREED_snp_tart_cherry_a_Pp5_17743459 & 5 & 17743459 & Y & $\mathrm{N}$ & Y \\
\hline 334 & ss490554898 & RosBREED_snp_sweet_cherry_Pp5_18100331 & 5 & 18100331 & $\mathrm{Y}$ & $\mathrm{N}$ & $\mathrm{N}$ \\
\hline 335 & ss490554904 & RosBREED_snp_sweet_cherry_Pp5_18146501 & 5 & 18146501 & $\mathrm{Y}$ & $\mathrm{N}$ & $\mathrm{N}$ \\
\hline 336 & ss490554953 & RosBREED_snp_sweet_cherry_Pp5_18423946 & 5 & 18423946 & $\mathrm{Y}$ & $\mathrm{Y}$ & $\mathrm{N}$ \\
\hline
\end{tabular}




\begin{tabular}{|c|c|c|c|c|c|c|c|}
\hline \multirow[b]{2}{*}{$\mathrm{SN}$} & \multirow[b]{2}{*}{ NCBI SS } & \multirow[b]{2}{*}{ Original Full Name } & \multirow[b]{2}{*}{ Chr } & \multirow[b]{2}{*}{ Physical position (bp) } & \multicolumn{3}{|c|}{ Present in sample sets } \\
\hline & & & & & 1 & 2 & 3 \\
\hline$\overline{337}$ & ss490554977 & RosBREED_snp_sweet_cherry_Pp6_00286381 & 6 & 286381 & $\mathrm{Y}$ & $\mathrm{N}$ & $\mathrm{Y}$ \\
\hline 338 & ss490554989 & RosBREED_snp_sweet_cherry_Pp6_00735222 & 6 & 735222 & $\mathrm{Y}$ & $\mathrm{Y}$ & $\mathrm{N}$ \\
\hline 339 & ss490555047 & RosBREED_snp_sweet_cherry_Pp6_01811133 & 6 & 1811133 & Y & $\mathrm{N}$ & Y \\
\hline 340 & ss490549593 & RosBREED_snp_tart_cherry_f_Pp6_01852409 & 6 & 1852409 & $\mathrm{Y}$ & $\mathrm{N}$ & $\mathrm{N}$ \\
\hline 341 & ss490555075 & RosBREED_snp_sweet_cherry_Pp6_02247834 & 6 & 2247834 & $\mathrm{Y}$ & $\mathrm{N}$ & $\mathrm{N}$ \\
\hline 342 & ss490559372 & RosCOS3322-362_snp_sweet_cherry_Pp6_03912624 & 6 & 3912624 & Y & $\mathrm{N}$ & $\mathrm{Y}$ \\
\hline 343 & ss490555169 & RosBREED_snp_sweet_cherry_Pp6_03920291 & 6 & 3920291 & Y & $\mathrm{N}$ & $\mathrm{N}$ \\
\hline 344 & ss490555172 & RosBREED_snp_sweet_cherry_Pp6_03973271 & 6 & 3973271 & Y & $\mathrm{N}$ & $\mathrm{N}$ \\
\hline 345 & ss490555175 & RosBREED_snp_sweet_cherry_Pp6_04050337 & 6 & 4050337 & Y & $\mathrm{N}$ & $\mathrm{N}$ \\
\hline 346 & ss490555200 & RosBREED_snp_sweet_cherry_Pp6_04315623 & 6 & 4315623 & $\mathrm{Y}$ & $\mathrm{N}$ & $\mathrm{N}$ \\
\hline 347 & ss490549680 & RosBREED_snp_tart_cherry_a_Pp6_04331813 & 6 & 4331813 & $\mathrm{Y}$ & $\mathrm{N}$ & $\mathrm{N}$ \\
\hline 348 & ss490559286 & RosCOS2579-487_snp_sweet_cherry_Pp6_04620418 & 6 & 4620418 & Y & $\mathrm{N}$ & $\mathrm{N}$ \\
\hline 349 & ss490559283 & RosCOS2579-485_snp_sweet_cherry_Pp6_04620420 & 6 & 4620420 & $\mathrm{Y}$ & $\mathrm{N}$ & $\mathrm{Y}$ \\
\hline 350 & ss490555236 & RosBREED_snp_sweet_cherry_Pp6_04806232 & 6 & 4806232 & Y & $\mathrm{N}$ & $\mathrm{N}$ \\
\hline 351 & ss490555284 & RosBREED_snp_sweet_cherry_Pp6_05460138 & 6 & 5460138 & Y & $\mathrm{N}$ & $\mathrm{N}$ \\
\hline 352 & ss490555293 & RosBREED_snp_sweet_cherry_Pp6_05542394 & 6 & 5542394 & Y & Y & $\mathrm{N}$ \\
\hline 353 & ss490555314 & RosBREED_snp_sweet_cherry_Pp6_05931170 & 6 & 5931170 & Y & $\mathrm{N}$ & Y \\
\hline 354 & ss490555316 & RosBREED_snp_sweet_cherry_Pp6_05978925 & 6 & 5978925 & Y & $\mathrm{N}$ & $\mathrm{N}$ \\
\hline 355 & ss490555328 & RosBREED_snp_sweet_cherry_Pp6_06245490 & 6 & 6245490 & $\mathrm{Y}$ & $\mathrm{N}$ & $\mathrm{N}$ \\
\hline 356 & ss490555360 & RosBREED_snp_sweet_cherry_Pp6_06843830 & 6 & 6843830 & $\mathrm{Y}$ & $\mathrm{N}$ & $\mathrm{Y}$ \\
\hline 357 & ss490555411 & RosBREED_snp_sweet_cherry_Pp6_07537950 & 6 & 7537950 & Y & $\mathrm{N}$ & $\mathrm{N}$ \\
\hline 358 & ss490555413 & RosBREED_snp_sweet_cherry_Pp6_07575939 & 6 & 7575939 & $\mathrm{Y}$ & $\mathrm{N}$ & $\mathrm{N}$ \\
\hline 359 & ss490555416 & RosBREED_snp_sweet_cherry_Pp6_07626959 & 6 & 7626959 & $\mathrm{Y}$ & $\mathrm{N}$ & $\mathrm{N}$ \\
\hline 360 & ss490555425 & RosBREED_snp_sweet_cherry_Pp6_07838040 & 6 & 7838040 & Y & $\mathrm{N}$ & $\mathrm{Y}$ \\
\hline 361 & ss490555428 & RosBREED_snp_sweet_cherry_Pp6_07901830 & 6 & 7901830 & $\mathrm{Y}$ & $\mathrm{N}$ & $\mathrm{N}$ \\
\hline 362 & ss490555481 & RosBREED_snp_sweet_cherry_Pp6_08691599 & 6 & 8691599 & $\mathrm{Y}$ & $\mathrm{N}$ & $\mathrm{Y}$ \\
\hline 363 & ss490555554 & RosBREED_snp_sweet_cherry_Pp6_10369567 & 6 & 10369567 & Y & $\mathrm{Y}$ & Y \\
\hline 364 & ss490555574 & RosBREED_snp_sweet_cherry_Pp6_11072866 & 6 & 11072866 & $\mathrm{Y}$ & $\mathrm{N}$ & Y \\
\hline 365 & ss490555577 & RosBREED_snp_sweet_cherry_Pp6_11128369 & 6 & 11128369 & $\mathrm{Y}$ & $\mathrm{N}$ & $\mathrm{N}$ \\
\hline 366 & ss490555580 & RosBREED_snp_sweet_cherry_Pp6_11210515 & 6 & 11210515 & $\mathrm{Y}$ & $\mathrm{N}$ & $\mathrm{Y}$ \\
\hline 367 & ss490555606 & RosBREED_snp_sweet_cherry_Pp6_11910096 & 6 & 11910096 & $\mathrm{Y}$ & $\mathrm{N}$ & $\mathrm{Y}$ \\
\hline 368 & ss490549926 & RosBREED_snp_tart_cherry_a_Pp6_12119303 & 6 & 12119303 & $\mathrm{Y}$ & $\mathrm{N}$ & $\mathrm{N}$ \\
\hline 369 & ss490555615 & RosBREED_snp_sweet_cherry_Pp6_12126728 & 6 & 12126728 & $\mathrm{Y}$ & $\mathrm{N}$ & $\mathrm{N}$ \\
\hline 370 & ss490555624 & RosBREED_snp_sweet_cherry_Pp6_12400263 & 6 & 12400263 & $\mathrm{Y}$ & $\mathrm{N}$ & $\mathrm{N}$ \\
\hline 371 & ss490555635 & RosBREED_snp_sweet_cherry_Pp6_12638852 & 6 & 12638852 & Y & $\mathrm{N}$ & Y \\
\hline 372 & ss490555682 & RosBREED_snp_sweet_cherry_Pp6_14555604 & 6 & 14555604 & $\mathrm{Y}$ & $\mathrm{N}$ & Y \\
\hline 373 & ss490559341 & RosCOS2633-261_snp_sweet_cherry_Pp6_14662485 & 6 & 14662485 & $\mathrm{Y}$ & $\mathrm{N}$ & $\mathrm{N}$ \\
\hline 374 & ss490559338 & RosCOS2633-161_snp_sweet_cherry_Pp6_14662583 & 6 & 14662583 & $\mathrm{Y}$ & $\mathrm{N}$ & $\mathrm{N}$ \\
\hline 375 & ss490559335 & RosCOS2633-111_snp_sweet_cherry_Pp6_14662633 & 6 & 14662633 & $\mathrm{Y}$ & $\mathrm{N}$ & $\mathrm{N}$ \\
\hline 376 & ss490555714 & RosBREED_snp_sweet_cherry_Pp6_15628669 & 6 & 15628669 & $\mathrm{Y}$ & $\mathrm{N}$ & $\mathrm{Y}$ \\
\hline 377 & ss490555746 & RosBREED_snp_sweet_cherry_Pp6_16636989 & 6 & 16636989 & $\mathrm{Y}$ & $\mathrm{Y}$ & $\mathrm{Y}$ \\
\hline 378 & ss490555771 & RosBREED_snp_sweet_cherry_Pp6_17629589 & 6 & 17629589 & $\mathrm{Y}$ & $\mathrm{N}$ & $\mathrm{N}$ \\
\hline 379 & ss490555792 & RosBREED_snp_sweet_cherry_Pp6_18081683 & 6 & 18081683 & Y & $\mathrm{N}$ & Y \\
\hline 380 & ss490559223 & RosCOS1983-146_snp_sweet_cherry_Pp6_19912441 & 6 & 19912441 & Y & $\mathrm{N}$ & Y \\
\hline 381 & ss490559226 & RosCOS1983-267_snp_sweet_cherry_Pp6_19912562 & 6 & 19912562 & Y & $\mathrm{N}$ & $\mathrm{N}$ \\
\hline 382 & ss490559229 & RosCOS1983-426_snp_sweet_cherry_Pp6_19912697 & 6 & 19912697 & $\mathrm{Y}$ & $\mathrm{N}$ & $\mathrm{N}$ \\
\hline 383 & ss490555845 & RosBREED_snp_sweet_cherry_Pp6_19982724 & 6 & 19982724 & $\mathrm{Y}$ & $\mathrm{N}$ & $\mathrm{N}$ \\
\hline 384 & ss490555857 & RosBREED_snp_sweet_cherry_Pp6_20091471 & 6 & 20091471 & $\mathrm{Y}$ & $\mathrm{N}$ & Y \\
\hline 385 & ss490555863 & RosBREED_snp_sweet_cherry_Pp6_20112900 & 6 & 20112900 & $\mathrm{Y}$ & $\mathrm{N}$ & $\mathrm{N}$ \\
\hline 386 & ss490555869 & RosBREED_snp_sweet_cherry_Pp6_20150761 & 6 & 20150761 & $\mathrm{Y}$ & $\mathrm{N}$ & $\mathrm{N}$ \\
\hline 387 & ss490555878 & RosBREED_snp_sweet_cherry_Pp6_20209981 & 6 & 20209981 & $\mathrm{Y}$ & $\mathrm{N}$ & $\mathrm{N}$ \\
\hline 388 & ss490555911 & RosBREED_snp_sweet_cherry_Pp6_20514744 & 6 & 20514744 & $\mathrm{Y}$ & $\mathrm{N}$ & $\mathrm{N}$ \\
\hline 389 & ss490555926 & RosBREED_snp_sweet_cherry_Pp6_20604253 & 6 & 20604253 & $\mathrm{Y}$ & $\mathrm{N}$ & $\mathrm{N}$ \\
\hline 390 & ss490558953 & RosCOS1197-398_snp_sweet_cherry_Pp6_20719389 & 6 & 20719389 & $\mathrm{Y}$ & $\mathrm{N}$ & $\mathrm{N}$ \\
\hline 391 & ss490555951 & RosBREED_snp_sweet_cherry_Pp6_20786682 & 6 & 20786682 & $\mathrm{Y}$ & $\mathrm{N}$ & $\mathrm{N}$ \\
\hline 392 & ss490550096 & RosBREED_snp_tart_cherry_a_Pp6_20850123 & 6 & 20850123 & $\mathrm{Y}$ & $\mathrm{Y}$ & $\mathrm{N}$ \\
\hline
\end{tabular}




\begin{tabular}{|c|c|c|c|c|c|c|c|}
\hline \multirow[b]{2}{*}{$\mathrm{SN}$} & \multirow[b]{2}{*}{ NCBI SS } & \multirow[b]{2}{*}{$\begin{array}{l}\text { Original Full Name } \\
\end{array}$} & \multirow[b]{2}{*}{ Chr } & \multirow[b]{2}{*}{ Physical position (bp) } & \multicolumn{3}{|c|}{ Present in sample sets } \\
\hline & & & & & 1 & 2 & 3 \\
\hline$\overline{393}$ & ss490555972 & RosBREED_snp_sweet_cherry_Pp6_20982940 & 6 & 20982940 & $\mathrm{Y}$ & $\mathrm{N}$ & $\mathrm{Y}$ \\
\hline 394 & ss490550124 & RosBREED_snp_tart_cherry_a_Pp6_21758738 & 6 & 21758738 & Y & $\mathrm{N}$ & $\mathrm{Y}$ \\
\hline 396 & ss490556014 & RosBREED_snp_sweet_cherry_Pp6_22578566 & 6 & 22578566 & Y & $\mathrm{N}$ & $\mathrm{N}$ \\
\hline 397 & ss490558923 & RosCOS1124-244_snp_sweet_cherry_Pp6_22953307 & 6 & 22953307 & Y & $\mathrm{N}$ & $\mathrm{N}$ \\
\hline 398 & ss490556048 & RosBREED_snp_sweet_cherry_Pp6_23138881 & 6 & 23138881 & $\mathrm{Y}$ & $\mathrm{N}$ & $\mathrm{N}$ \\
\hline 400 & ss490559115 & RosCOS1503-168_snp_sweet_cherry_Pp6_24324785 & 6 & 24324785 & Y & $\mathrm{N}$ & $\mathrm{N}$ \\
\hline 401 & ss490550220 & RosBREED_snp_tart_cherry_a_Pp6_24433974 & 6 & 24433974 & Y & $\mathrm{N}$ & $\mathrm{N}$ \\
\hline 402 & ss490556182 & RosBREED_snp_sweet_cherry_Pp6_24914294 & 6 & 24914294 & $\mathrm{Y}$ & $\mathrm{N}$ & Y \\
\hline 403 & ss490558886 & RosCOS0548-072_snp_sweet_cherry_Pp6_25325556 & 6 & 25325556 & Y & $\mathrm{N}$ & $\mathrm{N}$ \\
\hline 404 & ss490558890 & RosCOS0548-123_snp_sweet_cherry_Pp6_25325607 & 6 & 25325607 & $\mathrm{Y}$ & $\mathrm{N}$ & $\mathrm{N}$ \\
\hline 405 & ss490556207 & RosBREED_snp_sweet_cherry_Pp6_25429330 & 6 & 25429330 & Y & $\mathrm{N}$ & $\mathrm{N}$ \\
\hline 410 & ss 490556260 & RosBREED_snp_sweet_cherry_Pp6_26484157 & 6 & 26484157 & Y & $\mathrm{Y}$ & $\mathrm{N}$ \\
\hline 411 & ss490556308 & RosBREED_snp_sweet_cherry_Pp6_27373564 & 6 & 27373564 & $\mathrm{Y}$ & $\mathrm{N}$ & $\mathrm{Y}$ \\
\hline 412 & ss490559104 & RosCOS1493-311_snp_sweet_cherry_Pp6_28294400 & 6 & 28294400 & $\mathrm{Y}$ & $\mathrm{N}$ & $\mathrm{Y}$ \\
\hline 413 & ss490556376 & RosBREED_snp_sweet_cherry_Pp6_28590655 & 6 & 28590655 & Y & $\mathrm{N}$ & $\mathrm{N}$ \\
\hline 414 & ss490556421 & RosBREED_snp_sweet_cherry_Pp7_01298051 & 7 & 1298051 & $\mathrm{Y}$ & $\mathrm{Y}$ & $\mathrm{Y}$ \\
\hline 415 & ss490556424 & RosBREED_snp_sweet_cherry_Pp7_01392399 & 7 & 1392399 & Y & $\mathrm{N}$ & $\mathrm{N}$ \\
\hline 416 & ss490556436 & RosBREED_snp_sweet_cherry_Pp7_01783512 & 7 & 1783512 & $\mathrm{Y}$ & $\mathrm{N}$ & $\mathrm{N}$ \\
\hline 417 & ss490556439 & RosBREED_snp_sweet_cherry_Pp7_01835696 & 7 & 1835696 & Y & Y & $\mathrm{N}$ \\
\hline 418 & ss490556458 & RosBREED_snp_sweet_cherry_Pp7_02085075 & 7 & 2085075 & $\mathrm{Y}$ & $\mathrm{N}$ & $\mathrm{N}$ \\
\hline 419 & ss490556467 & RosBREED_snp_sweet_cherry_Pp7_02252124 & 7 & 2252124 & Y & $\mathrm{N}$ & $\mathrm{Y}$ \\
\hline 420 & ss490556479 & RosBREED_snp_sweet_cherry_Pp7_02530796 & 7 & 2530796 & $\mathrm{Y}$ & $\mathrm{N}$ & $\mathrm{N}$ \\
\hline 428 & ss490556684 & RosBREED_snp_sweet_cherry_Pp7_08954812 & 7 & 8954812 & $\mathrm{Y}$ & $\mathrm{N}$ & $\mathrm{N}$ \\
\hline 429 & ss490556699 & RosBREED_snp_sweet_cherry_Pp7_09635219 & 7 & 9635219 & Y & $\mathrm{N}$ & $\mathrm{N}$ \\
\hline 430 & ss490550496 & RosBREED_snp_tart_cherry_a_Pp7_09642445 & 7 & 9642445 & $\mathrm{Y}$ & $\mathrm{N}$ & $\mathrm{Y}$ \\
\hline 431 & ss490556768 & RosBREED_snp_sweet_cherry_Pp7_10992603 & 7 & 10992603 & $\mathrm{Y}$ & $\mathrm{Y}$ & $\mathrm{N}$ \\
\hline 432 & ss490556777 & RosBREED_snp_sweet_cherry_Pp7_11125571 & 7 & 11125571 & $\mathrm{Y}$ & $\mathrm{N}$ & $\mathrm{Y}$ \\
\hline 433 & ss490556795 & RosBREED_snp_sweet_cherry_Pp7_11504432 & 7 & 11504432 & Y & $\mathrm{N}$ & $\mathrm{N}$ \\
\hline 434 & ss490556804 & RosBREED_snp_sweet_cherry_Pp7_11774569 & 7 & 11774569 & Y & $\mathrm{N}$ & $\mathrm{N}$ \\
\hline 435 & ss490550555 & RosBREED_snp_tart_cherry_a_Pp7_11790341 & 7 & 11790341 & Y & $\mathrm{N}$ & $\mathrm{N}$ \\
\hline 436 & ss490559301 & RosCOS2599-403_snp_sweet_cherry_Pp7_12192907 & 7 & 12192907 & Y & $\mathrm{N}$ & Y \\
\hline 437 & ss490556971 & RosBREED_snp_sweet_cherry_Pp7_14253560 & 7 & 14253560 & Y & $\mathrm{N}$ & Y \\
\hline 438 & ss490556986 & RosBREED_snp_sweet_cherry_Pp7_14418839 & 7 & 14418839 & $\mathrm{Y}$ & $\mathrm{N}$ & $\mathrm{N}$ \\
\hline 439 & ss490550655 & RosBREED_snp_tart_cherry_a_Pp7_14527951 & 7 & 14527951 & $\mathrm{Y}$ & $\mathrm{N}$ & $\mathrm{N}$ \\
\hline 440 & ss490557026 & RosBREED_snp_sweet_cherry_Pp7_14929134 & 7 & 14929134 & $\mathrm{Y}$ & $\mathrm{N}$ & $\mathrm{N}$ \\
\hline 441 & ss490557029 & RosBREED_snp_sweet_cherry_Pp7_14967053 & 7 & 14967053 & $\mathrm{Y}$ & Y & $\mathrm{Y}$ \\
\hline 442 & ss490557035 & RosBREED_snp_sweet_cherry_Pp7_15029527 & 7 & 15029527 & $\mathrm{Y}$ & $\mathrm{N}$ & $\mathrm{N}$ \\
\hline 443 & ss490558905 & RosCOS1089-100_snp_sweet_cherry_Pp7_15241465 & 7 & 15241465 & Y & $\mathrm{N}$ & $\mathrm{N}$ \\
\hline 444 & ss490550700 & RosBREED_snp_tart_cherry_a_Pp7_15744830 & 7 & 15744830 & Y & $\mathrm{N}$ & $\mathrm{Y}$ \\
\hline 445 & ss490557186 & RosBREED_snp_sweet_cherry_Pp7_16660251 & 7 & 16660251 & Y & $\mathrm{N}$ & Y \\
\hline 446 & ss490557205 & RosBREED_snp_sweet_cherry_Pp7_16890828 & 7 & 16890828 & $\mathrm{Y}$ & $\mathrm{N}$ & $\mathrm{Y}$ \\
\hline 447 & ss490557244 & RosBREED_snp_sweet_cherry_Pp7_17591054 & 7 & 17591054 & $\mathrm{Y}$ & $\mathrm{N}$ & $\mathrm{N}$ \\
\hline 448 & ss490557253 & RosBREED_snp_sweet_cherry_Pp7_17697521 & 7 & 17697521 & $\mathrm{Y}$ & $\mathrm{N}$ & $\mathrm{N}$ \\
\hline
\end{tabular}




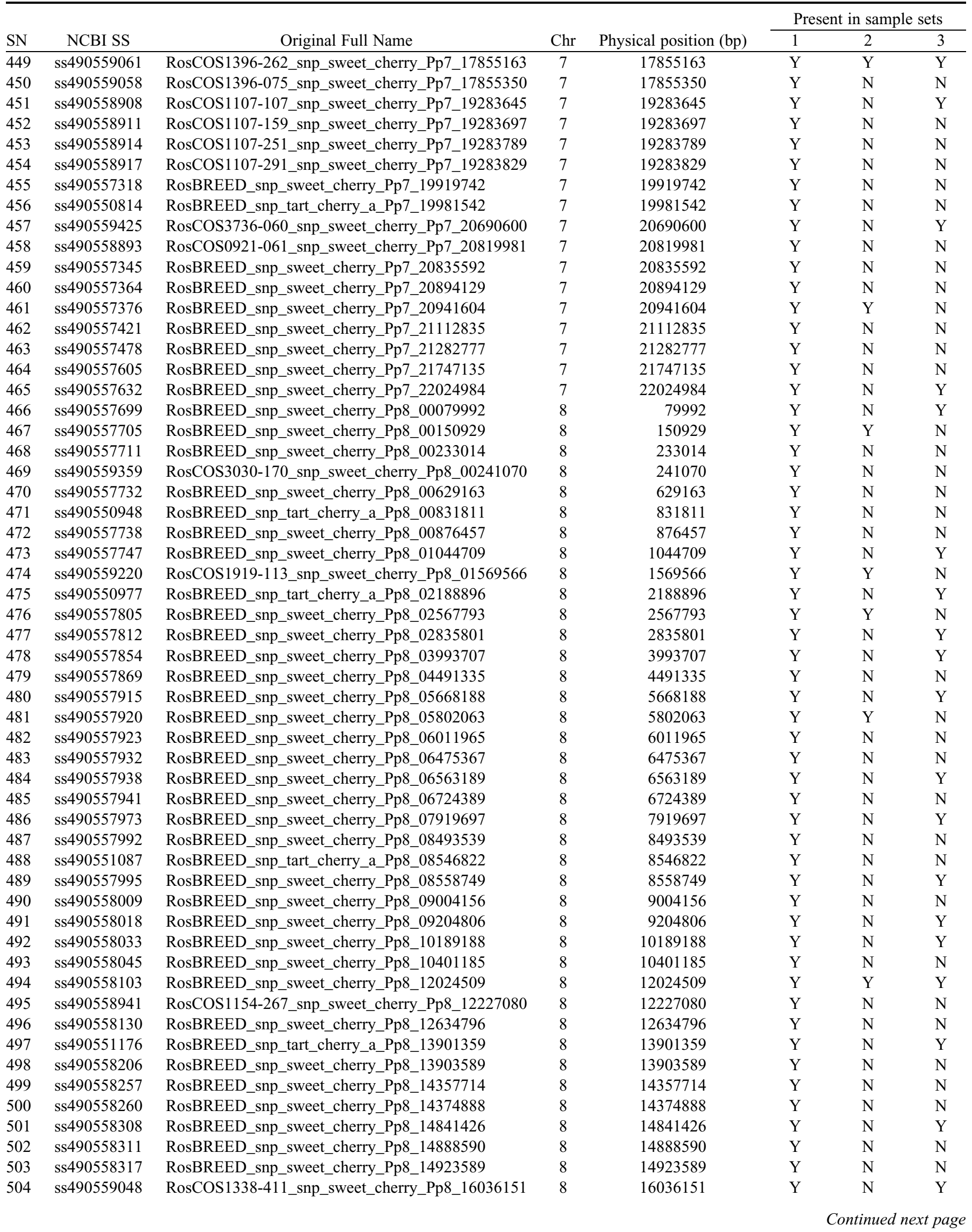


Supplemental Table S1. Continued.

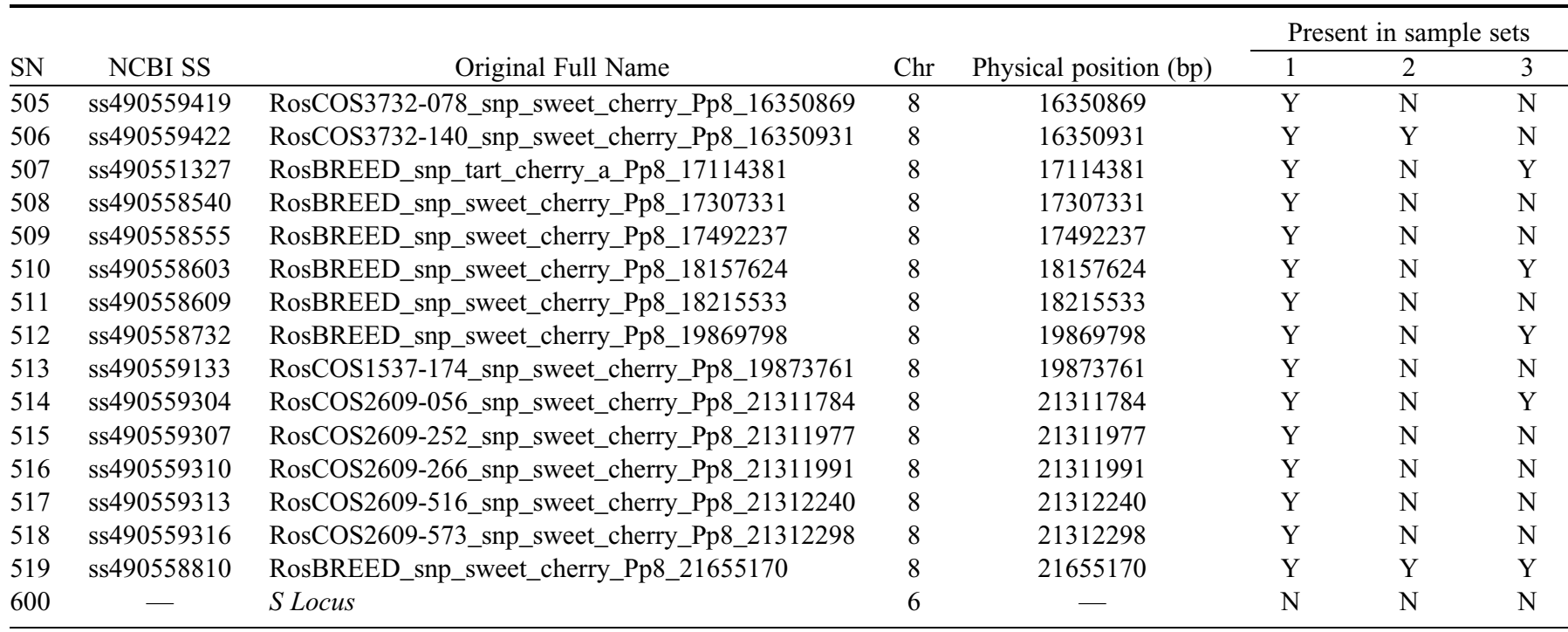

z"Y" indicates which markers were included in the marker sets. The number of markers in sample sets 1, 2, and 3 are 519, 180, and 60 markers, respectively.

$\mathrm{NCBI}=$ National Center for Biotechnology Information $($ Bethesda, MD); Chr = chromosome; ss $=$ submitted SNP. 